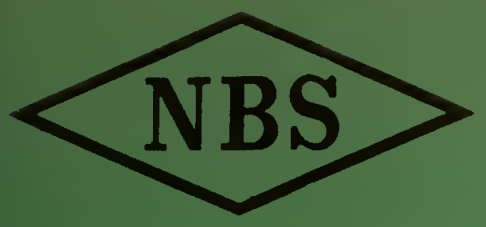

Eechnical Note

\title{
EXPERIMENTAL PLATING
}

OF GUN BORES TO

RETARD EROSION

U. S. DEPARTMENT OF COMMERCE NATIONAL BUREAU OF STANDARDS 


\section{THE NATIONAL BUREAU OF STANDARDS}

\section{Functions and Activities}

The functions of the National Bureau of Standards are set forth in the Act of Congress, March 3, 1901, as amended by Congress in Public Law 619, 1950. These include the development and maintenance of the national standards of measurement and the provision of means and methods for making measurements consistent with these standards; the determination of physical constants and properties of materials; the development of methods and instruments for testing materials, devices, and structures; advisory services to government agencies on scientific and technical problems; in. vention and development of devices to serve special needs of the Government; and the development of standard practices, codes, and specifications. The work includes basic and applied research, development, engineering, instrumentation, testing, evaluation, calibration services, and various consultation and information services. Research projects are also performed for other government agencies when the work relates to and supplements the basic program of the Bureau or when the Bureau's unique competence is required. The scope of activities is suggested by the listing of divisions and sections on the inside of the back cover.

\section{Publications}

The results of the Bureau's work take the form of either actual equipment and devices or pub. lished papers. These papers appear either in the Bureau's own series of publications or in the journals of professional and scientific societies. The Bureau itself publishes three periodicals available from the Government Printing Office: The Journal of Researoh, published in four separate sections, presents complete scientific and technical papers; the Technical News Bulletin presents summary and preliminary reports on work in progress; and Basic Radio Propagation Predictions provides data for determining the best frequencies to use for radio communications throughout the world. There are also five series of nonperiodical publications: Monographs, Applied Mathematics Series, Handbooks, Miscellaneous Publications, and Technical Notes.

Information on the Bureau's publications can be found in NBS Circular 460 , Publications of the National Bureau of Standards $(\$ 1.25)$ and its Supplement $(\$ 1.50)$, available from the Superintendent of Documents, Government Printing Office, Washington 25, D.C. 


\title{
NATIONAL BUREAU OF STANDARDS Eechnical Note
}

46

MAY 1960

\section{EXPERIMENTAL PLATING OF GUN BORES TO RETARD EROSION}

\author{
Vernon A. Lamb and John P. Young
}

\begin{abstract}
The work described in this Technical Note was sponsored by the Department of the Navy, Bureau of Ordnance; the Department of the Army, Office of the Chief of Ordnance, ORDTS; and Springfield Armory.
\end{abstract}

NBS Technical Notes a re designed to supplement the $\mathrm{Bu}-$ reau's regular publications program. They provide a means for making available scientific data that are of transient or limited interest. Technical Notes may be listed or referred to in the open literature. They are for sale by the Office of Technical Services, U. S. Department of Commerce, Washington 25, D. C.

\author{
DISTRIBUTED BY \\ UNITED STATES DEPARTMENT OF COMMERCE \\ OFFICE OF TECHNICAL SERVICES \\ WASHINGTON 25, D. C. \\ Price $\$ 2.50$
}


1. HISTORY OF GUN BARREL PLATING ........... 1

2. RESULTS OF THE PROGRAM SPONSORED BY THE NATIONAL DEFENSE RESEARCH COMMITTEE -.... 2

3. PHYSICAL PROPERTIES REQUIRED IN BORE SURFACE COATINGS -................ 4

4. CHARACTERISTICS OF ELECTRODEPOSITED CHROMIUM AS 'RELATED TO ITS APPLICATION TO GUN BORES -.......................... 4

5. METHODS AND PROCEDURES FOR CHROMIUM PLATING GUN BARRELS -.............. 10

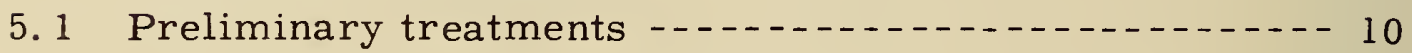

5. 2 Electropolishing -

5. 3 Chromium plating -

5. 4 Fixtures for plating $\ldots \ldots$

5. 5 Special procedures for applying LC chromium - - - 16

6. MISCELLANEOUS DATA RELATED TO CHROMIUM PLATING OF TUBES

6. 1 Effect of anode resistance on longitudinal variation of plate thickness

6. 2 Effect of trivalent chromium and iron on deposit taper

6. 3 Effect of current density on deposit taper------- 25

6. 4 Effect of anode eccentricity on plate eccentricity

6. 5 Changes in land contours caused by electropolishing and plating 
7. SUMMARY OF THE PERFORMANCE OF CHROMIUM PLATE IN BARRELS.

CALIBER . 22 TO 3 INCHES - .

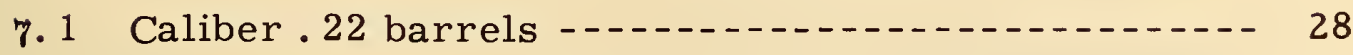

7.2 Caliber. 30 barrels _........ 29

7. 3 Caliber . 45 pistol barrels _...... 32

7. 4 Caliber. 50 barrels _..... 32

7. 5 Caliber.60 barrels _... 45

7. $620 \mathrm{~mm}$ barrels

7. $730 \mathrm{~mm}$ barrels

7. $840 \mathrm{~mm}$ barrels

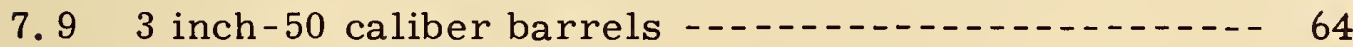

8. MISCELLANEOUS TESTS OF GUN BARRELS -...-- 66

8. 1 Heat-treatment of chromium plated barrels $\ldots 6$

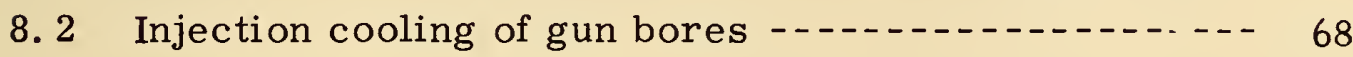

8. 3 Tests of barrels coated by the "Chromizing" process - 74

8. 4 Tests of barrels pre-treated by "Vapor-Honing"---- 76

8. 5 Tests of barrels plated with "Crack-Free" chromium- 79

8. 6 Bore coatings for combined corrosion and erosion protection of barrels for submarine service -...- 80

8. 7 Tests of barrels chromium plated by the Hausner process - 83 
8. 8 Experimental rifling designs - 85

9. OPERATING PROCEDURES - 89

9. 1 High speed plating - 89

9. 2 Application of LC chromium without forced solution flow -

9. 3 High speed electropolishing

9.4 Gas-port plating - 93

1U. FUTURE WORK

11. ACKNOWLEDGMENTS REFERENCES - 


\section{EXPERIMENTAL PLATING OF GUN BORES}

\section{TO RETARD EROSION}

\section{by}

Vernon A. Lamb and John P. Young

Methods for plating the bores of gun barrels are described, including details of fixture design, solution composition, and operating conditions. Extensive firing tests were performed, which show that chromium plate increases the life of barrels about 2 - to 5-fold, depending on the type and caliber of barrel. Optimum thickness of plate ranges from 0.0015 inch in the smallest calibers to 0.015 inch in cannon.

Certain modifications of the barrels enhance the improve ment provided by the chromium plate. Choking of the bore at the muzzle produces a marked improvement in accuracy life of caliber 0.30 and 0.50 barrels. It is less effective in barrels of larger caliber. Specially shaped lands, designed to reduce the concentration of engraving stresses at land corners, significantly improve the performance of $20 \mathrm{~mm}$ barrels. Other modifications, such as hardening of the basis steel by nitriding and increasing the length of the land "run-up", result in moderate improvements in some types of barrels. Physical properties of the chromium plates tested were varied. Ordinary "hard" chromium yields the best performance in most types of barrels.

Chromium plating has been adopted as standard production practice for caliber $0.30,0.50$, and $20 \mathrm{~mm}$ barrels, and for several calibers of cannon.

\section{HISTORY OF GUN BARREL PLATING}

Application of plated coatings to gun barrels has a fairly long history. In 1921, de Sveshnikoff and Haring of NBS carried out some experiments (1) in which they deposited nickel, copper, and iron in gun bores. They made no firing tests, but recommended that further studies be made, preferably. with iron, nickel, cobalt, and chromium. 
Between 1926 and 1928 some caliber. 30 machine gun barrels were chromium plated and tested at Frankford Arsenal by Major J. McDonald and Willard Scott (2). This work was continued at Frankford Arsenal by Lt. A. Willink (3). These tests did not indicate that chromium plating resulted in any outstanding improvement in barrel life.

From 1928 to about 1944, plating of the bores of Naval guns from calibers of 1.1 to 16 inches with 0.0005 to 0.001 inch thickness of chromium was standard production practice at the Washington Naval Gun Factory. These thin coatings did not greatly increase the life of the barrels, but no doubt furnished some protection against corrosion, especially in sea atmospheres. Additional early interest in chromium plated gun barrels was also evidenced by patents in this field $(4,5)$. Further tests by the Army Ordnance Depariment of a few barrels chromium plated by commercial firms still did not indicate any outstanding improvement due to chromium plating (6).

None of this early work was extensive or systematic, and only thin coatings were tried. The work done under the program at NBS has shown that a thick chromium plate does result in significant improvement in the life of a gun barrel. Similar findings were made by Springfield Armory $(7,8)$, by Battelle Memorial Institute, and Woolwich Arsenal, England (18).

\section{RESULTS OF THE PROGRAM SPONSORED BY THE NATIONAL DEFENSE RESEARCH COMMITTEE}

The initial portion of the experimental program at the National Bureau of Standards was performed in cooperation with the Geophysical Laboratory, under sponsorship of Division 1 of the National Defense Research Committee. The results of this portion of the program have been published elsewhere (9). For the sake of completeness of this report, the progress made under the above sponsorship (through 1945) is summarized briefly as follows: 
(a) Chromium electrodeposits prepared under a variety of bath operating conditions had been tested in special erosion tests and in barrel liners, and a type of chromium to be described later, designated as "LC" chromium, showed some promise of improved performance over other types of plate in gun barrels.

(b) Methods for depositing several erosion-resistant alloys, such as cobalt-tungsten, had been developed and some erosion tests of these materials had been made.

(c) Work with the caliber . 50 aircraft machine gun barrel had progressed to a point where the nitrided and chromium plated barrel with a muzzle choke had a life about five-fold that of the standard barrel. Pilot-plant and later full-plant production was in effect at Doehler-Jarvis Company, Grand Rapids, Michigan (under an Army contract). Even better performance of the caliber .50 barrel had been achieved with chromium ahead of a Stellite liner and this type was also in production. *

(d) Similar development had been started, but not completed to the production point, with caliber $.30, .60$, and $20 \mathrm{~mm}$ barrels.

*The NBS program did not include Stellite liner development. 
Work done by NDRC Division 1 showed that, to resist erosion, the bore surface material should have a high melting-point, high hotstrength and hot-hardness, adequate ductility both hot and cold, should undergo no abrupt change of volume with temperature, and should be resistant to chemical attack by hot powder gases.

Unfortunately, no such ideal material exists. Extensive tests have shown that of all of the elements, only the following and some of their alloys are resistant to chemical attack by powder gases: chromium, molybdenum, tungsten, tantalum, nickel, cobalt, copper, and certain platinum-group metals (10). The latter are too expensive and scarce to consider, and the melting points of nickel, cobalt, and copper are too low. Of the remaining resistant elements, only chromium can be electrodeposited readily. Molybdenum, tungsten and tantalum cannot be deposited from aqueous baths. Work has been done on the development of fused salt (1I) and nonaqueous baths, but the methods to date are still in the laboratory stage. Alloys of molybdenum and tungsten with cobalt can be deposited from aqueous baths and have some favorable properties, such as good resistance to powder gases and adequate ductility. They have therefore been tried in gun barrels, but have been inferior to chromium, mainly owing to low hot-hardness and to uncertain adhesion.

One is therefore left with chromium as the only pure metal that can be electrodeposited that has chemical and physical properties approaching those required. These properties will be briefly described.

\section{CHARACTERISTICS OF ELECTRODEPOSITED CHROMIUM} AS RELATED TO ITS APPLICATION TO GUN BORES

As noted before, chromium has excellent chemical resistance to powder gases. Its physical properties in part fulfill the requirements stated. For example, its melting-point of approximately $1900 \mathrm{C}$ is amply high. We have never observed evidence of melting of chromium plate in a gun bore. Extensive work on other physical properties of electrodeposited chromium has been reported (12). In Table 1 are summarized the operating conditions and deposit properties for three "types" of chromium that have been tried in gun bores. 
Correlation between operating conditions of the plating bath and some properties of the plates, for three types of electrodeposited chromium

Solution composition: $\mathrm{CrO}_{3}, 250 \mathrm{~g} /$ liter; $\mathrm{H}_{2} \mathrm{SU}_{4}, 2.5 \mathrm{~g} /$ liter

Standard

hard chro- Medium Soft or low

Type

mium (HC)

hardness (MH)

contraction (LC)

Operating

temp. C

50

75

85

Current density

$\left(\mathrm{amp} / \mathrm{dm}^{2}\right)$

20

60

80

Hardness (Knoop)

at room temp.

at $600 \mathrm{C}$

920

167

685

550

at $800 \mathrm{C}$

70

$-$

111

48

Ductility

zero

zero

zero

Tensile strength

$\left(1 b /\right.$ in $\left.^{2}\right)$

15,000

-

70,000

Oxide content

$\left(\right.$ wt $\left.\% 0_{2}\right)$

0.40

0.12

0.05

Linear contraction

after heating $(\%)$

to $450 \mathrm{C}$

0.3

to $1200 \mathrm{C}$

0.8

0.1

0.1 
Standard hard chromium is designated "HC" for its relatively high degree of contraction as a result of successive heating and cooling. This phenomenon is probably the result of loss of water and hydrogen from hydrated oxides that are occluded in the plate. Its hardness is adequate, since swaging of the plate itself is rarely a cause of gun barrel failure. Its main defects for gun barrel service, which are revealed in Table 1, are: (a) it is brittle; and (b) successive cycles of heating and cooling result in contraction which causes widening of the inherently present stress-cracks. These adverse properties lead to eventual failure of the plate in a gun barrel by the following mechanisms. First, owing to its brittleness and low tensile strength, the plate may chip off by breaking within itself, especially at highly stressed locations such as land corners. The local thinning of the plate by this mechanism results in reduced protection to the underlying steel in these areas. Second, hot powder-gases gain access to the steel below the plate through cracks. The steel undergoes chemical attack and is melted by the hot powder gases, with the formation of a mushroomed cavity under the plate at a crack site. Joining of two such cavities under the plate by their lateral growth, results in removal of chromium from the bore, and erosion of the exposed steel proceeds at an accelerated rate. Figures 1 and 2 show typical failures of these types.

The second mechanism of failure described above is partly the result of the poor chemical resistance and low melting point of steel. Another mechanism of failure is related to the low hot-hardness of steel. Under impact from the projectiles, the steel of the lands under the plate flattens out. The steel of the land flows both forward and laterally. Forward flow may produce a constriction in the bore, and lateral flow increases the land diameter and decreases the groove diameter. Figure 3 shows the latter effect. This distortion of the original surface contour results in buckling and cracking of the plate, which opens the way to erosion of the basis steel. In spite of the above types of failure, properly applied HC chromium produces a significant improvement in barrel life.

It was apparent, however, that if the chromium were stronger and more ductile, and if the basis steel had better hot-hardness, barrel improvement would be much greater. Therefore "low-contraction" chromium (Table 1) was tried, in conjunction with hardening of the steel by nitriding. Nitriding of the basis steel has been found to reduce the extent of barrel failure due to swaging. Low-contraction 


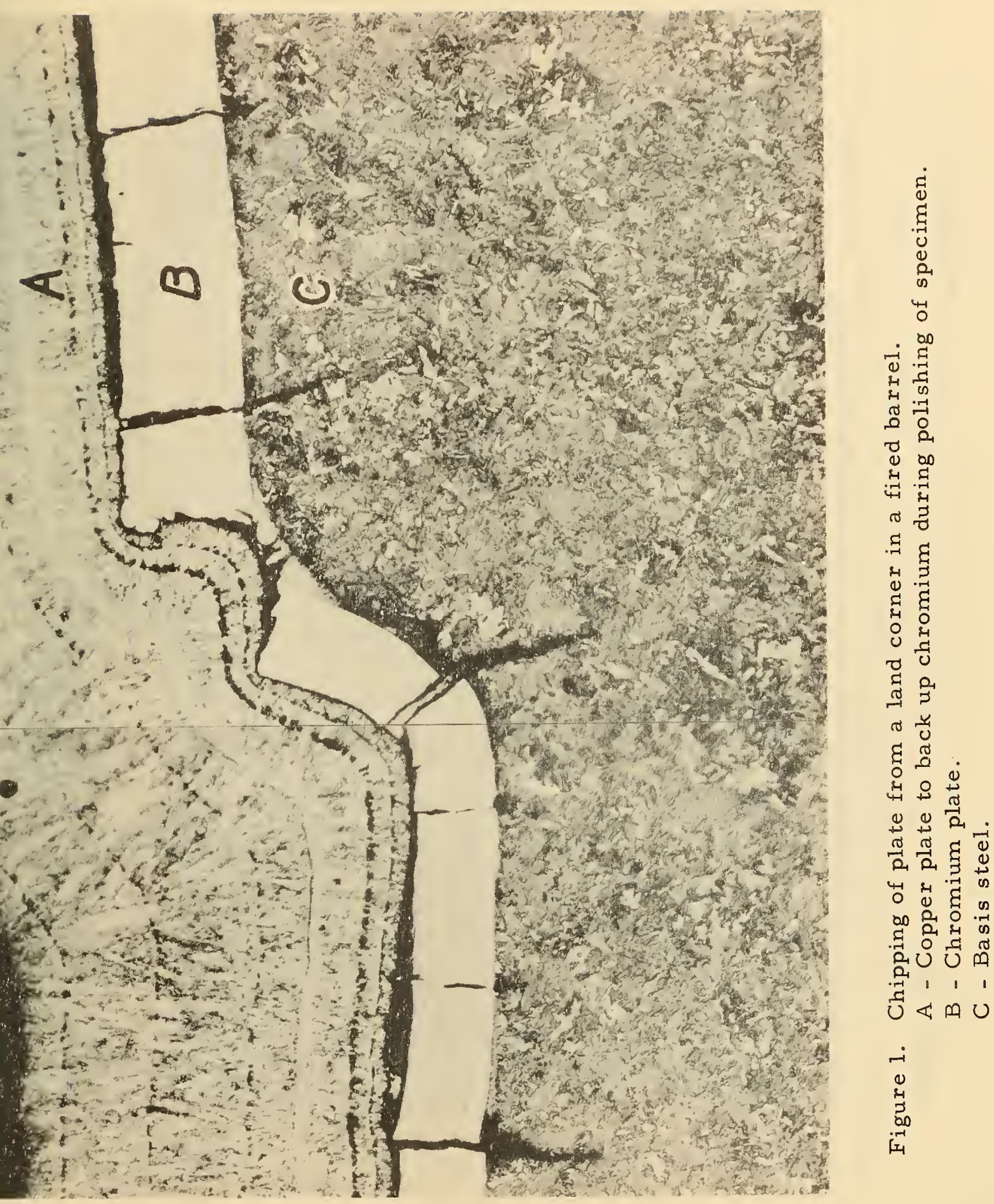




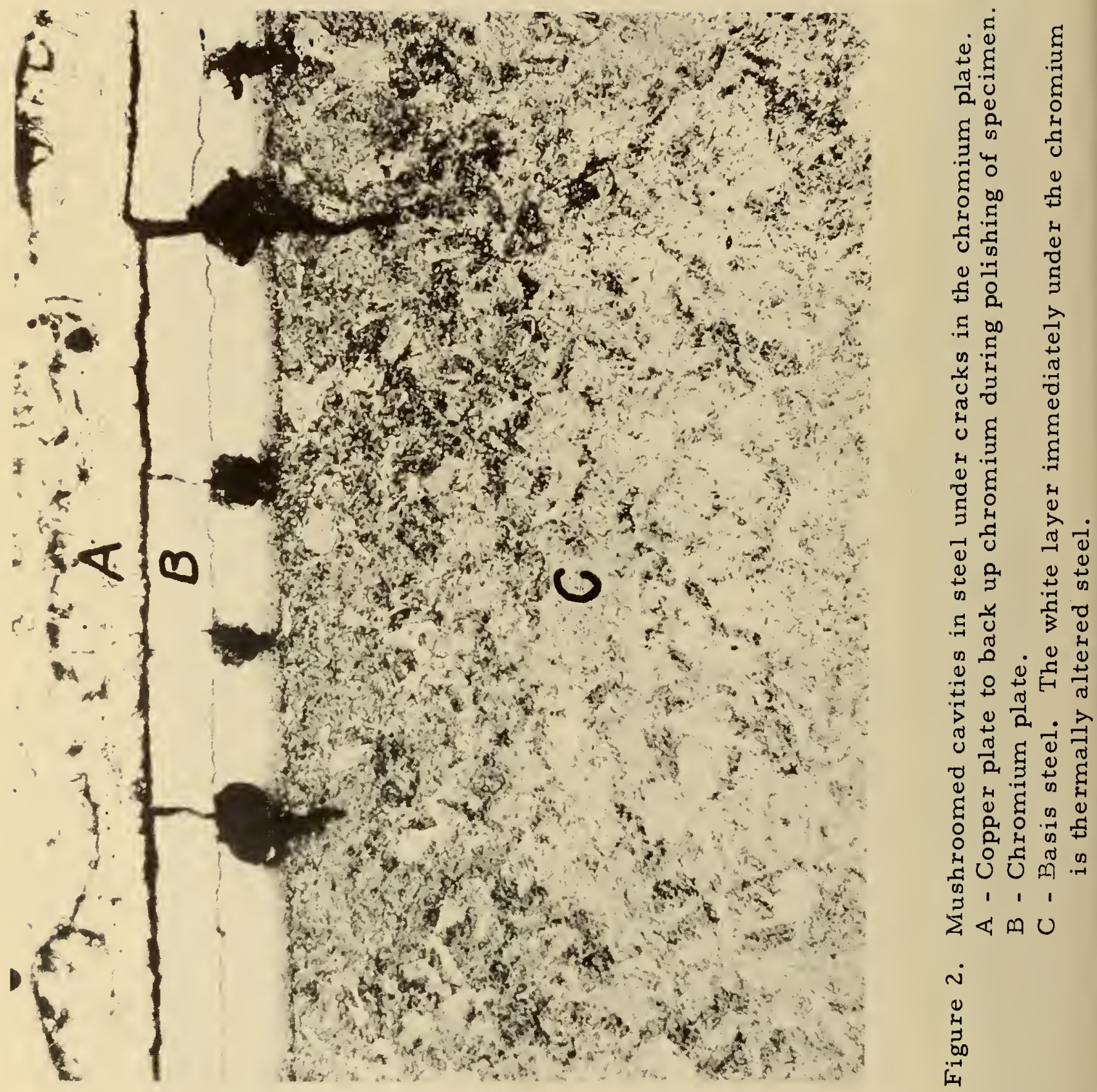


chromium results in better barrel life in some types and calibers of barrels, while in others it is no better than the HC type. Its chief defect is its low hot-hardness at medium high temperatures (400-500 C), which permits flattening of the lands due to swaging of the plate and steel. This deformation of the bore results in loss of barrel accuracy. "Medium-hardness" plate (Table 1) has been tried in the hope that it would combine the favorable properties of $\mathrm{HC}$ and LC plates. Unfortunately, the intermediate hardness plate has been found to combine their unfavorable properties.

In attempting to obtain greater improvement in barrel life than is afforded by chromium plate, a variety of other coatings have been tried. Some of these are: duplex coatings of HC and LC chromium; duplex coatings of chromium with copper, cobalt, or cobalt-tungsten alloy; cobalt and nickel alone; alloys of chromium with iron, nickel, and cobalt; and alloys of cobalt with tungsten (13). None of these are superior to chromium.

\section{METHODS AND PROCEDURES FOR CHROMIUM PLATING GUN BARRELS}

\subsection{Preliminary treatments}

There is no real difference between the processing steps required for preparing and plating gun barrels and those for plating many ordinary items. Following is a brief summary of the steps involved.

(a) Degrease the gun barrel by any standard method.

(b) Remove, by standard acid pickling, any scale or film that may be present, e.g., from Parkerizing or nitriding. Mechanical scrubbing with a cloth patch or a brush on a ramrod may be helpful in this step.

(c) Inspect the bore visually with a boroscope. If smears of copper, resulting from proof-firing, are present, remove them with any suitable copper stripping solution, e.g., a standard chromic acid-sulfuric acid composition, a proprietary solution, or by making the bore anodic in a chromic acid solution.

(d) Rinse, dry, and measure the bore diameter with a "star-gage" or other suitable bore gage.

(e) Calculate the thickness of steel to be removed by electropolishing and the electropolishing time. The thickness of steel to be removed depends on the initial bore diameter, the thickness of plate to be applied, and the final bore diameter. 
(f) Assemble the fixtures and carry out electropolishing for the calculated length of time.

(g) Dismantle the fixtures, rinse and dry, and me asure the bore diameter.

\subsection{Electropolishing}

Electropolishing is a valuable accessory process in gun bore plating, because: (a) it provides a convenient method for enlarging the bores of stock barrels before plating; (b) it produces a desirable rounding of land corners, thus preventing build-up of a bead of plate at this point, as shown in Figure 4; and (c) it removes small slivers and burrs of steel that remain after machining operations, thus contributing to the production of smooth, nodule-free, chromium plates.

The process has been described frequently in the literature.* The following solution composition and operating conditions have been found practical (14):

Phosphoric acid (commercial $85 \%$ )
Sulfuric acid (commercial 95\%)
Temperature
Anodic current density
Density
Permissible concentration of
dissolved salts, Fe plus Cr
Rate of steel removal

$50 \%$ by volume $50 \%$ by volume $40-60 \mathrm{C}$ 25 to $50 \mathrm{amp} / \mathrm{dm}^{2}$ 1.69 to $1.74 \mathrm{~g} / \mathrm{cc}$

$70 \mathrm{~g} /$ liter 0.003 to $0.006 \mathrm{inch} / \mathrm{hr}$.

The lower values of temperature and current density have usually been used, e.g., $40 \mathrm{C}$ and $25 \mathrm{amp} / \mathrm{dm}^{2}$, but higher values, such as $60 \mathrm{C}$ and $50 \mathrm{amp} / \mathrm{dm}^{2}$ can be used. In general, the higher current densities result in less uniform removal of steel from end-to-end of the bore. This is shown in Figure 5.

\subsection{Chromium plating}

The solution composition and operating conditions are indicated in Table 1, though for application of HC chromium, the higher plating rates obtained at higher temperatures and current densities, e.g. , $55 \mathrm{C}$ and 30 to $35 \mathrm{amp} / \mathrm{dm}^{2}$, are often used. Operations immediately preceding plating are indicated as follows:

\footnotetext{
*At the beginning of the gun barrel plating program, valuable information was obtained informally from C. L. Faust of Battelle Memorial Institute.
} 

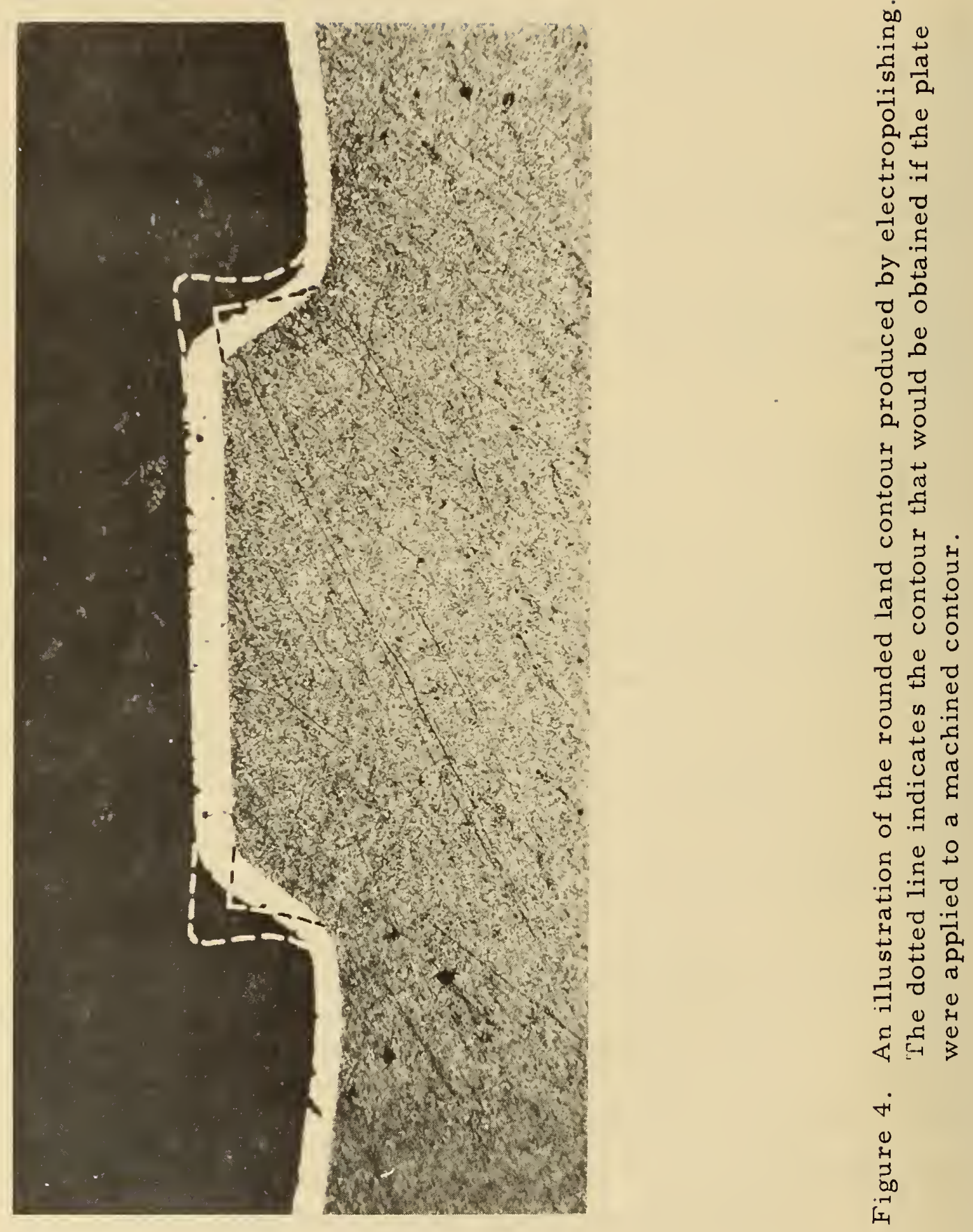


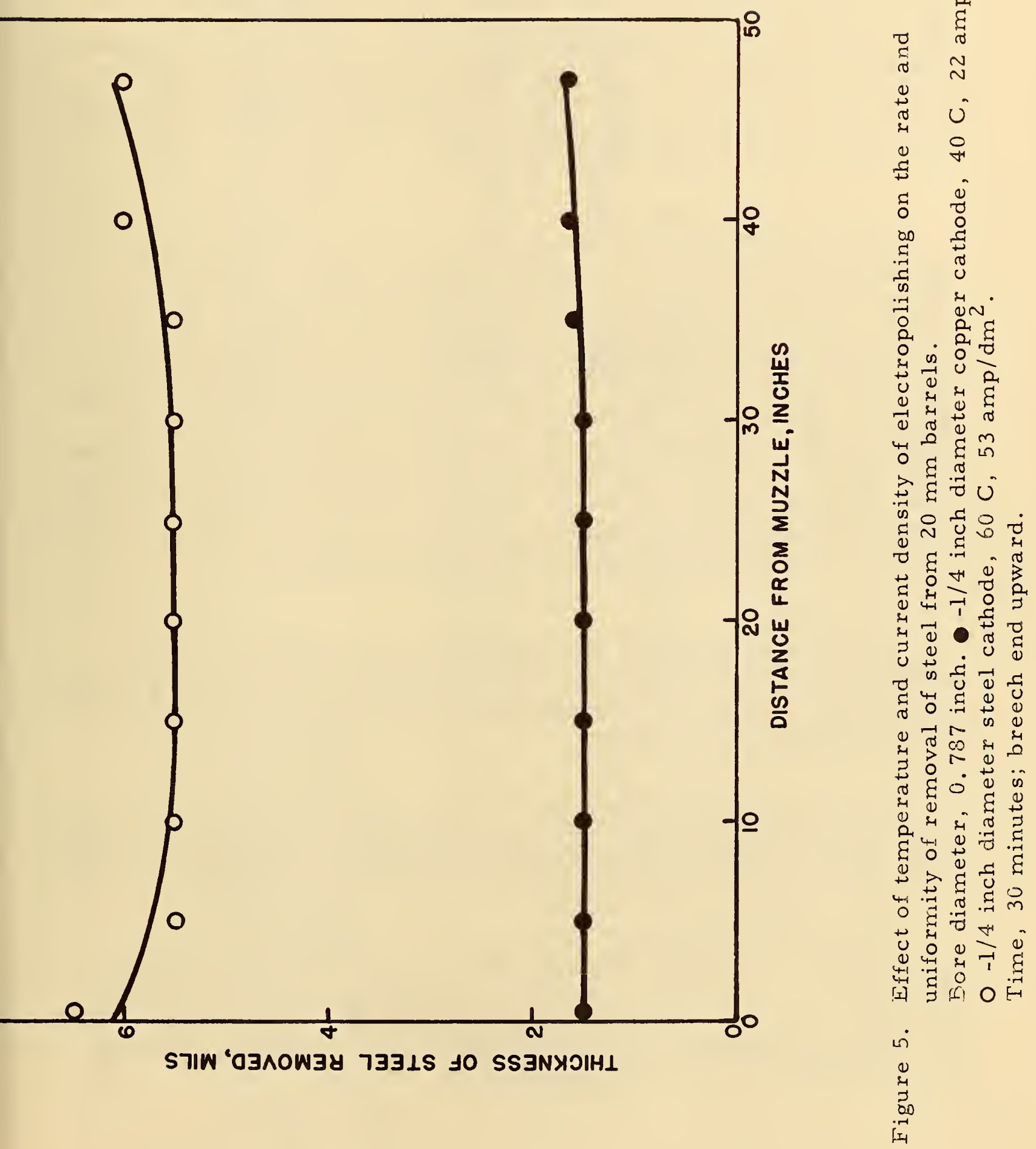




\section{3.1 Cleaning}

Several methods of cleaning the bore are suitable, but usually one of the following is used: (a) scrub mechanically with a cloth cleaningpatch or a brush on a ramrod, using a mixture of pumice and hydrochloric acid, followed by rinsing; or (b) assemble the fixtures and apply a short electropolish, rinse thoroughly, and transfer immediately to the chromic acid anodic etch. We prefer the latter method and have found that it results in slightly superior and more uniform adhesion, as measured by the results of firing tests of $40 \mathrm{~mm}$ barrels. The work of Williams and Hammond (15) also shows that a similar treatment results in excellent adhesion.

\section{3. 2 Anodic etching}

Anodic etching is done in a chromic acid bath, which may be the plating bath, but is preferably a separate bath, containing no sulfate. Use of a separate etch bath free of sulfate avoids introduction of iron into the plating bath (resulting from anodic attack of the bore surface) and also prevents formation of a chromium deposit on the center electrode, which would subsequently dissolve in the plating bath. Barrels are etched anodically for 3 to 5 minutes at $50 \mathrm{C}$ and $20 \mathrm{amp} / \mathrm{dm}$. Carefully contro!led firing tests showed that a relatively long anodic etch resulted in improved adhesion of the plate. Etching time of longer than five minutes yielded even better adhesion, but could not be generally used because on some steels a passivating film was formed that prevented complete covering by chromium.

\section{3. 3 Plating}

Transfer the barrel to the plating tank, etch anodically for an additional period of 15 to 30 seconds, then reverse the current, making the barrel cathodic. Plate under the selected operating conditions for the calculated length of time.

\section{3. 4 Final operations}

At the end of the plating period, remove the barrel from the plating tank, rinse, dismantle the fixtures, dry, measure the diameter of the bore, and inspect it visually.

\section{4 Fixtures for plating}

Typical fixtures are shown in Figure 6. A concentric electrode is held in place along the axis of the bore with insulating plugs in the end caps. The end caps are drilled with holes for solution circulation. The barrel is plated in a vertical position. Some important criteria for good fixture design are as follows: 

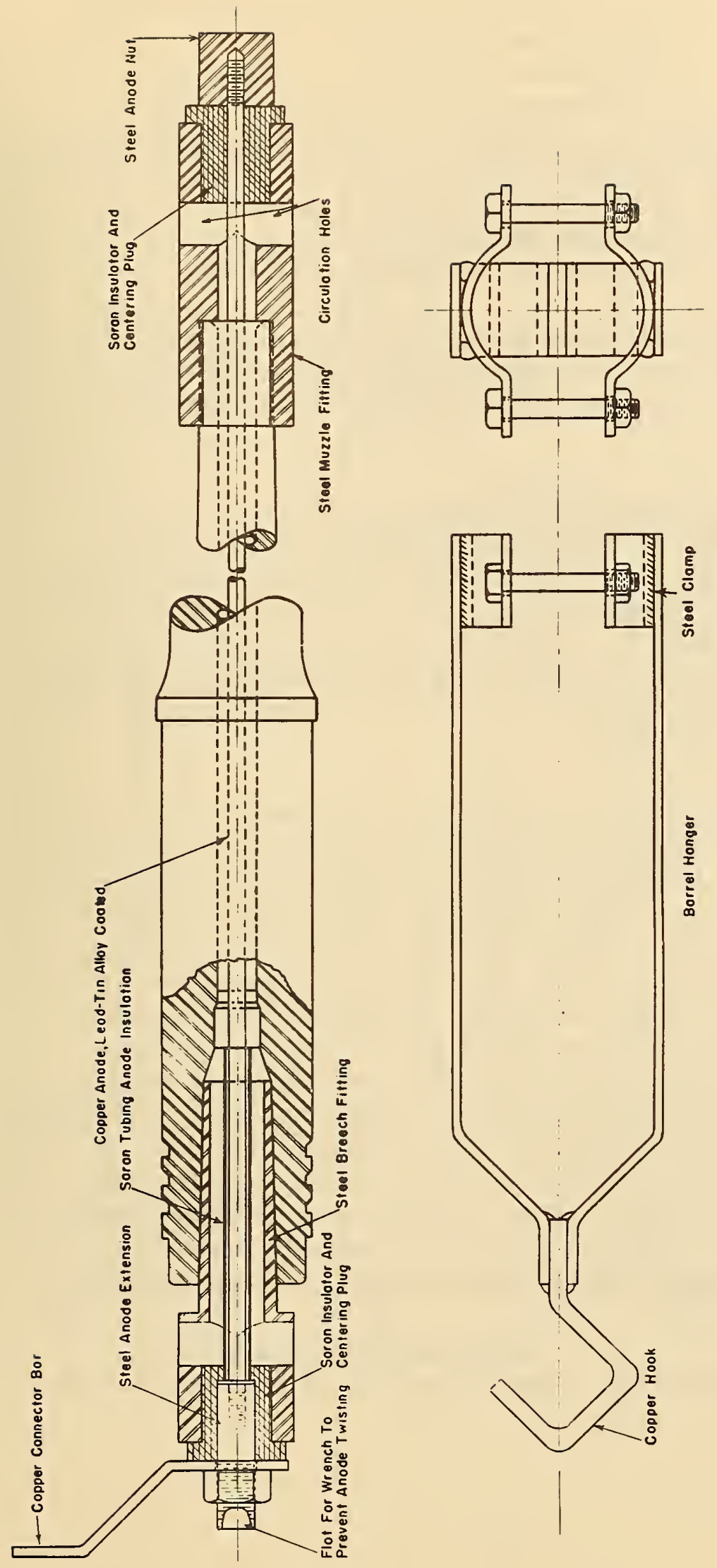

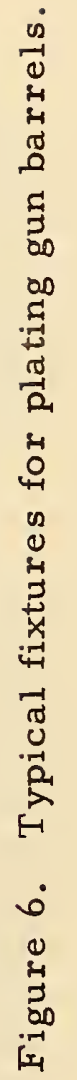


(a) End caps should seat positively so that they cannot wiggle or tip, thus misaligning the electrode.

(b) All surfaces on which anode concentricity depend must be machined to close tolerances of fit and concentricity.

"Close tolerances" is a relative term in this case. For a caliber .30 barrel the anode should be concentric within 0.001 to 0.002 inch, while for a 3 -inch cannon, an eccentricity of 0.020 to 0.030 inch may be permissible.

(c) Electrical connections must have adequate current-carrying capacity.

(d) The cross-sectional area of the solution circulation holes must be sufficient so that flow of the solution is not restricted, e.g. , two to four times the cross-section of the bore.

The diameter of the electrodes and the material from which they are made varies widely, depending on the caliber of the barrel and the desired longitudinal distribution of the plate thickness. In all cases, plating anodes are coated with lead, or with an alloy of $90 \%$ lead-10\% tin, which can be conveniently electrodeposited (16). The lead-tin alloy coating is necessary on anodes used for applying LC chromium, since at $95 \mathrm{C}$ a high-resistance film is formed on pure lead.

5. 5 Special procedures for applying LC chromium.

The high current density employed in depositing LC chromium results in excessive longitudinal taper in the thickness of the deposit, with the thickness much less at the upper end of the bore (Figure 7). Two factors operate to produce this effect, namely, entrainment in the solution of the hydrogen and oxygen formed at the electrodes, and a slight rise of the temperature of the solution as it passes upward through the bore. Entrainment of the gases causes an increase in the electrical resistance between the electrodes at the upper end of the bore. A higher solution temperature lowers the cathode efficiency. The temperature of the solution was measured at both the inlet and outlet of the bore while LC chromium was being plated. The observed temperature difference of $2 \mathrm{C}$ is too small to cause a significant change in cathode efficiency. Therefore gas entrainment must be the main cause of the taper.

To eliminate this taper, three methods were tried, as follows: 


\subsubsection{The moving anode method}

A short anode, e.g., one-fifth of the bore-length, is gradually drawn through the bore. This method does produce a uniform deposit. However, the method was unsatisfactory because the deposits had poor adhesion. The poor adhesion was caused by the formation of a passive film on the surface of the bore at areas ahead of the moving anode. These areas were in prolonged contact with the hot chromic acid solution before being covered with chromium. No remedy was found for this defect in the method.

\subsubsection{The anode resistance method}

In theory, it should be possible to design an anode with longitudinally varying resistance such that the drop in voltage and current along the anode exactly compensates for the gas -bubble and the temperature effects, with a resultant plate of uniform thickness. This has been accomplished with $20 \mathrm{~mm}$ barrels, but it is not as yet a generally practical method. A closely related method was successful with a 3 inch-50 caliber barrel, in which the bore diameter was tapered by electropolishing with a moving cathode to compensate for the taper in the chromium deposit.

\subsubsection{The pump-plating method}

This method, which was successful, consists of pumping the plating solution through the bore at a high velocity. The concentration of gas-bubbles at the upper end of the bore is reduced because the bubbles are removed from the bore rapidly and they are also compressed. Longitudinal temperature variation is also eliminated. It was found that, as an approximation, flow velocities 7 to 10 times the natural flow velocity practically eliminated longitudinal taper in plate thickness under plating conditions of $85 \mathrm{C}$ and $80 \mathrm{amp} / \mathrm{dm}^{2}$. Lower flow rates may be used to produce small controlled tapers, thus creating intentionally choked muzzles. Pump-plating data are summarized in Figure 7 and Table 2.

It has been reported in the literature on chromium plating that a high degree of agitation reduces the cathode current efficiency. In this work, it was found that these high flow-rates did not reduce the cathode efficiency.

In one case, in the plating of a barrel with an exceptionally high ratio of length to bore diameter, it was necessary to pump-plate to apply HC chromium uniformly. This was a $20-\mathrm{mm}$ barrel $(0.787$ inch bore diameter) with a length of 96 inches. 
TABLE 2

Longitudinal variation of the thickness of chromium plate in reveral caliber。 of barrela as a function of operating variables

\begin{tabular}{|c|c|c|c|c|c|c|c|c|c|c|c|c|c|c|c|}
\hline \multirow[t]{2}{*}{ Caliber } & \multirow[t]{2}{*}{$\begin{array}{l}\text { Length } \\
\text { (inch) }\end{array}$} & \multirow[t]{2}{*}{$\begin{array}{c}\text { Temp. } \\
\text { (C) }\end{array}$} & \multirow[t]{2}{*}{$\begin{array}{l}\text { Current } \\
\text { density } \\
\left(\mathrm{amp} / \mathrm{dm}^{2}\right)\end{array}$} & $\begin{array}{l}\text { An } \\
\text { Diam. } \\
\text { (inch) }\end{array}$ & Metal & \multirow[t]{2}{*}{$\begin{array}{l}\text { Time } \\
(\mathrm{hr})\end{array}$} & \multirow[t]{2}{*}{$\begin{array}{l}\text { Flow rate* } \\
\text { (liter per min) }\end{array}$} & \multicolumn{8}{|c|}{$\begin{array}{l}\text { Plate thickness on landa (mils) at given diatance (inch) } \\
\text { from lower end of barrel }\end{array}$} \\
\hline & & & & & & & & 0 & 4 & 8 & 12 & 16 & 20 & & \\
\hline \multirow[t]{2}{*}{0.3 inch } & 24 & $\begin{array}{l}50 \\
50 \\
50 \\
85 \\
85\end{array}$ & $\begin{array}{l}20 \\
20 \\
20 \\
60 \\
80\end{array}$ & $\begin{array}{l}0.1 \\
0.1 \\
0.1 \\
0.1 \\
0.1\end{array}$ & $\begin{array}{l}\mathrm{Cu} \\
\mathrm{Al} \\
\text { Steel } \\
\text { Steel } \\
\mathrm{Cu}\end{array}$ & $\begin{array}{l}2.5 \\
3.8 \\
5.5 \\
3.0 \\
2.7\end{array}$ & $\begin{array}{c}- \\
- \\
- \\
- \\
5.0\end{array}$ & $\begin{array}{l}1.1 \\
1.8 \\
2.2 \\
1.4 \\
3.3\end{array}$ & $\begin{array}{l}1.2 \\
1.8 \\
2.3 \\
1.1 \\
3.7\end{array}$ & $\begin{array}{l}1.1 \\
1.8 \\
2.6 \\
0.9 \\
3.9\end{array}$ & $\begin{array}{l}1.2 \\
2.1 \\
3.3 \\
0.9 \\
3.8\end{array}$ & $\begin{array}{l}1.2 \\
2.2 \\
3.6 \\
0.9 \\
3.6\end{array}$ & $\begin{array}{l}1.2 \\
2.3 \\
4.0 \\
0.9 \\
3.3\end{array}$ & & \\
\hline & & & & & & & & 0.5 & 5 & 10 & 20 & 30 & 40 & & \\
\hline \multirow[t]{2}{*}{$0.5 \mathrm{inch}$} & 45 & $\begin{array}{l}50 \\
50 \\
50 \\
50 \\
85 \\
85\end{array}$ & $\begin{array}{l}15 \\
15 \\
20 \\
20 \\
80 \\
80\end{array}$ & $\begin{array}{l}0.187 \\
0.25 \\
0.219 \\
0.187 \\
0.187 \\
0.187\end{array}$ & $\begin{array}{l}\mathrm{Cu} \\
\mathrm{Cu} \\
\text { Steel } \\
\text { Steel } \\
\mathrm{Cu} \\
\mathrm{Cu}\end{array}$ & $\begin{array}{r}17.0 \\
11.0 \\
5.0 \\
6.5 \\
2.4 \\
3.2\end{array}$ & $\begin{array}{l}- \\
- \\
- \\
20 \\
27\end{array}$ & $\begin{array}{l}6.3 \\
4.0 \\
1.4 \\
1.5 \\
6.0 \\
6.8\end{array}$ & $\begin{array}{l}6.1 \\
4.3 \\
1.4 \\
1.6 \\
- \\
-\end{array}$ & $\begin{array}{l}6.0 \\
3.8 \\
1.5 \\
1.7 \\
5.4 \\
6.8\end{array}$ & $\begin{array}{l}5.8 \\
3.7 \\
2.0 \\
2.2 \\
3.5 \\
6.1\end{array}$ & $\begin{array}{l}5.7 \\
3.7 \\
2.5 \\
3.6 \\
3.0 \\
6.0\end{array}$ & $\begin{array}{l}5.8 \\
3.8 \\
3.1 \\
5.3 \\
2.8 \\
5.9\end{array}$ & & \\
\hline & & & & & & & & 0.5 & 5 & 15 & 25 & 35 & 45 & 54 & \\
\hline \multirow[t]{2}{*}{0.6 inch } & 60 & $\begin{array}{l}50 \\
50 \\
55 \\
55 \\
85 \\
85\end{array}$ & $\begin{array}{l}20 \\
20 \\
30 \\
30 \\
80 \\
80\end{array}$ & $\begin{array}{l}0.25 \\
0.375 \\
0.25 \\
0.25 \\
0.25 \\
0.25\end{array}$ & $\begin{array}{l}\mathrm{Cu} \\
\text { Steel } \\
\text { Cu } \\
\text { Steel } \\
\mathrm{Cu} \\
\mathrm{Cu}\end{array}$ & $\begin{array}{l}4.8 \\
6.0 \\
6.2 \\
3.5 \\
1.1 \\
1.3\end{array}$ & $\begin{array}{l}- \\
- \\
- \\
- \\
-\end{array}$ & $\begin{array}{l}2.5 \\
3.8 \\
5.7 \\
1.6 \\
5.2 \\
4.1\end{array}$ & $\begin{array}{l}2.1 \\
3.5 \\
5.7 \\
1.8 \\
3.0 \\
3.3\end{array}$ & $\begin{array}{l}2.0 \\
3.3 \\
5.4 \\
1.7 \\
1.5 \\
3.5\end{array}$ & $\begin{array}{l}2.1 \\
3.4 \\
5.5 \\
2.7 \\
1.2 \\
3.9\end{array}$ & $\begin{array}{l}2.1 \\
3.7 \\
5.5 \\
3.3 \\
0.8 \\
3.2\end{array}$ & $\begin{array}{c}2.0 \\
- \\
5.6 \\
- \\
0.8 \\
2.9\end{array}$ & $\begin{array}{l}1.7 \\
4.0 \\
5.6 \\
6.7 \\
1.0 \\
3.1\end{array}$ & \\
\hline & & & & & & & & 0.5 & 5 & 15 & 25 & 35 & 40 & 47 & \\
\hline \multirow[t]{2}{*}{$20 \mathrm{~mm}$} & 54 & $\begin{array}{l}50 \\
55 \\
65\end{array}$ & $\begin{array}{r}20 \\
35 \\
100\end{array}$ & $\begin{array}{l}0.25 \\
0.25 \\
0.25\end{array}$ & $\begin{array}{l}\mathrm{Cu} \\
\mathrm{Cu} \\
\text { Steel }\end{array}$ & $\begin{array}{c}19.2 \\
10.0 \\
1.0\end{array}$ & - & $\begin{array}{r}9.5 \\
11.5 \\
6.5\end{array}$ & $\begin{array}{c}9.5 \\
11.5 \\
6.0\end{array}$ & $\begin{array}{r}9.5 \\
11.3 \\
6.0\end{array}$ & $\begin{array}{r}9.5 \\
11.5 \\
5.5\end{array}$ & $\begin{array}{r}9.5 \\
11.0 \\
6.0\end{array}$ & $\begin{array}{r}9.5 \\
10.7 \\
5.5\end{array}$ & $\begin{array}{r}9.5 \\
10.7 \\
5.5\end{array}$ & \\
\hline & & & & & & & & 0.25 & 10 & 20 & 30 & 50 & 60 & 73 & \\
\hline \multirow[t]{2}{*}{$40 \mathrm{~mm}$} & 88 & $\begin{array}{l}55 \\
85 \\
85\end{array}$ & $\begin{array}{l}35 \\
75 \\
70\end{array}$ & $\begin{array}{l}0.5 \\
0.5 \\
0.5\end{array}$ & $\begin{array}{l}\mathrm{Cu} \\
\mathrm{Cu} \\
\mathrm{Cu}\end{array}$ & $\begin{array}{l}5.2 \\
5.0 \\
5.0\end{array}$ & $\begin{array}{c}- \\
28 \star * \\
200\end{array}$ & $\begin{array}{l}6.0 \\
8.0 \\
5.5\end{array}$ & $\begin{array}{l}5.5 \\
7.0 \\
5.5\end{array}$ & $\begin{array}{l}5.0 \\
5.8 \\
5.3\end{array}$ & $\begin{array}{l}5.0 \\
5.2 \\
5.2\end{array}$ & $\begin{array}{l}5.0 \\
4.8 \\
5.3\end{array}$ & $\begin{array}{l}5.0 \\
4.6 \\
5.2\end{array}$ & $\begin{array}{l}5.0 \\
3.5 \\
4.7\end{array}$ & \\
\hline & & & & & & & & 0 & 4 & 14 & 24 & 44 & 64 & $84 \quad 104$ & 124 \\
\hline 3 inch & 150 & $\begin{array}{l}55 \\
85\end{array}$ & $\begin{array}{l}35 \\
75\end{array}$ & $\begin{array}{l}1.25 \\
1.25\end{array}$ & $\begin{array}{l}\mathrm{Cu} \\
\mathrm{Cu}\end{array}$ & $\begin{array}{l}4.8 \\
5.0\end{array}$ & - & $\begin{array}{r}6.5 \\
13.0\end{array}$ & $\begin{array}{r}6.5 \\
13.0\end{array}$ & $\begin{array}{r}6.5 \\
13.0\end{array}$ & $\begin{array}{r}6.5 \\
13.0\end{array}$ & $\begin{array}{r}6.5 \\
11.0\end{array}$ & $\begin{array}{r}7.5 \\
10.0\end{array}$ & $\begin{array}{ll}7.5 & 7.5 \\
7.0 & 7.0\end{array}$ & $\begin{array}{l}6.5 \\
6.0\end{array}$ \\
\hline
\end{tabular}

* With the exception noted below (Note**) all barrels were plated with natural solution flow unless a value for flow rate is given in this column, in which case the solution was pumped. By natural flow is meant the flow of solution induced through the bore by rising gas bubbles.

* Plated with natural solution flow. 
Pump-plating equipment is relatively simple. Three designs are shown schematically in Figure 8. The designs shown as A and $B$ have been used with good results, but $C$ is believed best for production plating.

\section{MISCELLANEOUS DATA RELATED TO CHROMIUM PLATING OF TUBES}

\section{1 Effect of anode resistance on longitudinal variation in plate thickness}

It was found that most types and calibers of barrels are improved in both target pattern size and accuracy life if the bore diameter tapers gradually to a smaller value at the muzzle (17). By applying a plate having a tapering thickness, a choke can be produced much more easily than if it were made by machining.

The value of the choke was first discovered during our work in 1944. It was produced by a combination of enlargement of the bore at the breech end and constriction of the bore at the muzzle end. Breech enlargement was obtained by electropolishing with the breech end up, and muzzle constriction was obtained by plating in the same position with a copper anode, which yielded a plate that was slightly thicker at the muzzle end. In September of 1944, a British report appeared (18) which confirmed the value of the choked muzzle, but their method for obtaining the choke by utilizing the resistance of a lead-coated steel anode was more practical and was adopted by NBS. By suitable selection of anode resistance, almost any desired longitudinal configuration of plate can be obtained. This is illustrated in Figures 9 and 10.

\subsection{Effect of trivalent chromium and iron in the plating bath on deposit taper}

When plating is carried out with a resistance anode, the presence of trivalent chromium or iron in the plating bath appreciably decreases the degree of longitudinal taper in the thickness of the plate. This is shown in Figure 11. We postulate that the effect is primarily due to the fact that the trivalent ion causes an increase in cathode efficiency which varies inversely with the current density. This effect is of much importance in production plating of gun barrels to close diametral specifications. Control of the concentration of trivalent chromium is therefore usually necessary $(19,20)$. To, avoid the necessity for controlling the concentration of trivalent chromium, certain production contractors have compensated its effect by the use of tapered anodes or by obtaining part of the required bore taper by means of special electropolishing procedures (see Section 7.4.1.7). 

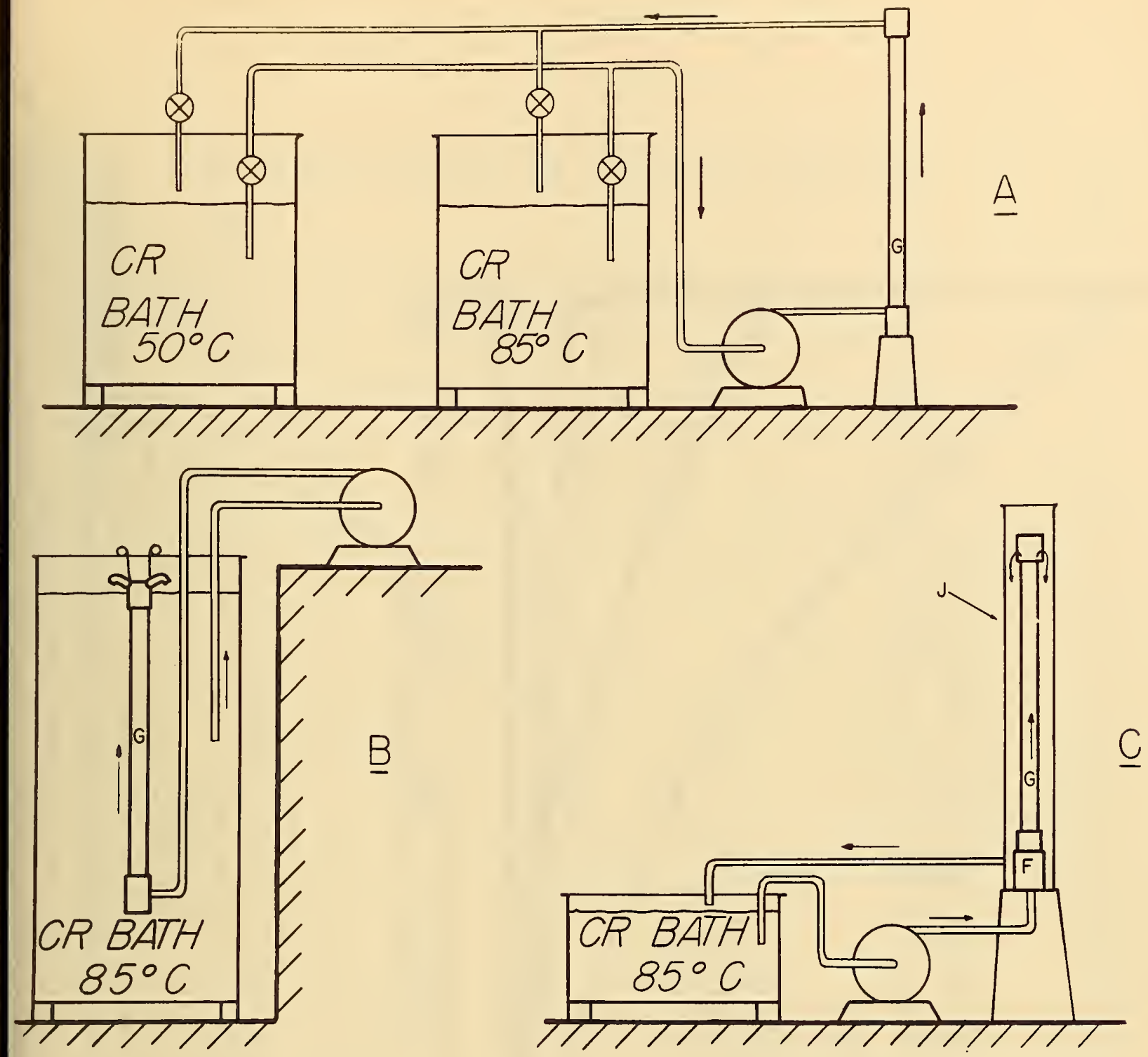

Figure 8. Diagram of three pump-plating systems.

A - Open stand method.

$B$ - Tank submersion method.

C - Quick-assembly method. In C, F is a quick-change solution-inlet fitting to which the barrel is connected by a taper joint or a one-half turn thread (detail not shown). $J$ is a steel jacket which serves to collect the overflow from the top of the barrel and return it to the tank. In each case $G$ is the gun barrel. An auxiliary chromium solution maintained at 50 to $55 \mathrm{C}$ is required in each case, for anodic etching prior to plating (not shown for $B$ and $C)$. Auxiliary items such as a flow-meter, pressure-gage, and flow-control valve are not shown. 


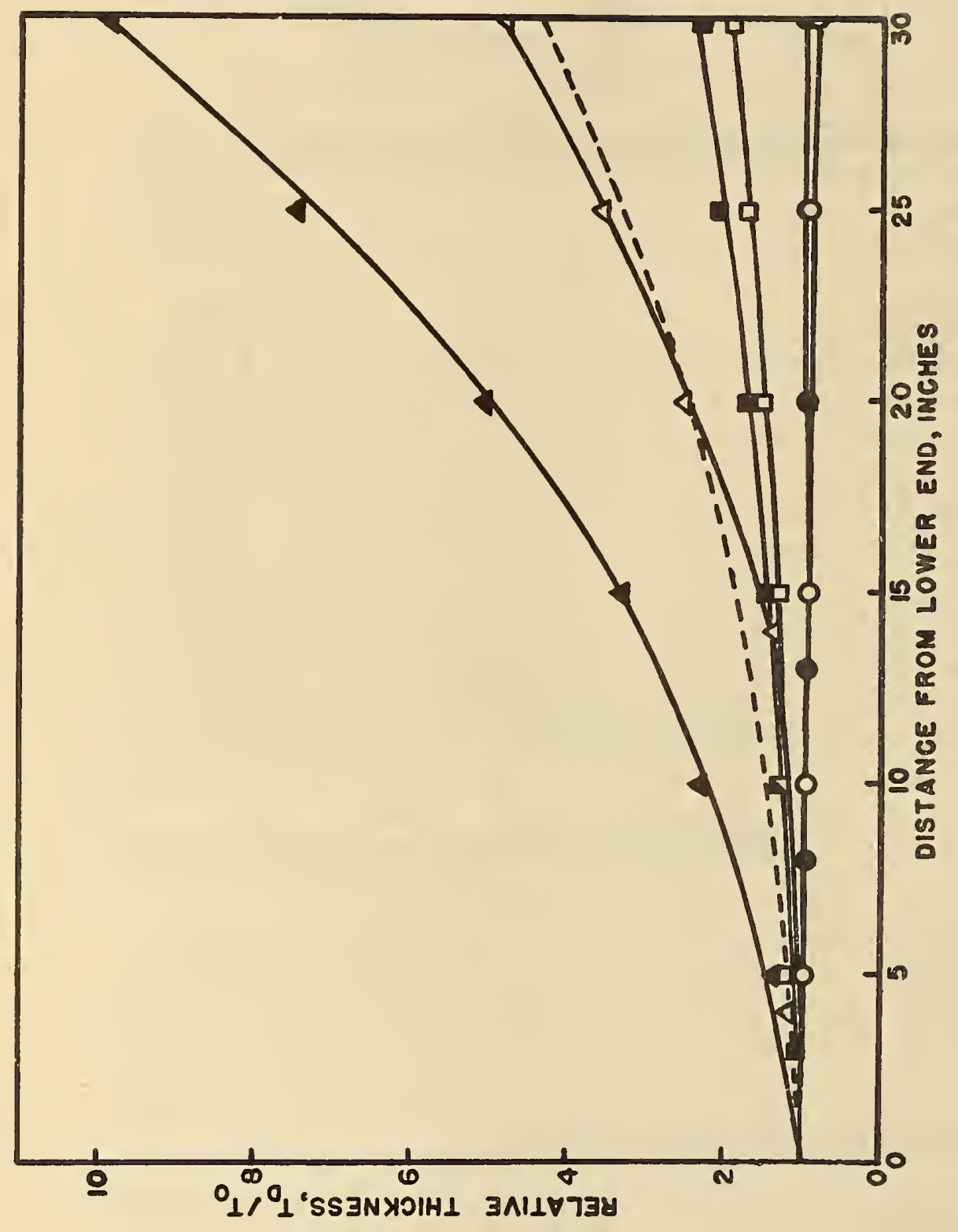

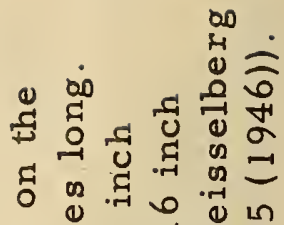

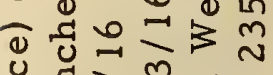
द्व $\bar{m}$, द्व की

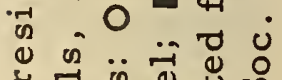
म न .

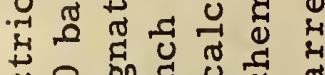

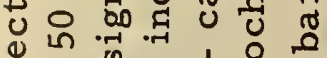

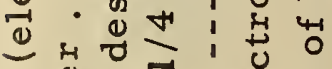

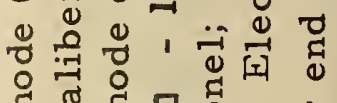
व व द्य द्व 离 फ क द्व . द्न $\mathrm{E}$

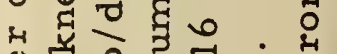
ه द्व द्वृ

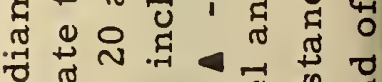

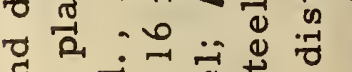

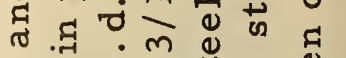

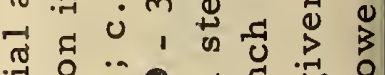

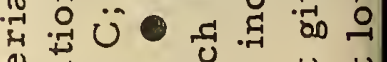

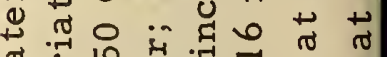

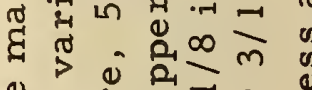

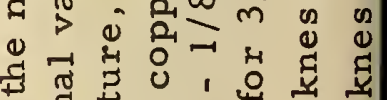

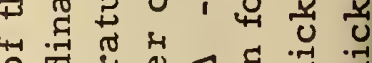
U ४ क द्व द्व ज्ञ

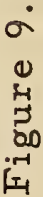




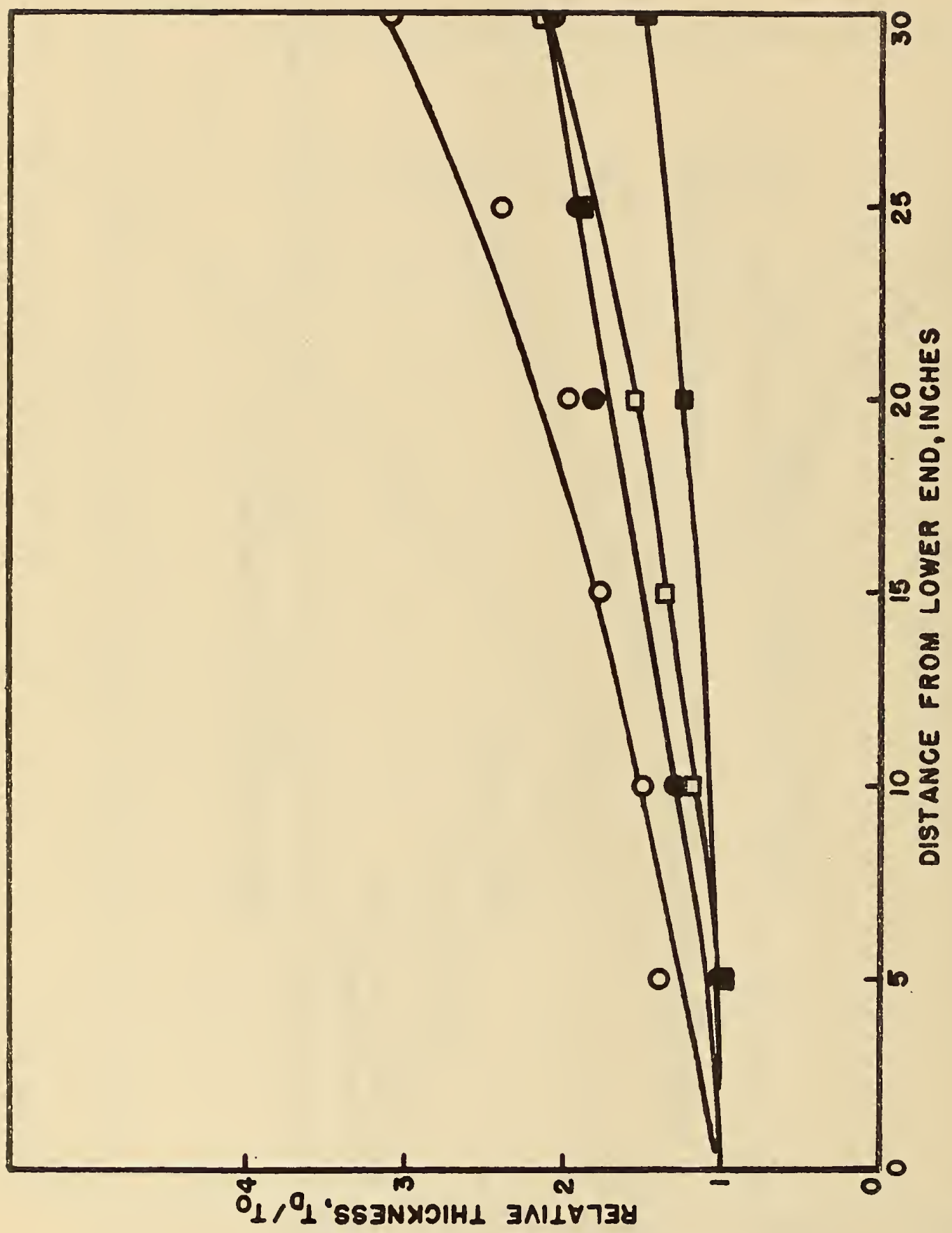

롤

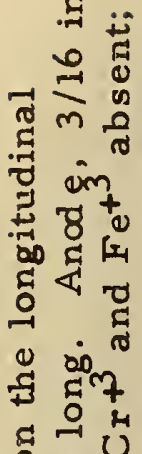

द्व

द्व

承

○ิ

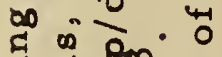

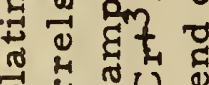

म

요요 4

झ 0.00

เ

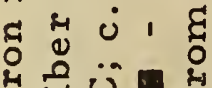

出

- 0 0 0

( ${ }^{+}+$\&

द्व

द 3 के

द्व

० 焉

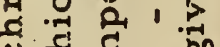

ठ द्व द्व

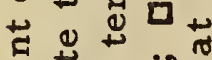

d

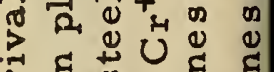

年

4 द म

- 욤

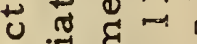

政

$=$ 


\subsection{Effect of current density on deposit taper}

The effect of current density on the longitudinal variation in the thickness of the deposit can be seen by examining the data in Table 2 . In general, increase in current density decreases the relative thickness of the plate at the upper end of the bore.

\subsection{Effect of anode eccentricity on plate eccentricity}

Circumferentially uniform thickness of plate in a gun barrel is very important. Obviously, if the plate is only a fraction of the required thickness for good performance on one side of the bore, as a result of anode eccentricity, the firing-life of the barrel will be sub-standard.

The results of a few measurements in caliber . 50 barrels are shown in Figure 12. As a rule-of-thumb criterion, we have designed fixtures on the basis that the radial eccentricity of the anode should not be more than $2 \%$ of the anode to cathode distance. Interpolating in Figure 12, an anode eccentricity of $2 \%$ corresponds to a plate eccentricity of about $15 \%$.

In addition to maintaining close concentricity of the plating fixtures, the anode must be straight. Experience has shown that an anode bent even slightly does not straighten completely when assembled under tension in a barrel. The British have made a careful study of anode problems and their specification calls for maximum possible straightness (21). They require a plumb-line straightness test and special packing and handling procedures to avoid flexing the anodes during shipping and assembly.

\section{5 Changes in land contours caused by electropolishing and plating}

At the request of the Artillery Branch, Research and Development Division of the Office of the Chief of Ordnance, a study was undertaken in 1946 to obtain data on changes in land contours caused by electropolishing and chromium plating. These data were to be used in designing "as-machined" lands for barrels which were to be plated, so that the final contours of the lands in the plated barrels would be as close as possible to the standard design. In view of the more recent work on land design described in section 8.8 , it is doubtful whether it is worthwhile to attempt to reproduce in a plated barrel the contours of standard machined lands. However, the data are recorded here for the sake of completeness. 


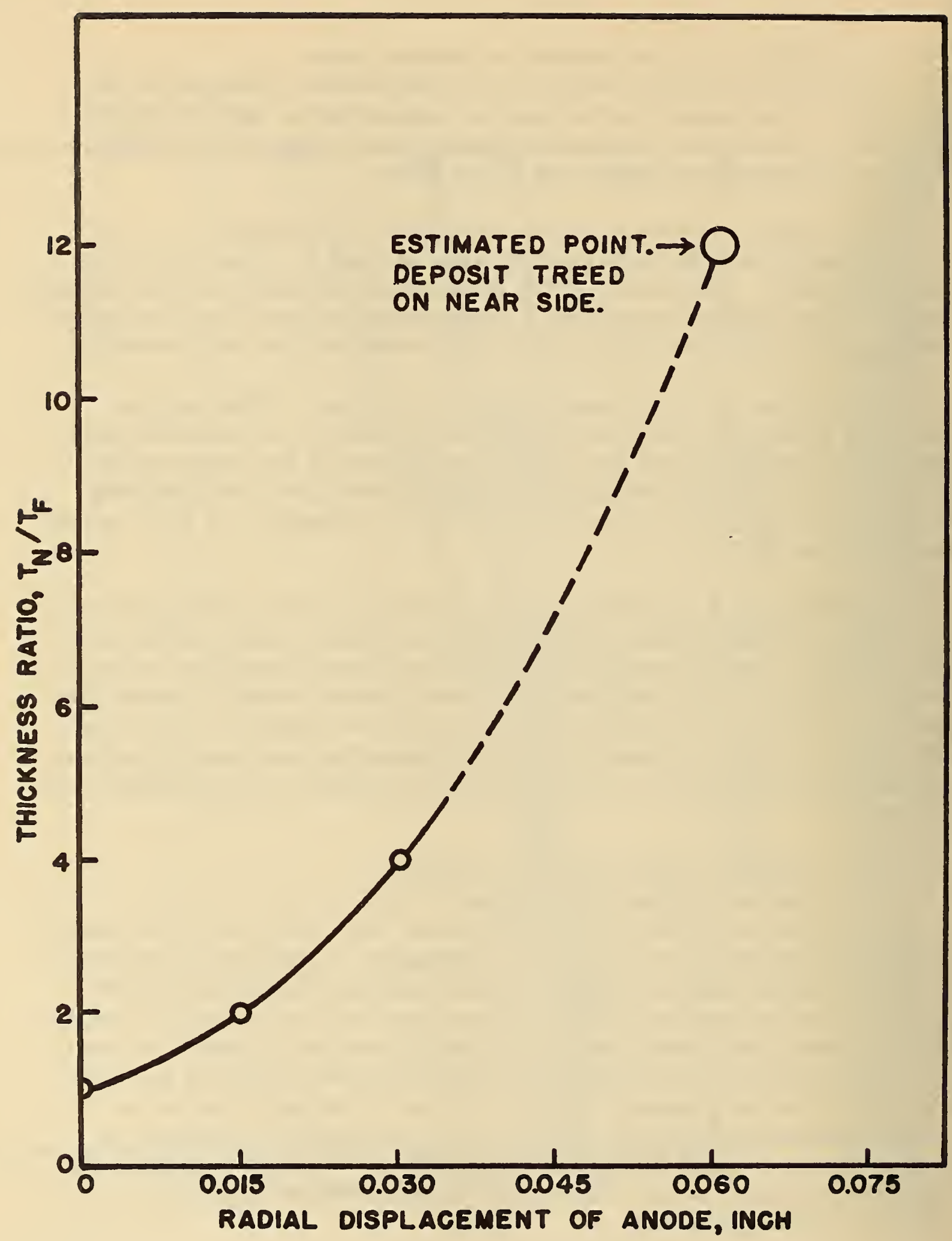

Figure 12. Eccentricity of plate as a function of anode eccentricity. Bore diameter, 0.5 inch; temperature, $50 \mathrm{C}$; current density, $20 \mathrm{amp} / \mathrm{dm}^{2}$; anode diameter, 3/16.inch. $\mathrm{T}_{\mathrm{N}}$ - plate thickness on side near the anode, and $\mathrm{T}_{\mathbf{F}}$ on side far from anode. 
Most of the work on this subject utilized short sections of a $90-\mathrm{mm}$ barrel. A few measurements were also made of the contours of the lands in caliber .60 and $20 \mathrm{~mm}$ barrels.

The results with $90 \mathrm{~mm}$ sections are summarized as follows:

\subsubsection{Effect of electropolishing}

The angle between the side-wall of the land and the radial line to its base increases about 1.2 degrees for each 0.001 inch thickness of steel removed by electropolishing, under polishing conditions of $50 \mathrm{C}$ and $25 \mathrm{amp} / \mathrm{dm}^{2}$. The bath described in section 5.2 was used. The above value of 1.2 degrees/mil is the average for both sides of the land. A marked difference was noted between the two sides of the land, with the rate of angular increase about 50 percent higher on the side of the land against which the rising solution impinged. Therefore, if it is desired to retain a uniform angle on both sides of the land, it would be necessary to electropolish in two steps, half the time with one end of the barrel upward, and half the time with the barrel reversed.

The width of the land decreased about 0.001 inch for each 0.001 inch removed from the top of the land. Electropolishing increased the radius of the land corner slightly, but facilities were not available for measuring the radius accurately.

\subsubsection{Effect of chromium plating}

The following tabulation shows the change in side-wall angle for three values of current density:

$\begin{array}{ll}20 \mathrm{amp} / \mathrm{dm}^{2}, 50 \mathrm{C} & \frac{\text { Decrease in angle } / \mathrm{mil} \text { of plate }}{0.8 \mathrm{degree}} \\ 30 \mathrm{amp} / \mathrm{dm}^{2}, 55 \mathrm{C} & 1.3 " 1 \\ 40 \mathrm{amp} / \mathrm{dm}^{2}, 60 \mathrm{C} & 1.8 \mathrm{ll}\end{array}$

The above values were obtained with plates in the range of thickness of 0.005 to $0.008 \mathrm{inch}$. In one experiment at $50 \mathrm{C}, 20 \mathrm{amp} / \mathrm{dm}^{2}$, in which the plate thickness was 0.015 inch, the decrease in angle per mil of plate was 1.1 degrees. 
At $50 \mathrm{C}, 20 \mathrm{amp} / \mathrm{dm}^{2}$, and $55 \mathrm{C}, 30 \mathrm{amp} / \mathrm{dm}^{2}$, no significant distortion of the corner of the land was noted, with plates up to 0.008 inch thick on a basis land that had been electropolished an equal amount. However, at $60 \mathrm{C}$ and $40 \mathrm{mp} / \mathrm{dm}^{2}$, the land-corners did build up. In one experiment under these conditions, the thickness of the deposit on the corner was 0.01 inch in comparison with 0.007 inch on top of the land.

In experiments in which different initial radii were formed on different lands by filing, it was found that in order to avoid corner build-up, an initial radius of at least 0.01 inch was required under 0.006 inch thickness of plate $\left(50 \mathrm{C}, 20 \mathrm{amp} / \mathrm{dm}^{2}\right)$.

Because electropolishing reduces the width of a land faster than plating restores its width, the combination of operations results in narrowing the top of a land about 0.0005 inch for each 0.001 inch thickness of plate $\left(50 \mathrm{C}, 20 \mathrm{amp} / \mathrm{dm}^{2}\right)$.

All of the above results were obtained with a 1 1/2-inch diameter anode. Several experiments repeated with a 3 -inch diameter anode gave essentially the same results.

Experiments to determine the effect of electropolishing and plating on the land contour of caliber .60 barrels showed that an electropolish of 0.001 inch is a satisfact ory pretreatment for HC chromium, but that longer electropolishing is desirable. For deposits of 0.01 inch thickness, 0.004 to 0.005 inch electropolish is optimum. When depositing LC chromium, an electropolish equal in depth to the total plate thickness is necessary, or corner build-up will occur. When plating HC chromium 0.01 inch thick in $20 \mathrm{~mm}$ barrels, an electropolish at least 0.005 inch deep is required to prevent corner build-up.

7. SUMMARY OF THE PERFORMANCE OF CHROMIUM PLATE IN BARRELS. CALIBER . 22 TO 3 INCHES

\subsection{Caliber .22 barrels}

Two barrels 28 inches long were plated for the Midwest Research Institute, Kansas City, Missouri, in April 1954. A thickness of 0.002 inch of HC chromium was applied from the standard bath at $50 \mathrm{C}$ and $15 \mathrm{amp} / \mathrm{dm}^{2}$. The anode was lead-plated copper, $1 / 8$ inch diameter. 
No test data for these barrels were received by NBS, but a verbal report from ORDTS indicated that their performance was significantly better than that of unplated barrels.

\subsection{Caliber .30 barrels}

Experimental chromium plating of caliber .30 barrels was started in 1945, and four barrels were prepared under the sponsorship of NDRC. The NDRC program terminated before these barrels were fired. They were, however, tested at Dahlgren in August 1946.

This group of plated caliber. 30 barrels included two with nonnitrided steel and two with nitrided steel. Two standard unplated barrels were fired as controls. In the plated barrels, a thickness of 0.002 inch of $\mathrm{HC}$ chromium was used, with the muzzles choked to 0.291 to 0.294 inch. They were fired on a schedule of two 300 -round bursts with two minutes air-cooling between bursts, and with complete cooling after 600 rounds (abbreviated $2 \times 300_{2}$ ).

The results are summarized in Table 3 . It is seen that the life of the plated barrels was four to five times longer than that of the unplated barrels, and that the nitrided barrels were about 20 percent better than the unnitrided.

Not shown in the table is the fact that the barrels choked to about 0.291 caused excessive build-up of copper in the muzzle recoil booster. Subsequent work showed that 0.294 to 0.296 was an optimum muzzle diameter.

In January of 1946, twelve caliber . 30 barrels, numbered C-1 to C-12, were plated for Springfield Armory. These were not nitrided. Plate thickness was 0.002 inch at the origin of rifling. The barrels were divided into three groups with respect to choke: one group with no choke, one group choked to 0.297 , and one to $0.294 \mathrm{inch}$. We have no report on the test results.

No further work was done with caliber .30 barrels until 1949, after which several groups of barrels were plated for test-firing at Aberdeen Proving Ground. These are described in Table 4. Also included in Table 4 is a group of barrels plated for the Aviation Ordnance Section of Naval Ordnance. 


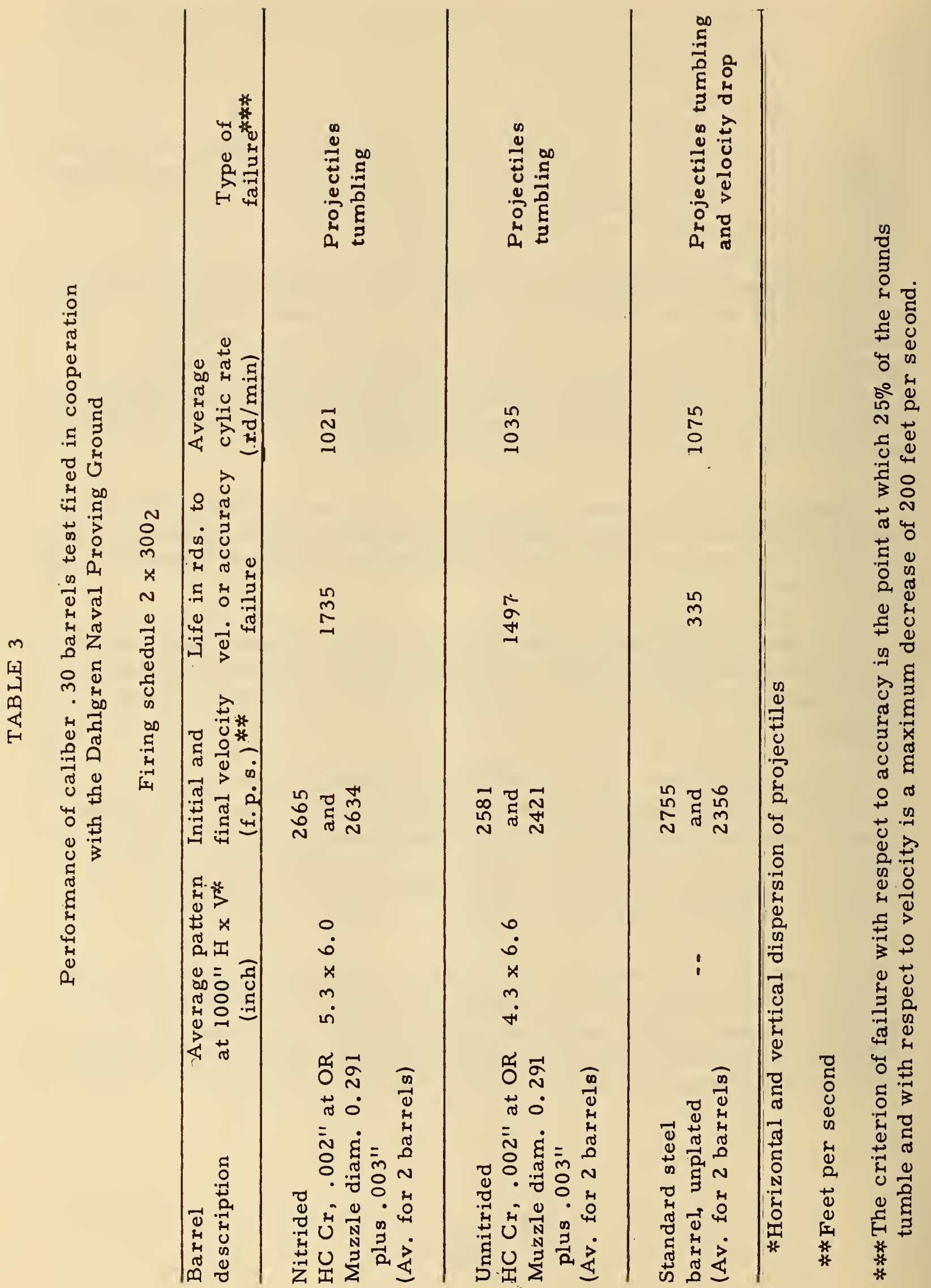




\section{Date delivered Description of to APG}

APG

Report reference Results of tests
Sept. 1949

None nitrided.

16 th Report,

OCO Project

All with 0.0025 inch

No. TS3-3039,

4 - No choke

3 - Choked to 0.296

plus .002

3 - Choked to 0.292

plus .002

Model M1919A6

Sept. 6, 1950
Schedule, continuous $\times 200_{2}$. The choked barrels and comparison Stellite-lined barrels all had lives in the range 1200-1500 rounds. Unchoked barrels about 700 rounds. Corresponding data for plain steel barrels not shown. Tests of $\mathrm{Cr}_{\mathrm{r}}$ plate ahead of Stellite with an intermediate choke of 0.294 plus .002 inch recommended.

\section{Jan. 19514 barrels, Model A4 No record.}

None nitrided.

Stellite-lined, $\mathrm{HC} \mathrm{Cr}$

ahead of liner, 0.003

inch thick, choked to

0.294 plus .002 inch.
Schedule, continuous $\times 300_{2} \cdot 1500-1700$ rounds on lst phase, 600-900 rounds on 2nd phase. No comparison data for unlined or plain steel barrels available.

Jan. -March 19 barrels plated for SA,

No reports received by NBS. 1952 and 40 for APG. Some Stellite-lined, some plated full-length, all 0.002-3 inch thickness $\mathrm{HC} \mathrm{Cr}$, choked to 0.294 plus .002 inch.

10 BAR, caliber.30, 39th Report, M1918A2. 5 with $0.001-2$ OCO Project inch thickness, 5 with No. TS2-2015, 0.002-3 inch thickness October 7, 1954 of $\mathrm{HC} \mathrm{Cr}$. All choked to $0.298-9$ inch.
Schedule, 40 rounds/min. for 3 minutes, complete cooling each 120 rounds. On this relatively mild schedule, none of the barrels reached end of life at end of test ( 6000 rounds), but the chromium plated barrels had superior erosion resistance and the chromium plating prevented formation of metallic fouling of the bore with ball-type propellants.
8 machine gun barrels, nitrided, 0.002 inch $\mathrm{HC}$ chromium, choked to 0.294 inch.
Plated for Aviation Ordnance Section of Naval Ordnance
No formal report on test procedure or performance received by NBS. Verbal reports indicated 5 to 10 fold life in comparison with unplated barrels. No data on firing schedule. 
In summary, it may be stated that no systematic study has been made of the effect on performance of thickness and type of plate in caliber .30 barrels, but that the thickness of about 0.002 inch, which has been used in most of the test barrels, is probably a good choice. A choke diameter of about 0.296 inch has been established as optimum.

Barrels plated to these specifications have a performance life on several firing schedules about four times that of unplated barrels.

\section{3 Caliber . 45 pistol barrels}

During the period from January to July 1955, a total of 115 caliber 45 pistol barrels were plated with HC chromium for ORDTS-MG. A thickness of 0.0015 to 0.002 inch was applied. No performance data are available to NBS.

\subsection{Caliber. 50 barrels}

\subsubsection{Aircraft type}

The intensive program on the caliber . 50 aircraft barrel during 1944 and 1945, in cooperation with the Geophysical Laboratory, which involved test-firing of several hundred barrels, established many facts and resulted in the specifications for plated barrels given in Table 5 . These specifications have been modified only slightly as the result of later work. The performance of these barrels is described in reference (9). Several questions concerning this type of barrel remained unanswered at the close of the NDRC program, and these were the basis for tests that were continued in cooperation with the interested groups in Army Ordnance, during 1946 and 1947. Most of the test firing was done at the Naval Proving Ground, Dahlgren, Virginia. Very little work directed primarily toward the improvement of caliber . 50 barrels has been done since 1947 . However, this barrel has bœn used since then as a test vehicle for several special tests, which are described in section 8 of this report. Following is a discussion of the tests carried out in 1946-47.

\subsubsection{Effect of a rough chromium plate}

A number of barrels plated by a production contractor were found on proof-firing to give immediate tipping, and in some cases, complete keyholing. Three of these barrels were examined by NBS and several tests were made to determine the cause of this behavior. The only visible defect was roughness of the plated bore. It was found that the rough surface of the bore scraped off part of the material of the projectile jacket. This probably reduced its diameter sufficiently to prevent complete engagement with the rifling, thus resulting in reduced projectile spin. 
The chromium was removed from some of the rough barrels by anodic stripping in an alkali solution. The surface of the bore in these barrels was found to be rough, corresponding to the roughness of the plate. In two of the barrels the roughness appeared to have been caused by severe etching of the steel. The etching may have been the result of either defective Parkerizing or of defective electropolishing. In one of the barrels, the roughness was of a different character, and was the result of incomplete de-coppering prior to electropolishing. These findings are cited to show the importance of a smoothly plated bore surface.

\subsubsection{Effect of exterior barrel design}

This factor is of importance primarily with barrels that are chromium plated ahead of a Stellite liner. Tests at the Geophysical Laboratory had shown that many barrels of this type failed under severe firing schedules as a result of bulging of the steel opposite the front end of the liner. Strengthening the barrels at this point by shrinking on a reinforcing sleeve opposite the end of the liner resulted in a marked increase in the life of this type of barrel. This type of reinforced barrel was in production for a period.

Testing of three new reinforced designs had been started, but not completed, by the Geophysical Laboratory. Two of their designs were designated as GLA and GLB. The third was a standard barrel reinforced with a wire winding. All of these performed significantly better than the sleeve-reinforced barrel. The best performance was obtained with the GLB design, which had a life of 5000 to 6000 . rounds compared with a life of about 2000 rounds for the sleeve-reinforced model. Comparative data for these barrels are shown in Table 6, and the GLA and B designs are shown in Figures 13 and 14. Based on our experience with these barrels, a design that was believed to be a further improvement was drawn, but no work was done with it because the interest of the sponsors had shifted to the development of larger caliber barrels.

\subsubsection{Hot-hard die steels as barrel materials}

It has been pointed out in section 4 of this report that swaging of the basis steel, owing to its low hot-hardness, is in part responsible for ultimate failure of the chromium plate in a gun bore. Nitriding of the steel is one approach toward overcoming this deficiency.. The staff of the Geophysical Laboratory had considered the uee of die steels, which have fairly good hot-hardness to about $600 \mathrm{C}$, as experimental barrel materials for evaluating the effect of improved hot-hardness in prolonging the life of chromium plate. The steels selected, from which barrels were made, are "Potomac", made by Allegheny-Ludlum; 


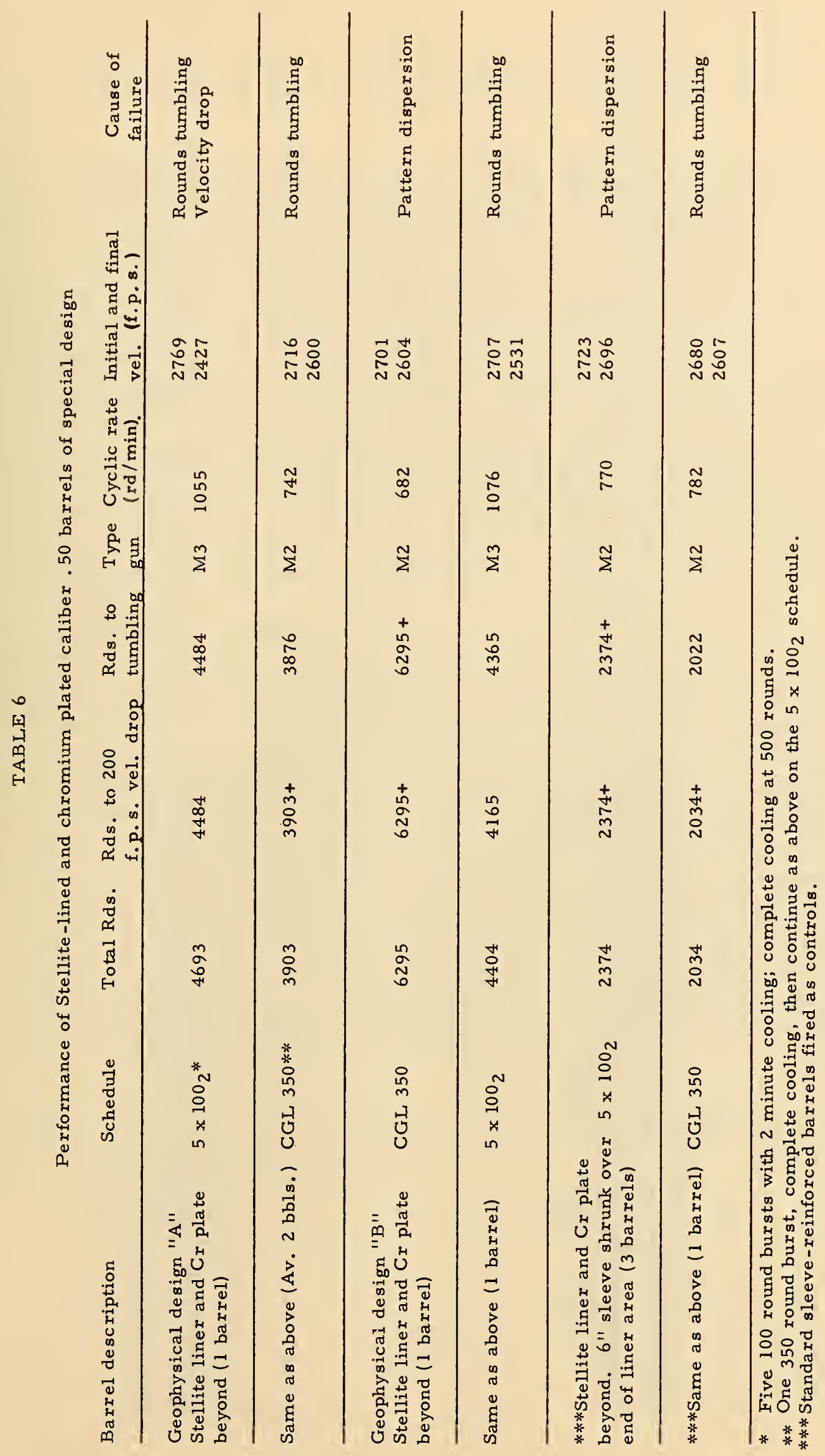



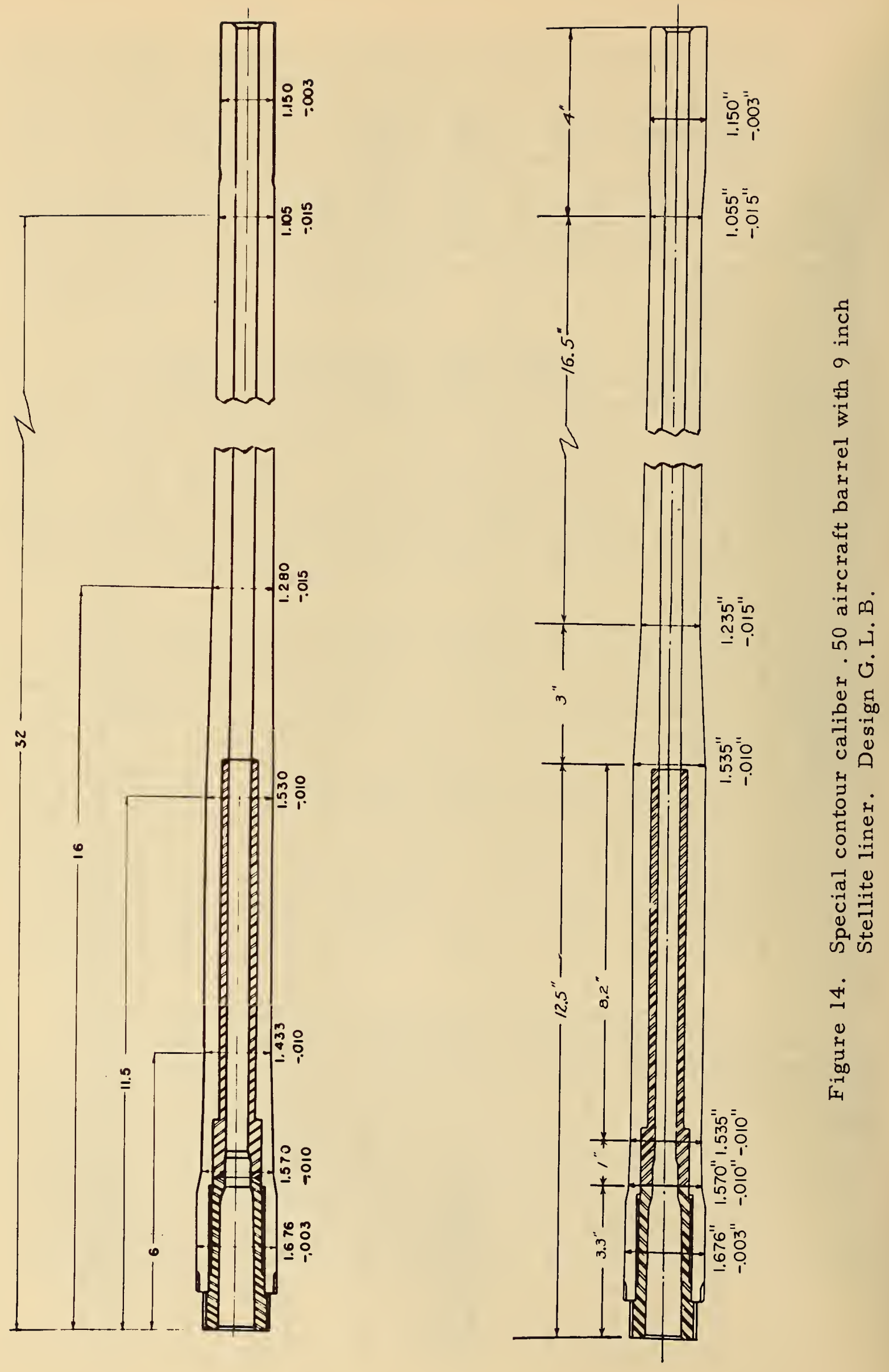
"Peerless-A" and "Cro-mow", made by Crucible Steel Company; "TK", made by Carpenter Steel Company; and medium alloy steels with $2 \%$ and $3 \%$ molybdenum. Plating and testing of these was completed by NBS after the close of the program at the Geophysical

Laboratory.

It was known from previous general experience that it is difficult to obtain good adhesion of chromium or other electroplates to these steels. Therefore before plating the barrels, considerable work was done on small specimens to develop a method for obtaining adequate adhesion of the plate. A variety of acid and alkaline etch treatments, and preplating treatments such as applying a flash of cobalt from a cobalt fluoride bath were tried, as well as low current density anodic and cathodic treatments in chromic acid, such as are used for plating chromium on chromium or on stainless steels. A low current density cathodic pretreatment in chromic acid was selected as most promising and was used on one "Potomac" and one "Peerless A" barrel. Both failed as a result of poor adhesion in 400 to 500 rounds. It was not considered practicable to pursue these experiments further, and no more work has been done along this line.

\subsubsection{Performance of thick chromium plates}

During the 1944-45 period, it had been established that about 0.0015 inch thickness is a minimum for good performance, and that 0.002 to 0.003 inch is significantly better. Very limited tests of thicker plates had been made. Therefore, two barrels were tested that were plated with 0.005 to 0.006 inch thickness of $\mathrm{HC}$ chromium. Their life on a firing schedule of $5 \times 1002$ was about 900 rounds. Nitrided barrels with chromium 0.01 inch thick also had a life of 900 rounds. Comparison of these results with those given in reference (9) (a life of 725 to 750 rounds on the same schedule) shows that the gain with respect to barrels plated with 0.002 to 0.003 inch thickness is significant, but probably not sufficient to warrant the additional cost of the thicker plate, especially in view of the low barrel cost. The same conclusion was reached regarding the value of a thicker plate ahead of a Stellite liner.

*Five 100 round bursts with 2 minutes air-cooling between bursts, complete cooling after 500 rounds. 
It may be noted at this point that a thickness of 0.005 to 0.006 inch in this barrel yields a solid chromium land. That is, the plate on the lands is not backed up laterally by steel. We have found that, in general, in other calibers also, this situation leads to breaking of lands with the break in the chromium itself, owing to its relatively low strength. In caliber $.60,20 \mathrm{~mm}$ and $40 \mathrm{~mm}$ barrels, optimum thickness is about one-half to two-thirds of the land height. An exception is found in the caliber. 50 heavy barrel, where 0.005 to 0.006 inch thickness performs significantly better than 0.002 to $0.003 \mathrm{inch}$.

\subsubsection{Effect of an extreme choke}

In connection with a question concerning a waiver of the specified minimum muzzle diameter of 0.492 inch, two barrels were test-fired that had muzzle diameters of 0.440 inch. The barrels were otherwise the standard full-length-plated type. Velocity and accuracy were normal, and the small muzzle diameter did not cause coppering of the muzzle recoil booster that was used in the test. (Barrel Nos. L2J143 and L2J223, May-June 1946).

\subsubsection{Testing done to determine the best method for plating ahead of Stellite liners}

Manufacture of barrels that are chromium plated ahead of a Stellite-liner involves several problems of choice between alternative methods. The main question is: Is it better to plate the bore ahead of the liner (or liner recess) before or after insertion of the liner? From the standpoint of the plating problems encountered, it is preferable to plate before insertion of the liner. However, from the standpoint of the mechanical operations and the amount of handling and shipping involved, it is preferable to plate after insertion of the liner.

The following problems are encountered in plating after insertion of the liner:

(a) It is very difficult to electropolish the bore ahead of the liner without some anodic etching and chemical attack of the liner surface.

(b) Corrosive processing solutions, including acid dips, electropolish solution and chromic acid solution, will flow into the minute crevices behind the liner, in the retainer threads, etc., and may be expected to cause corrosion during subsequent storage of finished barrels, owing to the impossibility of completely removing these materials by rinsing after plating. 
(c) It is more difficult to meet diameter and thickness specifications when plating only the short segment of bore ahead of the liner, than when plating the full length of the bore; as can be done when the liner has not been inserted, by using a "dummy" liner of steel.

The results of the firing tests led to the conclusion that the performance of the barrels was the same whether they were plated before or after insertion of the liner. However, no satisfactory means were found to eliminate the etching of the liner or the possibility of corrosion during storage, so plating before insertion of the liner became the accepted procedure.

Two difficulties were encountered in the course of the work with Stellite-lined barrels that warrant mention. First, poor reproducibility of barrel performance made it necessary to fire a large number of barrels. It was determined that variability in the resistance of the Stellite liner to swaging was the main cause of the poor reproducibility. The forward end of the liner, as a result of forward flow of the Stellite, developed an undersize constriction that sheared the projectile jacket.

This caused tumbling of the projectile, even though the bore was in excellent condition otherwise.

The second difficulty was related to the firing schedule and was corrected. Because of the very long life of Stellite-lined barrels, a severe schedule was adopted by the Geophysical Laboratory to shorten the tests. This schedule, designated as the CGL-350 schedule, consisted of an initial continuous burst of 350 rounds, followed by complete cooling, after which a $5 \times 100_{2}$ schedule was fired. This schedule was originally used with the $\mathrm{M}-2$ gun at a rate of fire of 700 to 800 rounds/minute. With the M-3 gun, having a rate of fire of 1000 to 1200 rounds/minute, it was found to be too severe. The initial 350 round burst caused bulging of the reinforced barrel wall near the forward end of the liner, which ended the test before other factors, related to the chromium plate, could be evaluated. Therefore the milder schedule of $5 \times 100_{2}$ was used, without the initial 350 round burst. 
7.4.1.7 Anode designs for plating ahead of a Stellite liner

If a "dummy" steel liner is used in the liner recess for plating the forward end of the bore, plating can be done with the same anode and under the same bath operating conditions as when plating a barrel full-length. Tolerances for plate thickness and bore diameter will be met. However, the cost of investment and maintenance of plating fixtures is less if a non-conducting tube is used in the liner recess. It is then necessary to use an anode with higher electrical resistance than is used for plating the full length of the bore, in order to obtain the required taper in the shorter bore.

In Figures 15 and 16 is shown the longitudinal variation in plate thickness in a liner barrel, where the non-conducting tube is used in the liner cavity, for anodes of several different materials, diameters, and tapers. A ratio of thickness ( $\left.\frac{\text { muzzle }}{\text { breech }}\right)$ of at least 2.0 is needed in order to meet thickness and diameter specifications for this barrel. It is seen that a $3 / 16$ inch diameter steel anode produces much too small a taper. The best anodes were $3 / 16$ inch monel, or a steel anode with a continuous taper from a diameter of $1 / 4$ inch at the muzzle (upper) end to $1 / 8$ inch at the breech end.

Because of the cost of making an anode of the latter type, anodes with stepped tapers were tried. These were made by butt-welding segments of different diameters, and machining short tapers at the joint. Barrels plated with anodes with very short connecting tapers, e.g., one inch, had poor accuracy performance. Longer connecting tapers, such as 2 inches or more between $1 / 4$ and $1 / 8$ inch diameter rods, produced satisfactory barrels. Figure 16 shows that the plate thickness follows the anode contour rather closely. One installation (Springfield Armory) avoided the need for a large taper in plate thickness by obtaining some of the taper in the electropolishing operation. The barrels with which we worked were electropolished to a uniform diameter.

\subsubsection{Smooth bore barrels}

It has been observed frequently by NBS and others who have worked on chromium plated gun barrels, that the presence of rifling in a gun bore contributes to the failure of the chromium plate. The engraving forces to which the plate is subjected, particularly on land corners at the origin of rifling, are very large, and cause the chromium to crack. 


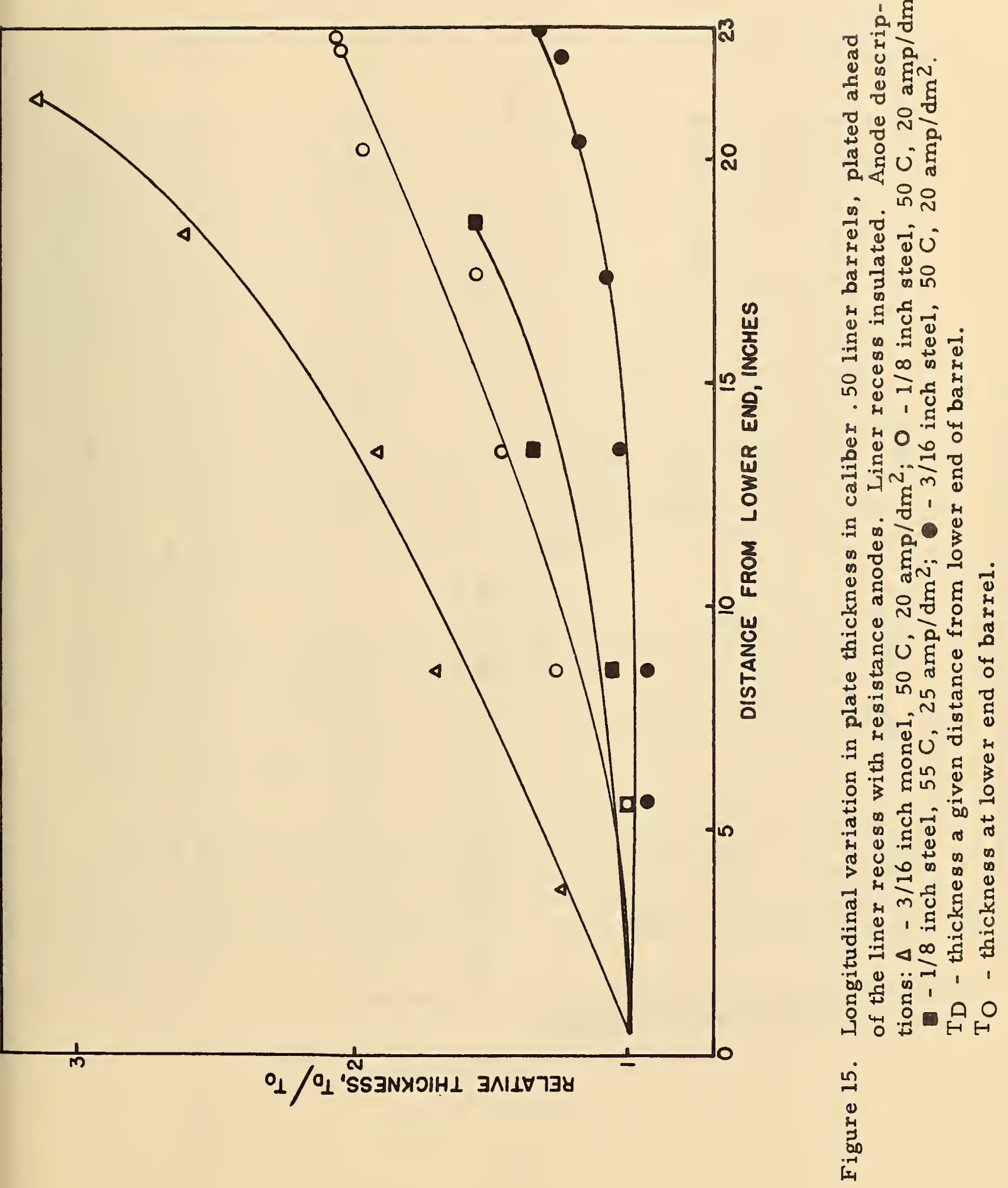




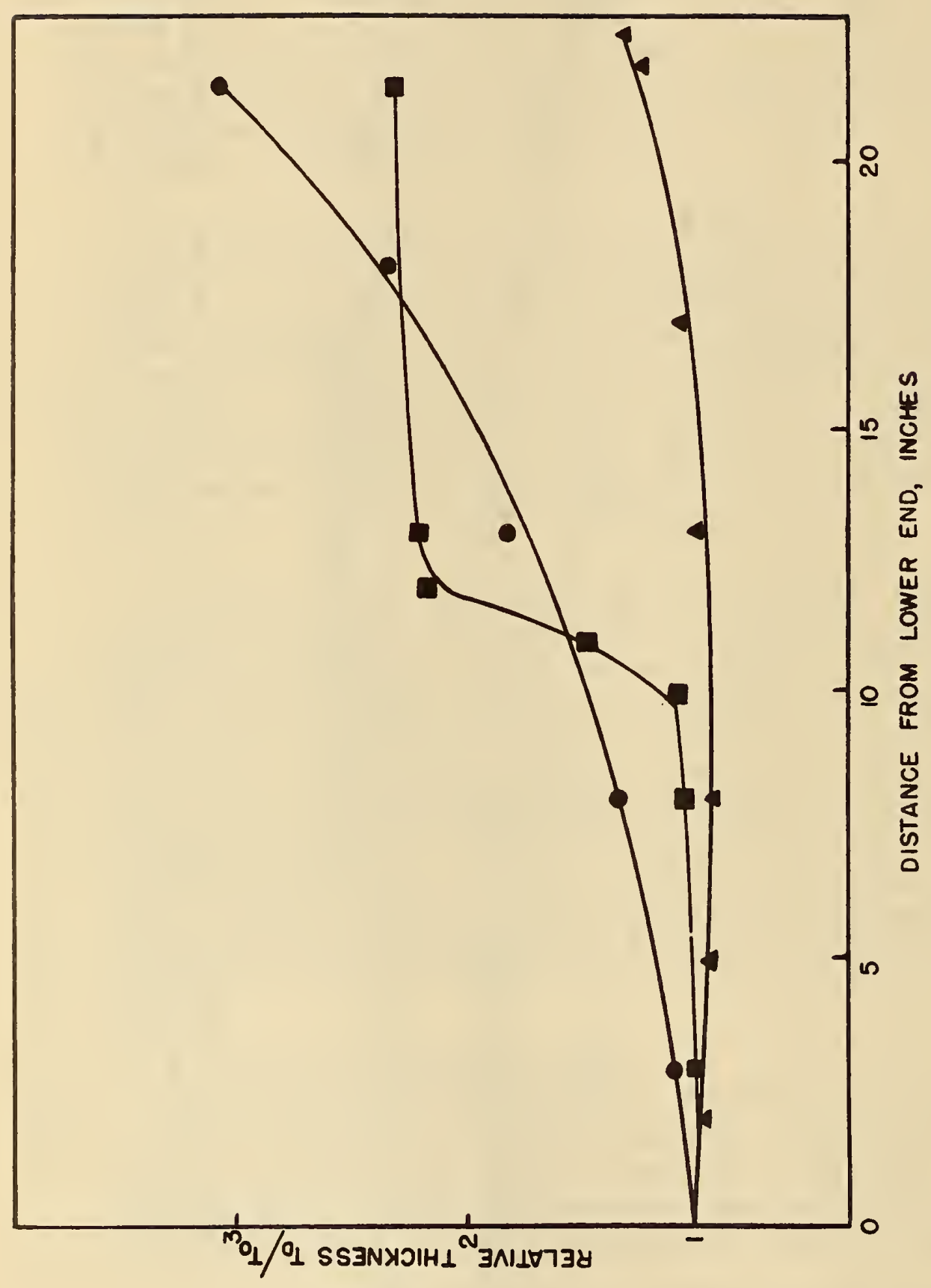

7.

范

द्य

0 00

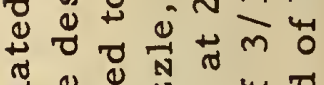

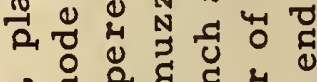

क 岳

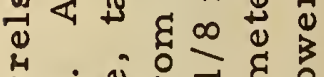

H

(1) $\mathrm{N}$,

๙

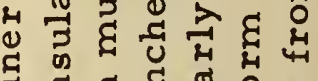

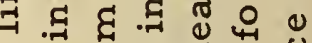

o

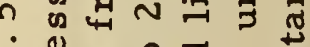

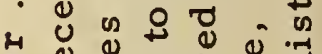

4 \&

얼

न

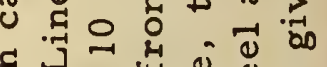

दम

क 8 ॠ

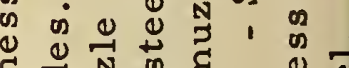

द्व

प्र ¿

मद व द्व द

ช $\varepsilon_{\infty}$

H $\infty{ }_{0}^{0}, 0$

م,

ङ

द्वृ

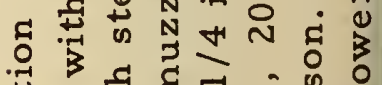

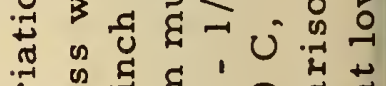

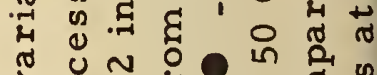

$\rightarrow$ U

न

出 1 过 N

नु

글 द्व

की

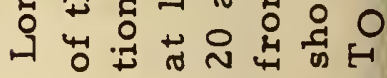

$\stackrel{0}{\rightarrow}$

$\stackrel{4}{3}$

[1 
Furthermore, the plate is thin in the groove corners, and this may lead to early failure. Loss of plate at either location is the start of the process that leads to failure of the barrel. If the bore were smooth, these factors would be absent, and the life of the plate should be prolonged. To check this prediction, a number of smooth-bore barrels were prepared.

Barrels were obtained from Springfield Armory which had a bore diameter of 0.499 plus 0.002 inch, but were not rifled. The breechend enlargements referred to below were made by electropolishing with a moving cathode. Twelve barrels were used for the tests. Thicknesses of HC chromium tried ranged from 0.002 to 0.01 inch, bore diameter from 0.505 to 0.515 inch at the origin of rifling and from 0.501 to 0.510 inch at the muzzle. The firing tests showed that optimum thickness was about 0.003 inch, and optimum diameter at the origin of rifling was 0.513 inch. A muzzle diameter greater than about 0.503 inch was undesirable. These barrels were fired with standard projectiles, which of course had no spin and therefore tumbled, so that neither velocity nor accuracy measureme nts had any meaning. Performance was judged on the basis of rate of removal of chromium and enlargement of the bore in the region of the origin of rifling. These criteria indicated that the life of a chromium-plated, smooth-bore barrel is about 75 percent greater than that of a corresponding rifled barrel.

The caliber . 50 barrel was used in these tests only because of its convenience. Projectiles stabilized with fins could probably not be designed for the caliber. 50 , but may be feasible for larger caliber barrels. The results indicated that smooth-bore barrels used with finned projectiles might have a significant advantage over rifled barrels with respect to barrel life.

7.4.1.9 Barrels plated with low-contraction (LC) chromium Work with LC chromium in caliber . 50 aircraft barrels was done prior to 1946 and has been described in the NDRC summary report. It is therefore merely mentioned here for completeness. In this type barrel, LC chromium did not give better performance than HC chromium. 


\subsubsection{Caliber.50 - 45-inch heavy barrel}

The life of the heavy, 45 inch caliber . 50 machine gun barrel, without chromium plate was much greater than that of the unplated aircraft barrel. Therefore there was less interest in improving it and work did not start until progress on the aircraft barrel was well along. A few barrels were plated at NBS and fired at the Geophysical Laboratory, but since the results were incomplete, they were not included in detail in the NDRC Summary Report (9). Preliminary tests included seven barrels. Three were plated with HC and four with LC chromium, with thickness ranging from 0.0015 to 0.005 inch. Two unplated control barrels were also fired. The results indicated that for equal thickness of plate, LC chromium was superior to the HC type. With regard to thickness, 0.005 inch was better than the thinner plates. On a schedule of $5 \times 100_{2}$, the standard barrels had a life of 500 to 700 rounds, based on both accuracy and velocity drop ( $200 \mathrm{fps}$ ), while the best plated barrel (with 0.005 inch of HC chromium) had a velocity life of about 1300 rounds, but it still had good accuracy.

Based on these results, two more barrels were prepared with 0.005 inch thickness of LC chromium. At 1000 rounds these showed no loss of either accuracy or velocity and at this point had lost plate for only about one inch at the origin of rifling. Analogous barrels plated with HC chromium lost 3 to 4 inches of plate after 1000 rounds. The barrels, plated with LC chromium were not fired further, so their ultimate life can only be estimated. It seems certain that it would be at least 1500 rounds on the $5 \times 100_{2}$ schedule.

To summarize, the limited tests that were made indicated that the best performance was given with 0.005 inch thickness of LC plate, and that the life of barrels with this plate is 2 to 3 times that of plain steel barrels. The barrels plated in this manner were nitrided, and the muzzles were choked to $0.492-.495$. The effects of the nitriding and of the choked muzzles were not tested as isolated variables, but by analogy with the aircraft barrels and other types of barrels tested subsequently, it is probable that these modifications are beneficial.

The fact that the thicker LC plate is best in the heavy barrel while the thinner HC plate is best in the aircraft barrel is of interest. Following is a probable explanation: The heavy barrel fires at a lower rate and the bore does not get as hot as that of the aircraft barrel. 
Therefore swaging of the LC plate, which softens at a lower temperature than does HC plate, does not occur in the heavy barrel. In the aircraft barrel, LC plate fails as a result of excessive swaging. Thick HC plate in the aircraft barrel failed because the chromium, which at this thickness formed a solid chromium land, unsupported by steel, was too weak and tended to break off as a complete land segment. LC chromium is sufficiently strong so that this type of failure does not occur.

In addition to the barrels described above, used for controlled firing tests, many heavy caliber . 50 barrels were plated for other agencies, mainly Franklin Institute and Crane Company. These were used for special purposes and did not yield data on barrel performance as such.

The pump-plating method described in section 5.5.3 was used for applying LC chromium to these barrels.

\section{5 Caliber .60 barrels}

The successful application of chromium plating to caliber . 50 barrels resulted in a request by Army Ordnance that a study be made of the application of chromium plating to caliber . 60 barrels. This project was started as part of the joint Geophysical Laboratory-NBS program, and was continued after 1945 by NBS.

About 170 caliber .60 barrels were plated during this study. These included barrels chromium plated full length, and plated barrels fitted with either Stellite liners or with steel liners plated with cobalt-tungsten alloy. A detailed summary of this work is given in an NBS report (22).

Stripping of projectile jackets during firing tests was a major problem. Extreme bore temperatures softened the basis steel, which flowed forward under impact of the projectiles, forming a severe construction at the edge of the cooler area of the barrel. This condition was improved by forming a tapered enlargement in the breech region of the bore for a distance of 5 to 10 inches. This was done by electropolishing with a moving cathode. Most of the work on caliber .60 barrels is covered in the following six categories. 


\subsubsection{Barrels plated full-length}

The caliber .60 barrel was found to be unusual, in that for best performance a different thickness of chromium was required in the breech and muzzle areas. At the breech, a thickness of at least 0.005 inch was required to prevent early erosion failure. However, if this thickness was applied throughout the bore, the plate failed quickly in the muzzle region due to removal caused by fractures within the chromium layer. Flexing of the barrel during firing, due to its long, slender, design, appeared to be the most likely explanation of this effect. If the plate thickness was less than about 0.004 inch in the muzzle region, the plate in this area did not fracture.

The best performance of full-length plated barrels was obtained with a thickness of 0.003 inch of $\mathrm{HC}$ chromium in the muzzle area (from muzzle to about 3 feet from muzzle), and with 0.006 inch of $\mathrm{HC}$ chromium in the breech end.

An enlarged bore at the breech end was necessary to prevent bullet stripping as described above in section 7.5. Optimum diameter at the origin of rifling of about 0.595 inch after plating, results in an initial velocity 50 to $70 \mathrm{f} . \mathrm{p} . \mathrm{s}$. below normal.

The variable thickness plate can be applied either in two operations, with a matched junction, or in one operation with a plate of tapering thickness.

7.5.2 Stellite-lined and plated barrels

Chromium plate 0.003 inch thick ahead of the liner increases the velocity life about 20 percent and the accuracy life about 50 percent, in comparison with a Stellite-lined but unplated barrel.

\subsubsection{Two-piece barrels and muzzle choke}

It was characteristic of both plated breech sections and Stellite liners to fail while the chromium plated muzzle region of the barrels was in relatively good condition. In the expectation that an improved liner would be developed, it was considered worth while to develop an optimum plating system for the muzzle area. This was done by the use of two-piece barrels, as shown in Figure 17. Separate muzzle and breech sections were joined with a threaded collar. The breech section was periodically replaced during the testing of a given muzzle section. Table 7 shows that the life of a muzzle section was at least 4 times greater than that of the best breech sections. 


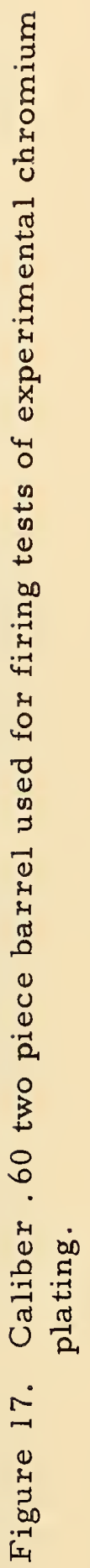


The two-piece barrels were used mainly to evaluate a choked muzzle. Contrary to the results in other calibers, a muzzle choke was found to produce very little improvement in the caliber .60 barrel. A muzzle diameter of 0.585 plus 0.002 inch was found to be best, but the accuracy advantage of these choked barrels over barrels with standard muzzle diameter was so small that it may not have been significant.

\subsubsection{Other erosion-resistant coatings}

Coatings other than chromium have not yielded promising results. Cobalt-tungsten alloys have insufficient hot-hardness. Limited trials of LC chromium indicate that it is as good or slightly better than HC, but its small advantage is over-shadowed by the difficulties involved in applying it.

\subsection{Modified Stellite liners}

High bore temperature in the caliber .60 barrels resulted in plastic flow of the Stellite which caused a constriction in the liner bore where it bears against the forward end of the liner recess. The constriction caused stripping of driving bands. Several liners were modified by relieving the outside contour in various ways (see Figure 18). A 45-degree taper on the forward end of the liner was the easiest contour to machine and it gave the greatest reduction in bullet stripping.

At the end of firing tests Stellite liners usually had holes melted through the side. It was thought that poor thermal contact between the liner and the liner recess resulted in excessive temperatures in the liner. Two liners were plated with 0.001 to 0.002 inch thick copper on the outside surface to improve conduction of heat away from the bore. These liners have not been test fired to date.

Table 7 lists firing data for typical examples of the more important barrel variations plated and tested. Table 8 shows a comparison of the performance of the best types of plated barrels with that of unplated control barrels.

\section{$7.620 \mathrm{~mm}$ barrels}

The activity of this laboratory in plating and testing of $20 \mathrm{~mm}$ barrels is fairly recent. Table 9 lists a few barrels plated for the Bell and Gossett Company in 1946, and for others, mainly Aberdeen Proving Ground, in 1950-52. However, the types and thicknesses of plate used were empirical choices. No controlled work to determine the optimum type, thickness, etc. of chromium plate was done with $20 \mathrm{~mm}$ barrels until late in 1952 . 
TABLE 7

Typical examples of several variations of caliber .60 barrele plated and tested by NBS

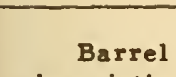

description

$\begin{array}{ccl}\text { Firing } & \text { Round } & \text { Round to } 200 \\ \text { chedule } & \text { fired } & \text { f.p.s. vel. drop }\end{array}$

Vel. otart and

Av. pattern

at $1000^{\prime \prime}$

$\mathrm{HxV}$ (inch)

Remark

finish (f.p.o.)

\title{
Thin HC Cr (.002")
}

on steel

\begin{abstract}
Cont.
\end{abstract}
640
$(680$ f.p. s. drop
at 450 rd.)

3544

2571

$10 \times 15$

Cr off 7"' at breech, 19" at muzzle.

Thick HC Cr (.006')

on nitrided steel

\section{Cont.}

199

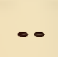

3514

3508

$14 \times 17$

Breech O.K.

Cr off lands

at muzzle.

Thick HC Cr (.006")

on nitrided steel.

\section{Cont.}

440

$\times \mathrm{SO}_{2}$

325

3479

2992

$10 \times 16$

Cr off 12 " at

breech. Some

Cr off at muzzle.

at breech

* Thin HC Cr $(.0025 ")$
on muzzle, thick LC

$6 \times 5 \mathrm{O}_{2}$

358

3320

Cr partly off

4-5" at breech. Muzzle O.K.

(.009") on breech.

Not nitrided.

Schedule inter.

rupted during

3 rd burst.

*Thin HC Cr (.0025")

on muzzle, thick $\mathrm{HC} \mathrm{Cr}$

Cont.

690

375

3474

2425

$9 \times 10$

Cr O.K. at muz zle, off 6" at

breech.

$\left(.005^{\prime \prime}\right)$ on breech.

Nitrided steel.

$\begin{array}{lll}\times 50_{2} & 375 & 2425\end{array}$

\begin{tabular}{|c|c|c|c|c|c|c|}
\hline $\begin{array}{l}\text { * Thin HC Cr }\left(.002^{\prime \prime}\right) \text { on } \\
\text { muzzle, thick } \mathrm{HC} \mathrm{Cr} \\
\text { (.010") on breech. } \\
\text { Muzzle choked.010" } \\
\text { on diam. }\end{array}$ & $6 \times 50_{2}$ & 340 & 275 & $\begin{array}{l}3403 \\
2988\end{array}$ & $9 \times 8$ & $\begin{array}{l}\text { Cr partly off } \\
\text { breech for } 17^{\prime \prime} \text {. } \\
\text { Evidence of } \\
\text { poor adhesion. }\end{array}$ \\
\hline $\begin{array}{l}\text { Stellite liner, etched } \\
\text { oversize, .002" HC Cr } \\
\text { beyond liner. Muzzle } \\
\text { choked . } 008 \text { " on diam. }\end{array}$ & $\begin{array}{l}\text { Cont. } \\
\times 50_{2}\end{array}$ & 440 & $\begin{array}{l}375 \\
\text { (hot) }\end{array}$ & $\begin{array}{l}3476 \\
3291\end{array}$ & $9 \times 15$ & $\begin{array}{l}\text { Slight Cr remov- } \\
\text { al. Rds. tumbling }\end{array}$ \\
\hline $\begin{array}{l}\text { Two piece barrel, HC Cr } \\
.0025^{\prime \prime} \text { thick in muzzle } \\
\text { section. }\end{array}$ & $8 \times 50_{2}$ & $\begin{array}{l}1759 \\
\text { (muzzle } \\
\text { section) }\end{array}$ & $\begin{array}{c}\text { (350 av. for breech } \\
\text { sections) }\end{array}$ & ${ }_{3125}^{3423}$ Av. & $11 \times 15$ & $\begin{array}{l}\text { Some Cr off muz. } \\
\text { zle section. } \\
\text { Bore swaged. } \\
\text { Rds. tumbling } \\
\text { during last burst. }\end{array}$ \\
\hline
\end{tabular}

* One piece barrels, plated with different thicknesses in muzzle and breech zones,

in separate operations, with matching plated diameter at the junction. 


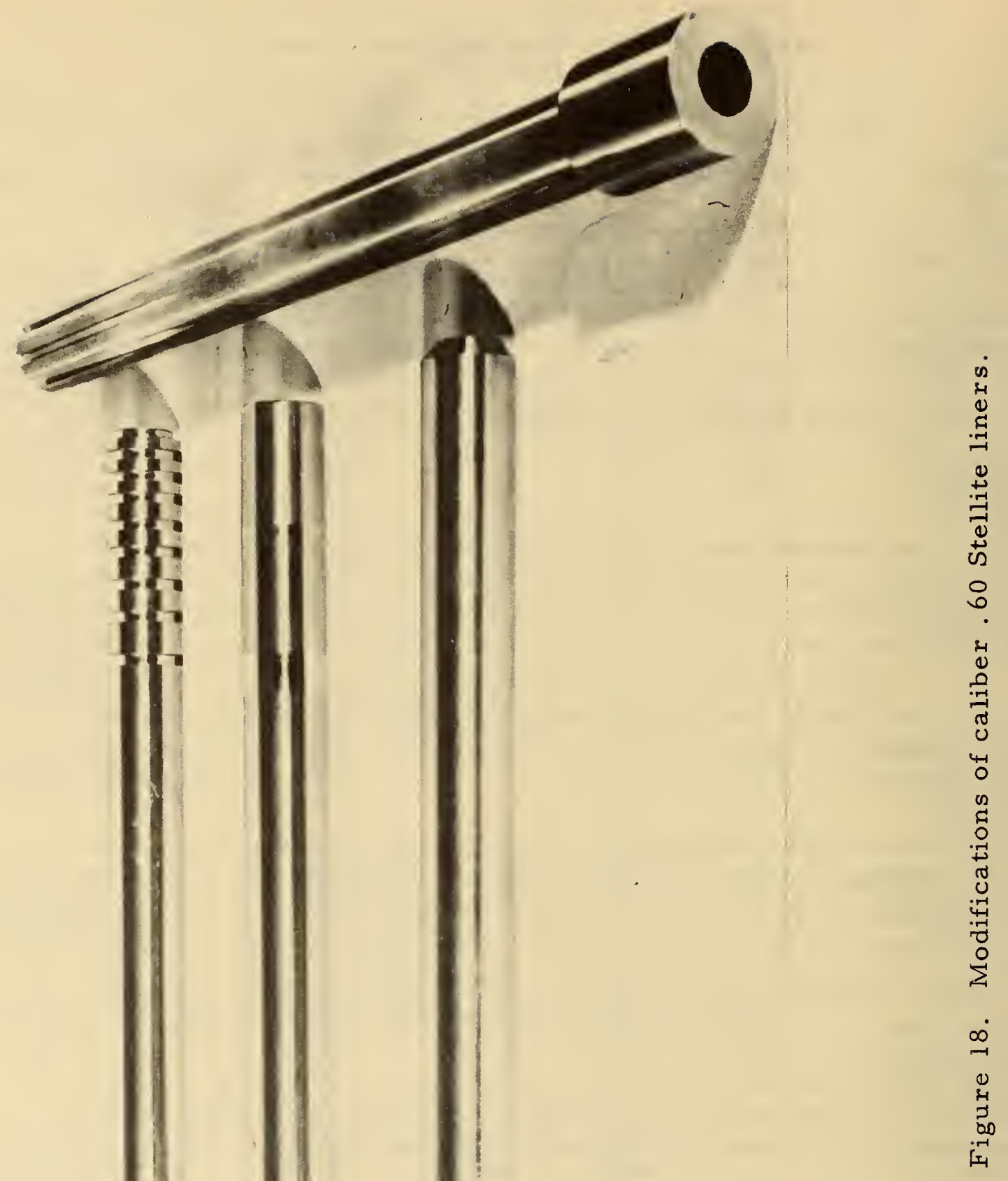




\section{TABLE 8}

A summary of the performance of plated caliber .60 barrels

Firing schedule - Continuous $\times 5_{2}$

Average rounds to

200 f.p. s. velocity drop
Average rounds

to tumbling

1. $0.006 " \mathrm{HC} \mathrm{Cr}$ in breech end, $0.003^{\prime \prime} \mathrm{HC} \mathrm{Cr}$ in muzzle end, with breech bore enlargement (0.005" diam.)

2. Stellite-lined with $0.003^{\prime \prime} \mathrm{HC} \mathrm{Cr}$ beyond liner

3. Control barrels

a. plain steel

b. Stellite-lined, unplated beyond liner 
$20 \mathrm{~mm}$ Barrels plated for other groups

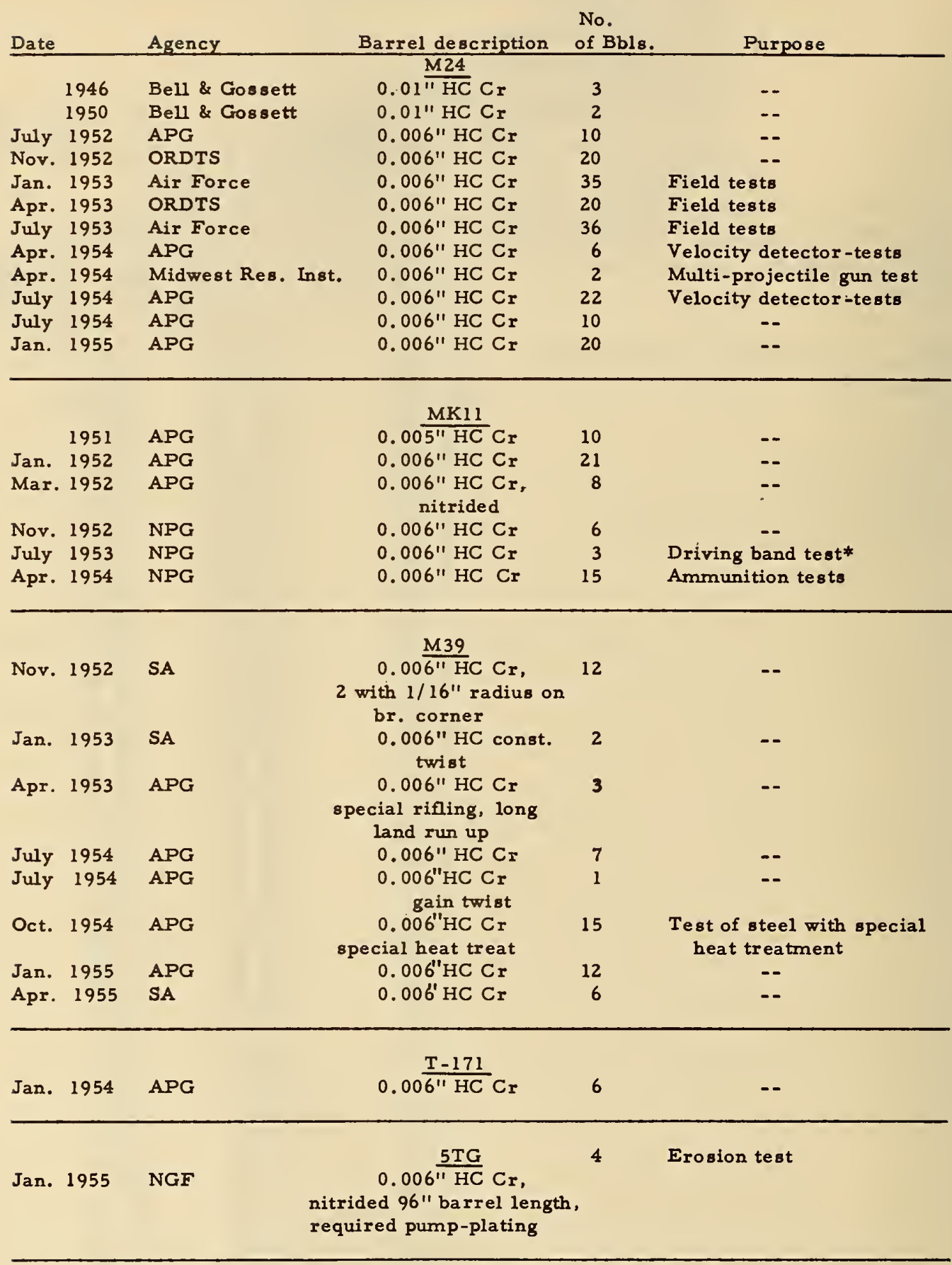

* Barrels showed very little wear and improved the performance of plastic bands. 
Since several models of $20 \mathrm{~mm}$ barrels have been used, and the firing conditions and optimum plates vary, the different models will be considered separately.

7.6.1 M-24 barrels

7.6.1.1 Deposit thickness

During the first quarter of 1953, nine barrels were supplied to Aberdeen Proving Ground, that had been plated with three thicknesses of HC chromium as follows:

3 with $0.002-3$ inch
3 " $0.003-4 "$
3 " $0.004-5 "$

It was reported to us verbally that the thickest plate was best.

\subsubsection{Effect of a nitrided base}

In April of 1954, ten M-24 barrels plated with 0.006 inch of HC chromium over nitrided steel were delivered to Aberdeen Proving Ground for testing in comparison with barrels that were plated but not nitrided. No report of the results has been received.

\subsubsection{Long land run-up}

The origin of rifling is the zone in a chromium plated barrel at which failure initiates. This is due in part to the fact that it is here that the engraving of the projectile band exerts maximum forces on the lands, so that the plate chips from the land corners and deforms and cracks due to yielding of the basis steel.

It was thought that if the run-up of the lands were longer (i.e., the distance from the forward end of the bullet seat to the point at which the lands reach full height), and hence the engraving of the projectile occurred over a greater length of bore, the forces on the plate and the basis steel would be reduced, and this should contribute to longer life of the plate.

The first tests of barrels with a long run-up were completed in the period October-December 1953. Eight barrels with 2, 4, and 10 inch run-ups were tested at the Dahlgren Naval Proving Ground. Indications were that the barrels with a 10 -inch run-up, plated with 0.006 inch HC chromium, were superior to standard plated barrels. 
Therefore a more extensive test was carried out, in which a total of 22 barrels were used. The results have been described in an NBS Quarterly Report (23). All of these barrels had a run-up of 10 to 11 inches. The results are summarized in Table 10.

In the two series combined, 19 of the barrels failed due to tumbling of projectiles. In most cases the tumbling was caused by swaging of the lands beneath the chromium. The long land run-up did not give improved barrel life when used with a type and thickness of plate that failed by swaging rather than by removal of chromium. The thick ( 0.012 inch) HC chromium plate, which normally fails by loss of chromium because of mechanical stress on the lands, gave excellent performance in barrels with long land run-up. There is no apparent explanation for the large spread of barrel life for a given type of barrel, shown in Table 10. Further work on this phase of gun barrel improvement is planned.

\subsubsection{MK-1.1 barrels, $20 \mathrm{~mm}$}

This type of barrel is fired at an appreciably higher rate of fire and muzzle velocity than the $M-24$. The consequent more severe erosion might be expected to require a different thickness, etc. of plate than is used in the M-24. Since the Aircraft Armament Section of the Navy Bureau of Ordnance was concerned with production of these barrels, and it appeared that chromium plating would be necessary in order to provide a practical barrel life, they requested NBS to under take a program to develop an optimum plated barrel.

Prior to the above tests, which were started in the spring of 1955 , a number of MK-1l barrels had been plated for testing at Aberdeen by the Naval Gun Factory, and a small number had been fired at the Naval Proving Ground. The former are listed in Table 9, and the results with the latter are combined with those for the barrels tested at the Naval Proving Ground in 1955. The main variables were thickness, type of plate, nitriding, and muzzle choke.

The results of tests of 56 barrels tested under this program are shown in Table 11. Examination of these results leads to the following conclusions: 
TABLE 10

Performance of $20 \mathrm{~mm}, \mathrm{M} 24$ barrels with an eleven inch run-up at the origin of rifling

\begin{tabular}{lccc}
$\begin{array}{l}\text { Type and thick } \\
\text { ness of plate (inch) }\end{array}$ & $\begin{array}{l}\text { No. of } \\
\text { barrels }\end{array}$ & $\begin{array}{l}\text { Barrel life, based on data for } \\
\text { both accuracy and velocity (rounds) }\end{array}$ \\
\hline & 4 & Spread & Average \\
$0.003 \mathrm{HC} \mathrm{Cr}$ & 4 & $2016-5245$ & 3376 \\
$0.003 \mathrm{LC} \mathrm{Cr}$ & 4 & $694-3083$ & 1995 \\
$0.006 \mathrm{HC} \mathrm{Cr}$ & 2 & $1863-3435$ & 1533 \\
$0.006 \mathrm{LC} \mathrm{Cr}$ & 2 & $1244-1821$ & 5808 \\
$0.012 \mathrm{HC} \mathrm{Cr}$ & 6 & $5353-6263$ & 3332 \\
$\begin{array}{l}0.006 \mathrm{HC} \text { Std. 1/4" } \\
\text { run-up. (Control) }\end{array}$ & & $2133-5712$
\end{tabular}


TABLE 11

Performance of $20 \mathrm{~mm}$ MK-11 barrels plated in connection with the production program of NGF and ReW4a

Data are averages of the number of barrels thown in the last column

Schedule: $12 \times 50_{2}$

\begin{tabular}{|c|c|c|c|c|c|c|c|c|c|}
\hline $\begin{array}{l}\text { Barrel. } \\
\text { description }\end{array}$ & $\begin{array}{l}\text { Av. pattern at } \\
1000^{\prime \prime} \mathrm{H} \times \mathrm{V} \text { (inch) }\end{array}$ & $\begin{array}{l}\text { Velocity, initial } \\
\text { and final (f.p. s) }\end{array}$ & $\begin{array}{l}\text { Total } \\
\text { rounds }\end{array}$ & $\begin{array}{c}\text { Rds. at } 200 \\
\text { f.p. s. vel. drop }\end{array}$ & $\begin{array}{l}\text { Rds, to } \\
\text { tumbling }\end{array}$ & $\begin{array}{l}\text { Av, cyclic } \\
\text { rate (r.p. m) }\end{array}$ & $\begin{array}{l}\text { Type of } \\
\text { failure }\end{array}$ & $\begin{array}{l}\text { Advance of } \\
\text { O.BPx(inch) }\end{array}$ & $\begin{array}{l}\text { No. of } \\
\text { barrela }\end{array}$ \\
\hline $\begin{array}{l}\text { Nitrided steel }\left(.025^{\prime \prime}\right. \\
\text { case) .006" HC Cr } \\
\text { Muzzle choked }\end{array}$ & $8.5 \times 9$ & $3303-2601$ & 1690 & 890 & 1515 & 932 & Cr removal & 17.5 & 1 \\
\hline $\begin{array}{l}\text { Nitrided steel } \\
.006 " \text { LC Cr. Muz- } \\
\text { zle choked }\end{array}$ & $8.5 \times 8.5$ & $3251-2782$ & 1869 & 1296 & 1670 & 938 & $\begin{array}{l}\text { Swa ging and } \\
\text { Cr removal }\end{array}$ & 27.5 & 2 \\
\hline $\begin{array}{l}\text { Std. steel + } \\
.006 " \mathrm{HC} \mathrm{Cr} \\
\end{array}$ & $12 \times 12.5$ & $3212-2957$ & 1371 & 1088 & 1212 & 949 & Swaging & 45 & 2 \\
\hline $\begin{array}{l}\text { Std. steel t } \\
.003^{\prime \prime} \mathrm{LC} \mathrm{Cr} \\
\end{array}$ & $12 \times 11$ & $3252-2943$ & 1270 & 1246 & 1112 & 945 & Swaging & 28 & 2 \\
\hline $\begin{array}{l}\text { Std. steel + } \\
.006 " \text { LC Cr } \\
\end{array}$ & $10.5 \times 10$ & $3230-3000$ & 1.145 & 1027 & 987 & 960 & Swaging & 33 & 4 \\
\hline $\begin{array}{l}\text { Std. steel }+ \\
.012^{\prime \prime} \text { LC Cr } \\
\end{array}$ & $13 \times 11.5$ & $3127-2853$ & 1089 & 1062 & 1089 & 972 & Swaging & 47 & 2 \\
\hline $\begin{array}{l}\text { Nitrided steel + } \\
.006 " \mathrm{HC} \mathrm{Cr} \\
\end{array}$ & $10.5 \times 10.5$ & $3255 \div 2635$ & 2067 & 1176 & 1661 & 953 & $\begin{array}{l}\text { Swaging } \\
\text { Cr removal }\end{array}$ & 23 & 3 \\
\hline $\begin{array}{l}\text { Nitrided steel }+ \\
.006 " \text { LC Cr } \\
\end{array}$ & $11 \times 10.5$ & $3201-2695$ & 1600 & 1275 & 1527 & $94 \mathrm{I}$ & Cr removal & 35 & 3 \\
\hline $\begin{array}{l}\text { Nitrided steel + } \\
.01 z^{\prime} L C \mathrm{Cr}_{r} \\
\end{array}$ & $13 \times 12$ & $3156-2772$ & 1261 & 1155 & 1141 & 949 & Swaging & 42.5 & 3 \\
\hline $\begin{array}{l}\text { Std. Bteel } \\
\text { Control }\end{array}$ & $13 \times 11.5$ & $3244-3059$ & 536 & $536+$ & 440 & 915 & $\begin{array}{l}\text { Swaging } \\
\text { Erosion }\end{array}$ & 47.5 & 4 \\
\hline $\begin{array}{l}\text { Nitrided steel } \\
\text { 006" HC Cr } \\
\text { Straight bore, } \\
\text { choke control } \\
\end{array}$ & $12 \times 12$ & $3324-2680$ & 2141 & 1399 & 2051 & 1026 & $\begin{array}{l}\text { Swaging } \\
\text { Cr removal }\end{array}$ & 32.5 & 2 \\
\hline $\begin{array}{l}\text { Nitrided steel } \\
\text { 003" LC Cr } \\
\text { Choked muzzle }\end{array}$ & $9 \times 11$ & $3347-2709$ & 1823 & 1245 & 1724 & 978 & Swaging & 30 & 3 \\
\hline $\begin{array}{l}\text { Nitrided a te elxxx } \\
.003^{\prime \prime} \text { to } .006 " \mathrm{LC} \mathrm{Cr}\end{array}$ & $14 \times 13$ & $3319-2688$ & 1894 & 1430 & 1698 & 911 & Dispersion & 30 & 3 \\
\hline $\begin{array}{l}\text { Nitrided steelkxx } \\
.006^{\prime \prime ~ H C} \\
.012 \mathrm{LC} \mathrm{Cr} \\
\end{array}$ & $15 \times 13.5$ & $3285-2676$ & 1705 & 1377 & 1465 & 932 & $\begin{array}{l}\text { Swaging } \\
\text { Cr removal } \\
\end{array}$ & 32 & 3 \\
\hline $\begin{array}{l}\text { Nitrided steelxxx } \\
.006 " \mathrm{HC}, .006 " \mathrm{LC} \\
\end{array}$ & $16.5 \times 14$ & $3334-2639$ & 1849 & 1159 & 1704 & 909 & $\begin{array}{l}\text { Swaging } \\
\text { Cr removal }\end{array}$ & 32.5 & 2 \\
\hline $\begin{array}{l}\text { Nitrided steel } \\
003^{\prime \prime} \text { to .006" } \\
\text { L. R. U. * }\end{array}$ & $15 \times 13.5$ & $3307-2832$ & 1800 & 1580 & 1534 & 925 & Dispersion & 44 & 3 \\
\hline $\begin{array}{l}.005^{\prime \prime} \text { to } .010^{\prime \prime} \mathrm{HC} \mathrm{Cr} \\
\text { L. R. U. }\end{array}$ & $13 \times 11.5$ & $3296-2795$ & 1508 & 1403 & 1051 & 941 & Cr removal & 38 & 3 \\
\hline $\begin{array}{l}\text { Nitrided steel } \\
003^{\prime \prime} \text { LC Cr } \\
\text { Choked muzzle } \\
\text { L.R. U. }\end{array}$ & $8.5 \times 10$ & $3215-2997$ & 1497 & 1327 & 1329 & 986 & Swaging & 30 & 3 \\
\hline $\begin{array}{l}\text { Nitrided steelXXX } \\
\text { 003" to .006" } \\
\text { MH** Cr }\end{array}$ & $15.5 \times 13$ & $3378-2656$ & 1318 & 793 & 1165 & 924 & $\begin{array}{l}\text { Swaging } \\
\text { Cr removal } \\
\end{array}$ & 32 & 3 \\
\hline $\begin{array}{l}\text { Nitrided steel } \\
\text { 006" HS Cr*** } \\
\text { Choked muzzle }\end{array}$ & $10.5 \times 9$ & $3347-2538$ & 1801 & 963 & 1630 & 932 & $\begin{array}{l}\text { Swa ging } \\
\text { Cr removal }\end{array}$ & 27 & 3 \\
\hline $\begin{array}{l}\text { Cold test }(-70 \bar{C}) \\
\text { Nitrided steel } \\
006 " \text { HC Cr } \\
\text { Choked muzzle }\end{array}$ & $9 \times 8.5$ & $3102-2584$ & 1826 & 1246 & 1746 & 951 & $\begin{array}{l}\text { Swaging } \\
\text { Cr removal }\end{array}$ & 34 & 2 \\
\hline
\end{tabular}

*Long land run-up at the origin of rifling (approx. 10 inches).

* Medium hardness chromium.

4* Chromium plated at the high speed rate of 0.006 inch $/ \mathrm{hr}$

$x x$ Origin of bore.

xox Barrels described as having a range of plate thicknes s were plated with a tapered deposit, using a resistance anode, and have choked muzzles: Those in which a combination plate is indicated have HC plate from the muzzle to 38 inches from the muzile, and LC plate in the breech region. Taper plated barrels have thick plate at breech end.

+ Barrels have partial choke at muzzle, averaging about 0.003 inch below nominal diameter. (Full choke is 0.006 to 0.007 inch below nominal.) 
(a) All of the plated barrels, regardless of thickness, type of plate, etc., are significantly longer-lived than the unplated control barrels by a factor of approximately 3 .

(b) The performance of all of the plated barrels, regardless of just how they are plated, has an over-all spread of about 20 percent based on velocity life, or 70 percent based on rounds to keyholing. Keyholing generally occurs after a 200 f.p.s. velocity drop. With the differences in life this small, especially with respect to velocity, it is difficult to draw significant conclusions from this test as to what is the best plate.

(c) About 0.006 inch is an optimum thickness.

(d) Nitriding of the basis steel produces about a 10 percent improvement.

(e) LC plate, of the proper thickness and on a nitrided base, is about 10 percent better than HC plate.

(f) A muzzle choke provides a 20 percent reduction in pattern size at 1000 inches from the muzzle.

In view of the relatively small differences in performance, and to avoid the production problems involved in applying LC chromium, the Aircraft Armament Section of Navy Ordnance decided to adopt 0.006 inch of HC chromium for production.

7.6.3 M-39 barrels, $20 \mathrm{~mm}$

Several barrels were fired in tests to determine the optimum thickness of chromium. No attempt can be made to interpret the results as of December 31, 1955, because of the limited amount of data available, and because of the occurrence of frequent gun stoppages during test firing. Tests are continuing.

7. $730 \mathrm{~mm}$ barrels

Eight $30 \mathrm{~mm}$ barrels were plated with $\mathrm{HC}$ chromium during the fourth quarter of 1953. Three were plated with a thickness of 0.003 inch and five with a thickness of 0.006 inch. They were delivered to APG for test firing.

\section{$7.840 \mathrm{~mm}$ barrels}

Systematic experimental plating of $40 \mathrm{~mm}$ barrels was started in the fall of 1948, shortly after the installation of plating tanks of adequate depth. The work with these barrels was sponsored by Section ReS5a of the Department of the Navy, Bureau of Ordnance. 
The results were of interest for application to $40 \mathrm{~mm}$ barrels as such, but were also intended to apply to larger cannon. The pattern of wear and erosion in cannon is different than in small arms, and in general one cannot predict from data on small arms what type of chromium plating will be best in cannon, or what degree of improvement will be obtained. It was believed that the erosion character istics of $40 \mathrm{~mm}$ barrels would be similar to those of larger cannon. Furthermore, it is practicable to plate $40 \mathrm{~mm}$ barrels in moderate experimental quantities. Another factor that was considered in choosing this caliber was that the cost of ammunition for test-firing is moderate in comparison with that for larger cannon.

The work was divided into three distinct phases, which were carried out in succession. These were, respectively, (a) determination of pre-plating procedures that yield maximum adhesion; (b) determination of optimum thickness of plate; and (c) evaluation of different types of plate. The results of each of these phases has been described in detail in separate reports to the Bureau of Ordnance (24). The results with $40 \mathrm{~mm}$ barrels will be summarized under the above headings.

\subsubsection{Adhesion of chromium}

Three basically different preplating cleaning procedures were tried. These were:(a) scrubbing with a mixture of pumice and hydrochloric acid (concentrated $\mathrm{HCl}$ diluted with 1 volume of water), followed by thorough swab and flow rinsing; (b) anodic alkali cleaning, followed by rinsing; and (c) electropolishing, i.e., transferring the barrel directly from the electropolishing to the plating bath, except for a thorough rinse between baths. With each method, the barrels were anodically etched in the plating bath at $20 \mathrm{amp} / \mathrm{dm}^{2}$, before plating current was applied. Anodic etch time was an additional variable, ranging from zero to 10 minutes. For all tests, 0.005 inch thickness of HC chromium ( $50 \mathrm{C}, 2.0 \mathrm{amp} / \mathrm{dm}^{2}$ ) was used. Three unplated control barrels were fired along with the plated barrels. In all, 18 barrels were used in the adhesion test program. The results are summarized in Table 12 .

Since adhesion was evaluated by firing performance, conclusions were based not only on the ultimate life of the barrel, but also on the condition of the plate, e.g., the presence and extent of blistering, and the amount of plate removed by erosion. A significant difference in the rate of fire for different barrels also had to be considered in judging the results. 


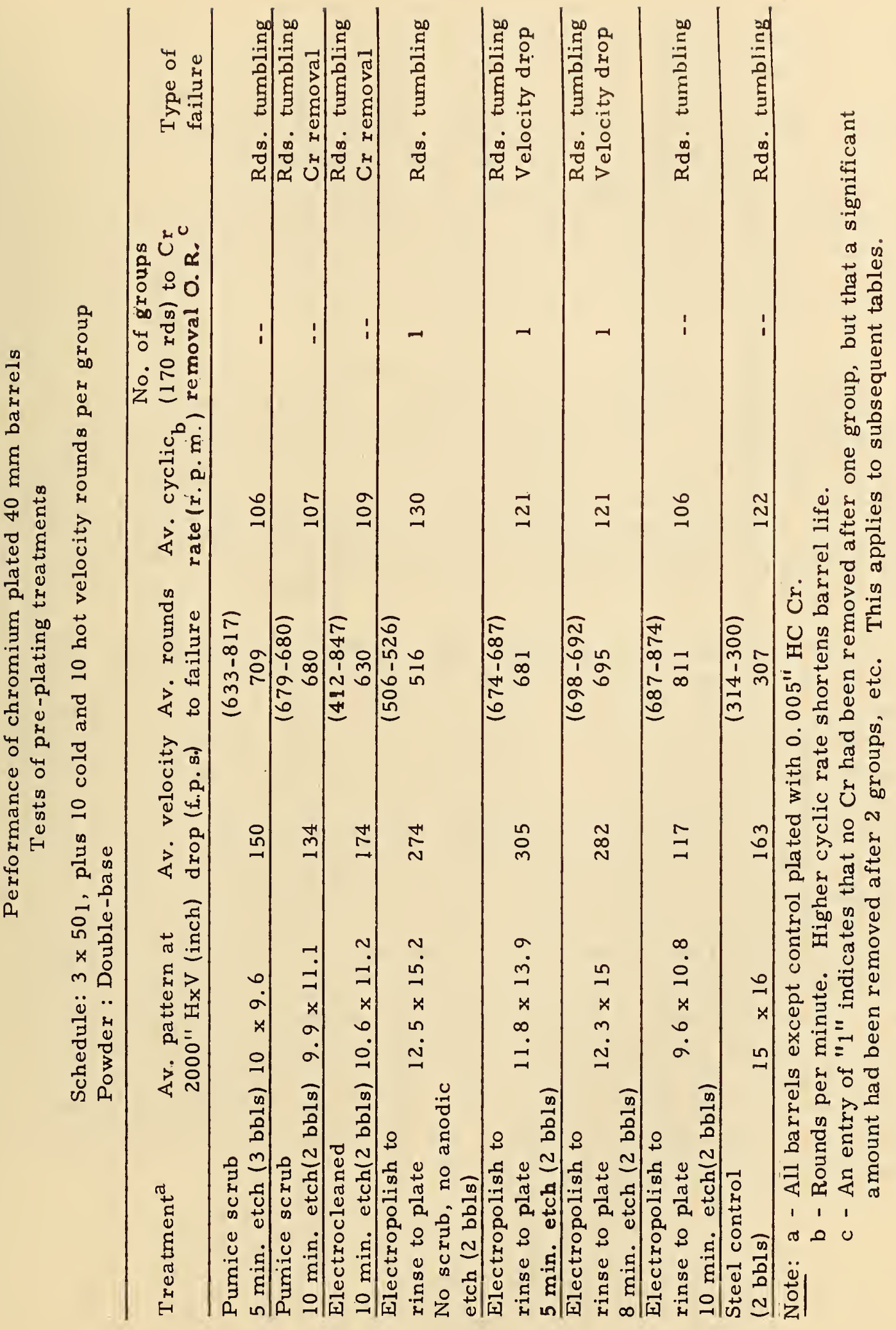


The conclusions reached were that: (a) Alkali clectrocleaning is inferior to either pumice scrubbing or direct transfer from the electropolish. (b) The difference betwcen pumice scrubbing and direct transfer from the electropolish is very slight. The difference is probably not significant, but since the result leaned toward superiority of direct transfer from the clectropolish, this method was selected as best. Electropolish cleaning also requires less hand labor and results in more uniform treatment than does hand scrubbing. (c) Barrels which were not anodically etched were definitely inferior in firing life to anodically etched barrels. An etch of 5 minutes duration is satisfactory. Etch times up to 10 minutes may be used, but do not result in significantly better adhesion than results from a 5-minute etch.

\subsection{Determination of the best thickness of plate}

In this phase of the $40 \mathrm{~mm}$ program, use was made of the preceding results. All barrels were treated by the direct polish to plate method, with a 5-minute anodic etch. Thicknesses of $0.010,0.015$, and 0.020 inch of $\mathrm{HC}$ chromium were used. A thickness of 0.005 inch was not used, because data for the barrels with this thickness of plate, obtained in the first phase of the program, were included in the present thickness comparisons.

Interpretation of the results was complicated by a unique type of failure in a zone several inches long, starting 8 to 10 inches beyond the origin of rifling. The failure consisted of breaking of chromium from the lands. One theory is that the effect is caused by a shock-wave phenomenon. When service powder was used rather than double-base powder, this abnormal type of failure did not occur. Because of this difficulty the powder charge was later changed from double base to a combination load consisting of 25 percent 1.1 inch "master standard" powder and 75 percent double base powder. This combination gave approximately the same ballistic characteristics and inhibited the development of the eroded zone beyond the origin of rifling. The presence of this eroded zone in some of the barrels resulted in less than normal barrel'life and made it impossible to evaluate the performance of the various thicknesses in terms of barre1 life. Rate of removal of chromium at the origin of rifling was therefore chosen as a basis for evaluating the effect of plate thickness. The following tabulation summarizes the results. More complete data are shown in Table 13. 


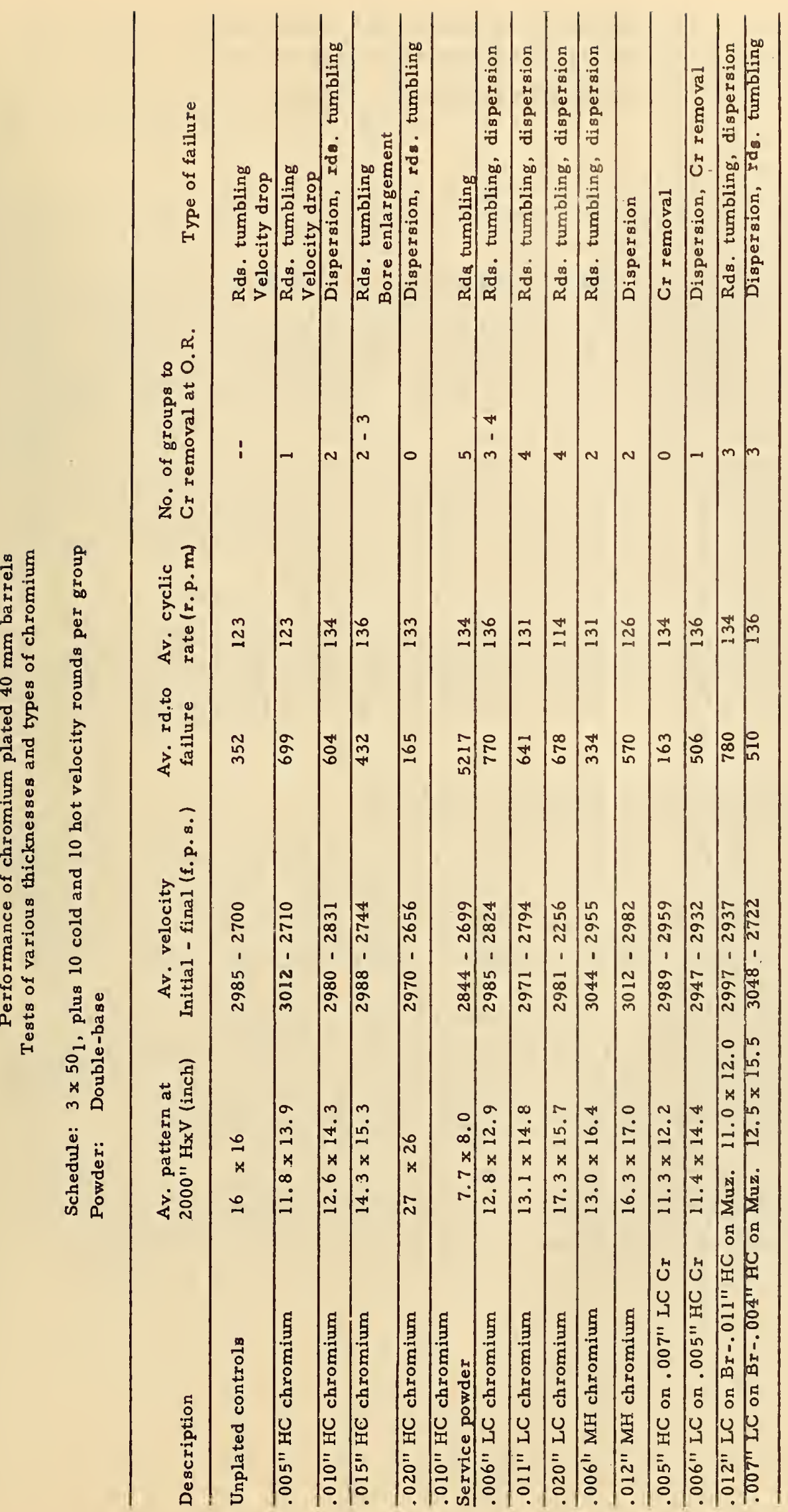


Plate thickness

0.005 inch

$.010 "$

$.015 "$

$.020 " 11$
Number of the group (170 rd/group)

during which plate began to chip

from origin of rifling

It is seen that the duration of protection of the origin of rifling by the chromium plate increased roughly linearly up to $0.015 \mathrm{inch}$ thickness. With a thickness of 0.02 inch, the land is nearly solid chromium. The chromium, which is weak, breaks off quickly when unsupported by a backing of steel.

Two barrels plated with 0.01 inch of $\mathrm{HC}$ chromium were fired the same schedule, but with service powder. They had lives of 4900 and 5500 rounds, respectively. Control results employing the same powder with unplated barrels are not available.

Based on the above results, a thickness in the range of 0.010 to 0.012 inch is considered a good compromise between the indicated "best" thickness 0.015 inch, and a thickness that is practicable for application in production.

\subsubsection{Investigation of different types of} plate in $40 \mathrm{~mm}$ barrels

The types of plate tried in $40 \mathrm{~mm}$ barrels included "low-contraction" (LC), "medium hardness" (MH), and combinations of these. (See Table 1). Combinations tried were both "zonal", which refers to one type of chromium in the breech end and another type in the muzzle end of the barrel, and "superposed", which refers to one type of chromium as an overlay on another type. The performance of standard, or HC, plate had been determined in the previous phases of the $40 \mathrm{~mm}$ program. Uniform longitudinal distribution of thickness of both LC and MH plates was obtained by the use of forced solution flow (pump-plating).

The firing tests showed that 0.006 inch thickness of LC chromium gave about 10 percent longer life than the optimum thickness of HC chromium. Thicker LC deposits gave superior erosion resistance at the origin of rifling, but the barrels failed earlier due to plastic 
deformation of the configuration of the bore. Barrels plated with MH chromium, or with either zonal or superposed combinations had somewhat poorer performance than those plated with the optimum thickness of HC chromium.

An attempt was made to determine the reason for the early failure due to poor accuracy of the barrels plated with thick coatings of LC chromium (0.01-.02 inch). To this end, a detailed examination of the condition of the bores, measurements of projectile spin, and visual examination of the driving band of recovered projectiles were made. It was concluded that a constriction of the bore that developed a short distance forward of the origin of rifling caused the projectile driving band to deform and swage undersize, thus preventing normal land engagement and resulting in about 50 percent reduction in spin. The bore constriction resulted mainly from forward flow of the steel under the plate, and in part from swaging of the plate itself. These results for the different types of plate are summarized in Table 13.

7.8.3.1 Effect of muzzle choke in $40 \mathrm{~mm}$ barrels

By tapering the bore of barrels plated with LC and MH chromium to a muzzle diameter two to four thousandths of an inch under the nominal minimum, a 20 percent improvement in accuracy (size of target pattern) was obtained.

7.8.4 Test of $40 \mathrm{~mm}$ barrels nitrided before chromium plating Eight barrels were nitrided after electropolishing and before plating. Six of these were then plated as shown below:

Nitrided (0.015" case) $-0.006 " \mathrm{HC} \mathrm{Cr}, 0.006 " \mathrm{LC} \mathrm{Cr}, 0.012^{\prime \prime ~ L C ~ C r ~}$ Nitrided (0.025" case) $0.012 " \mathrm{HC} \mathrm{Cr}, 0.006 " \mathrm{LC} \mathrm{Cr}, 0.012^{\prime \prime ~ L C ~ C r ~}$

All barrels with the thinner nitrided case, and barrels with 0.006 inch thickness of plate on the thicker nitrided case, performed about the same as corresponding non-nitrided barrels. The barrel with 0.012 inch thickness of LC chromium on the thick nitrided case performed distinctly better ( 50 to 70 percent) than any other type of plated $40 \mathrm{~mm}$ barrel. Since this result with one barrel cannot be considered conclusive, it would be necessary to confirm it with additional tests. These have not been made to date. 


\subsection{3 inch-50 caliber barrels}

As a result of a decision by the Bureau of Ordnance, Department of the Navy, to adopt heavy chromium plating of 3 inch-50 caliber barrels for production, a limited experimental program with these barrels was undertaken. Since our experimental plating shop did not have capacity for 3 inch-50 caliber barrels, the plating was done in close cooperation with the Washington Naval Gun Factory. The barrels were test-fired at the Dahlgren Naval Proving Ground. Work was started in September 1950, and extended through the first quarter of 1955.

Three thicknesses of HC chromium, namely $0.005,0.010$, and 0.020 inch, and one thickness of LC chromium were tried. The thickness of the LC plate tapered from 0.005 inch at the muzzle end of the barrel to 0.010 inch at the origin of rifling. The chambers of the barrels were plated.

In section 5.5 of this report, the problems imposed as a result of the taper normally obtained in LC deposits are described. As shown there, the most practicable method for obtaining an untapered plate involves pumping the solution through the bore at a high flow-rate. The pumping method has been used successfully on an experimental scale for all calibers through $40 \mathrm{~mm}$. For the 3 inch barrels, adequate pump capacity was not available, so another method of plating was sought. The method selected, which was used and was satis factory, consisted of electropolishing the bore with a moving cathode, thus producing a taper which matched the normal taper in the LC plate, so that the final plated bore was straight. The normal taper in the plate was first determined in a separate plating experiment. The results of the firing tests are shown in Table 14.

The general conclusions are that 0.01 inch thickness of $\mathrm{HC}$ chromium is about 15 percent better than 0.005 inch, with respect to rate of loss of chromium at the origin of rifling, accuracy, and life to VT fuse failure. The limiting factor in the life of these barrels is VT fuse performance. The criterion for end of life is that at least 30 percent of the rounds must function normally.

The barrels with 0.020 inch thickness of $\mathrm{HC}$ chromium failed early in the second group as a result of excessive loss of chromium from the bore. A plate of this thickness is relatively unsupported on the lands by basis steel, and tends to break off because the chromium itself lacks strength. The same result has been obtained with 


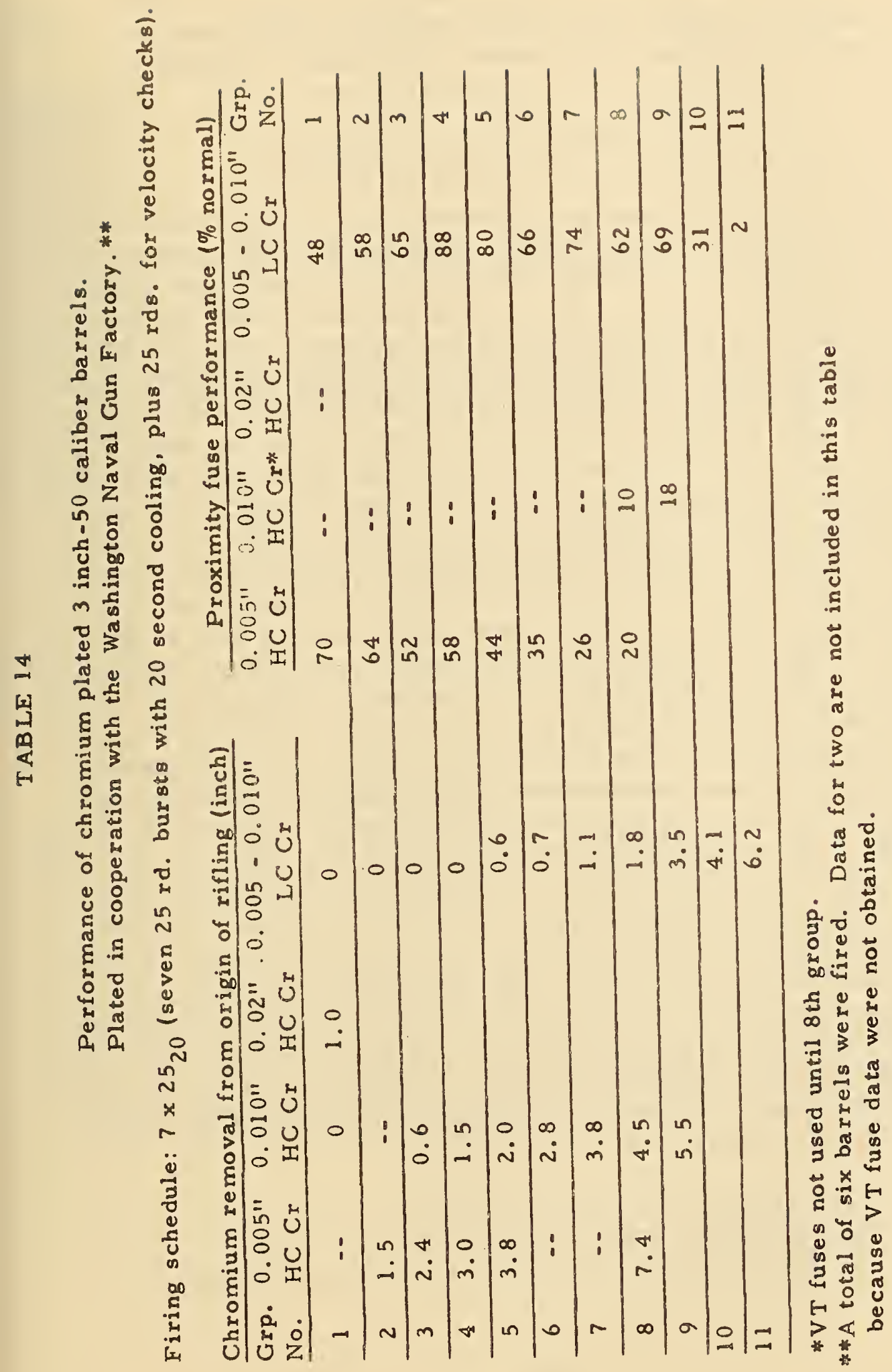


plates of this order of thickness in smaller caliber barrels.

The best performance was given by the barrel plated with the tapered LC chromium plate, which had a life of ten firing groups, compared with seven for the barrel with 0.01 inch $\mathrm{HC}$ chromium, and six for the barrel with 0.005 inch $\mathrm{HC}$ chromium.

\section{MISCELLANEOUS TESTS OF GUN BARRELS}

8.1 Effect of heat-treatment of chromium-plated barrels Heat-treatment of chromium plated cutting tools, dies, etc., to relieve stress and hydrogen embrittlement is a common practice. It is therefore natural that the question of the possible value of heattreatment of chromium-plated gun barrels should arise. In general, it is considered that hydrogen embrittlement of chromium plated tools, etc., requires elimination through heat-treatment only if the hardness of the basis steel is greater than Rockwell C-40. Since gun steel is not this hard, and since no gun barrel failures had been observed that were attributable to hydrogen embrittlement, experimental tests of chromium-plated and heat-treated gun barrels had not been seriously considered in the earlier stages of the program. However, due to the persistence of interest in this question in several quarters, it was decided early in 1950 to initiate some tests. During July 1950 four caliber. 50 barrels were plated to standard specifications with HC chromium at NBS and heat-treated at the Naval Gun Factory. Two were heated to $200 \mathrm{C}$ for eight hours and two to $600 \mathrm{C}$ for six hours. The temperature of $200 \mathrm{C}$ was chosen because it is approximately that which is commonly used for relief of hydrogen embrittlement, and $600 \mathrm{C}$ was chosen because it is close to the upper limit to which the steel can be heated without changing its properties, yet high enough to produce appreciable annealing of the chromium. The performance of these barrels is shown in Table 15. Their firing life was about two-thirds that of unheated barrels, and one of the barrels heated to $600 \mathrm{C}$ burst during firing. Metallographic examination of. the steel showed normal structure and hardness for all of the barrels. No explanation for their poor performance was found. About this time we learned of the work on the same subject carried out at Woolwich Arsenal (25) which indicated that the adhesion of chromium in $40 \mathrm{~mm}$ barrels was improved by a cycle consisting of:

(a) Heating at $75 \mathrm{C}$ /hour to $400 \mathrm{C}$

(b) Holding at $400 \mathrm{C}$ for 1 hour

(c) Slow cooling to room temperature in the furnace. 
TABLE 15

Performance of barrels heat-treated after chromium plating

\begin{tabular}{|c|c|c|c|c|c|c|}
\hline $\begin{array}{l}\text { Barrel } \\
\text { description }\end{array}$ & $\begin{array}{l}\text { To } \\
\text { rour } \\
\end{array}$ & $\begin{array}{l}\text { Av. pattern at } \\
1000 " \mathrm{HxV} \text { (inch) }\end{array}$ & $\begin{array}{l}\text { Rounde to } \\
\text { failure }\end{array}$ & $\begin{array}{l}\text { Velocity } \\
\text { Initial - flnal (f. p. s.) }\end{array}$ & $\begin{array}{l}\text { Cr off at } \\
\text { O.R. (inch) }\end{array}$ & Type of failure \\
\hline \multicolumn{7}{|c|}{ Caliber. 50} \\
\hline $\begin{array}{l}\text { Nitrided, choked } \\
.0025 " \text { HC Cr. Heated } \\
8 \text { hr. at } 200 \mathrm{C}\end{array}$ & 556 & $10 \times 11$ & 483 & $2912-2584$ & 2 to 4 & $\begin{array}{l}\text { Velocity drop } \\
\text { Tumbling }\end{array}$ \\
\hline Duplicate of above & 575 & $10 \times 10$ & 520 & $2889-2744$ & 2 to 3 & Tumbling \\
\hline $\begin{array}{l}\text { Same a s above but } \\
\text { heated } 6 \mathrm{hr} \text {. at } 600 \mathrm{C}\end{array}$ & 530 & $6.4 \times 7.6$ & 465 & $2930-\ldots$ & - & Barrel burst 5 th burat \\
\hline Duplicate of above & 568 & $16 \times 14.5$ & 443 & $2969-2538$ & 3 to 7 & $\begin{array}{l}\text { Velocity drop } \\
\text { Tumbling }\end{array}$ \\
\hline
\end{tabular}

Unheated Cr plated control(9) 725 (Average llfe based on 200 f.p. s. velocity drop)

Caliber $.60 \quad$ Schedule: eight $50 \mathrm{rd}$. bursts, 1 burst each $2 \mathrm{~min}$. , complete cooling at $600 \mathrm{rds}$.

Two piece barrel .003"

HC Cr on muzzle, .006" HC Cr $440 \quad 8 \times 12 \quad-3503-3379 \quad 2 \quad$ removal

on breech. Heated in $21 / 2 \mathrm{hrs}$.

to $460 \mathrm{C}$ for $1 \mathrm{hr}$.

\begin{tabular}{|c|c|c|c|c|c|c|}
\hline Same as above & 440 & $8 \times 8$ & -- & $3492-3281$ & 2.5 & $\begin{array}{l}\text { Velocity drop } \\
\text { Cr removal }\end{array}$ \\
\hline Same as above & 439 & $8.5 \times 8$ & -- & $3484-3405$ & 2 & Cr removal \\
\hline $\begin{array}{l}\text { Placed in furnace at } \\
460 \mathrm{C} \text { for } 1.5 \mathrm{hr} \text {. }\end{array}$ & 904 & $8.3 \times 10.2$ & 539 & $3474-2732$ & 12 & Velocity drop \\
\hline Same as above & 908 & $10.2 \times 11.3$ & 540 & $3489-2688$ & 14 & Velocity drop \\
\hline Same as above & 857 & $10.1 \times 9.3$ & 540 & $3554-3028$ & 1.5 & Velocity drop \\
\hline
\end{tabular}

$40 \mathrm{~mm}$

$.006^{\prime \prime} \mathrm{LC} \mathrm{Cr}$ heated $1 \mathrm{hr}$.

at $400 \mathrm{C}$.

Schedule: three $50 \mathrm{rd}$. burste, 1 min, cooling, complete cooling 170 rde.*

.006 " LC control-not heated

Av. pattern at $2000^{\prime \prime}$

.006 " HC $\mathrm{Cr}$ heated $1 \mathrm{hr}$.

at $400 \mathrm{C}$

$14 \times 15$

$1082 \quad 2996-2857$

$3050-2942$

Tumbling

$\frac{1082}{857}$

$15 \times 13.5$

857

$12.5 \times 13$

1054

$3035-2887$

.006 " HC Cr control

not heated

$13.5 \times 15$

1199

$3057-2890$

1.5

Oversize bore

.012 " HC $\mathrm{Cr}$ heated $1 \mathrm{hr}$.

at $400 \mathrm{C}$

1538

$13.5 \times 12$

1538

$3046-2834$

3

Oversize bore

012 " HC control

not heated

1545

$11 \times 12$

1545

$3037-2865$

*Combination powder used for these tests (75\% double-base, 25\% 1. 1" "Ma ster standard"). 
Two further tests were therefore carried out, one with caliber . 60 barrels and one with $40 \mathrm{~mm}$ barrels. The results of these tests are also shown in Table 15 . The heating cycle used for the caliber . 60 and $40 \mathrm{~mm}$ barrels was essentially the same as that recommended in the Woolwich report. The higher temperatures of $460 \mathrm{C}$ used for the caliber . 60 barrels was in line with later Woolwich recommendations for barrels to be used on rapid-fire schedules.

In the heated caliber .60 barrels, rate of removal of plate at the origin of rifling was somewhat less than from unheated barrels, but plate was lost slightly faster than normal from the muzzle regions. Overall performance, was if anything, slightly inferior to that of unheated barrels.

The conclusion was that the results do not show that heattreating after plating has significant value. The reason for the variance between this conclusion and the opposite conclusion reached in the early Woolwich reports may lie in the difference in the testing schedules or in differences in steels. The Woolwich report did indicate that improvement was greater under single-shot firing schedules than under rapid-fire schedules.

\section{2 Injection cooling of gun bores}

Erosion of gun bores under conditions of rapid firing is primarily a consequence of the high temperature reached by the surface of the bore. If the bore could be kept cool, performance should be improved. Several devices for this purpose were tested by other NDRC contractors, but were not successful. Therefore, one of the authors, working at the Geophysical Laboratory in 1945, undertook to design an improved model of injection cooler [26]. The initial tests appeared promising, so work was continued at NBS after the termination of the gun barrel program at the Geophysical Laboratory in 1945.

An injection cooler is a device for injecting coolant into the bore, i. e., for cooling the bore from the inside. This is the logical place to apply a coolant, since the heat imparted to the bore can then be removed without traveling through the barrel wall. Cooling by means of an external water jacket is of course commonly used for some types of guns, but this method has the disadvantage that conduction of heat through the wall is slow, and under severe rapid-fire schedules, the bore surface may still reach an excessively high temperature. 
An injection cooling system may be designed to cool the bore between each round, or during non-firing periods between bursts, or both. An effective system must employ a coolant with high heat capacity. Some of the earlier models which utilized a gas as the coolant are inherently impractical, because the heat capacity of any gas is relatively low and cannot remove enough heat, at least during "between-round"injection. Water absorbs approximately 850 calories/gram in passing from liquid at a temperature of $30^{\circ}$ to vapor at $600^{\circ} \mathrm{C}$, whereas for the same temperature interval, air will absorb only about 150 and carbon dioxide about 120 calories/gram. The advantage of water is apparent.

The major part of the heat absorbed by water is that absorbed by vaporization. For vaporization to occur within the fraction of a second available between rounds, the water must be inserted into the bore in an atomized form, that is, as a fine spray. If it is inserted as a "slug" of liquid, a negligible amount vaporizes and the excess liquid passes ineffectively through the bore. Further requirements for a practical injection cooler are: mechanical simplicity, lightness, non-interference with the normal functioning of the gun, and capability of operating satisfactorily under a range of service conditions, e.g., at low temperatures and against high wind pressures.

The design of the cooler is indicated in Figures 19 and 20. It consists of a steel block mounted between the side plates of the receiver. The block carries a hinged injector nozzle (A). Air and water are $f \in d$ to the nozzle through tubes leading from the inputs (D). The nozzle is forced down by the forward motion of the bolt when the gun mechanism goes into battery. Valves in the cylinder (B) of the nozzle-hinge automatically stop the flow of air and water when the nozzle is in this position. After the round is fired and the cartridge case is extracted, the nozzle, activated by a spring $(\mathrm{C})$, returns to the injection position and the flow of water, atomized by the air stream, automatically begins. Injection continues as long as the gun mechanism remains out of battery.

In the tests described below, the flow of water was about $4 \mathrm{ml} /$ round. Consumption of air during continuous operation was $25 \mathrm{cu}$. ft. per minute (measured at atmospheric pressure). The operating air pressure required is about $50 \mathrm{lb}$ in. ${ }^{2}$. Approximate estimates 

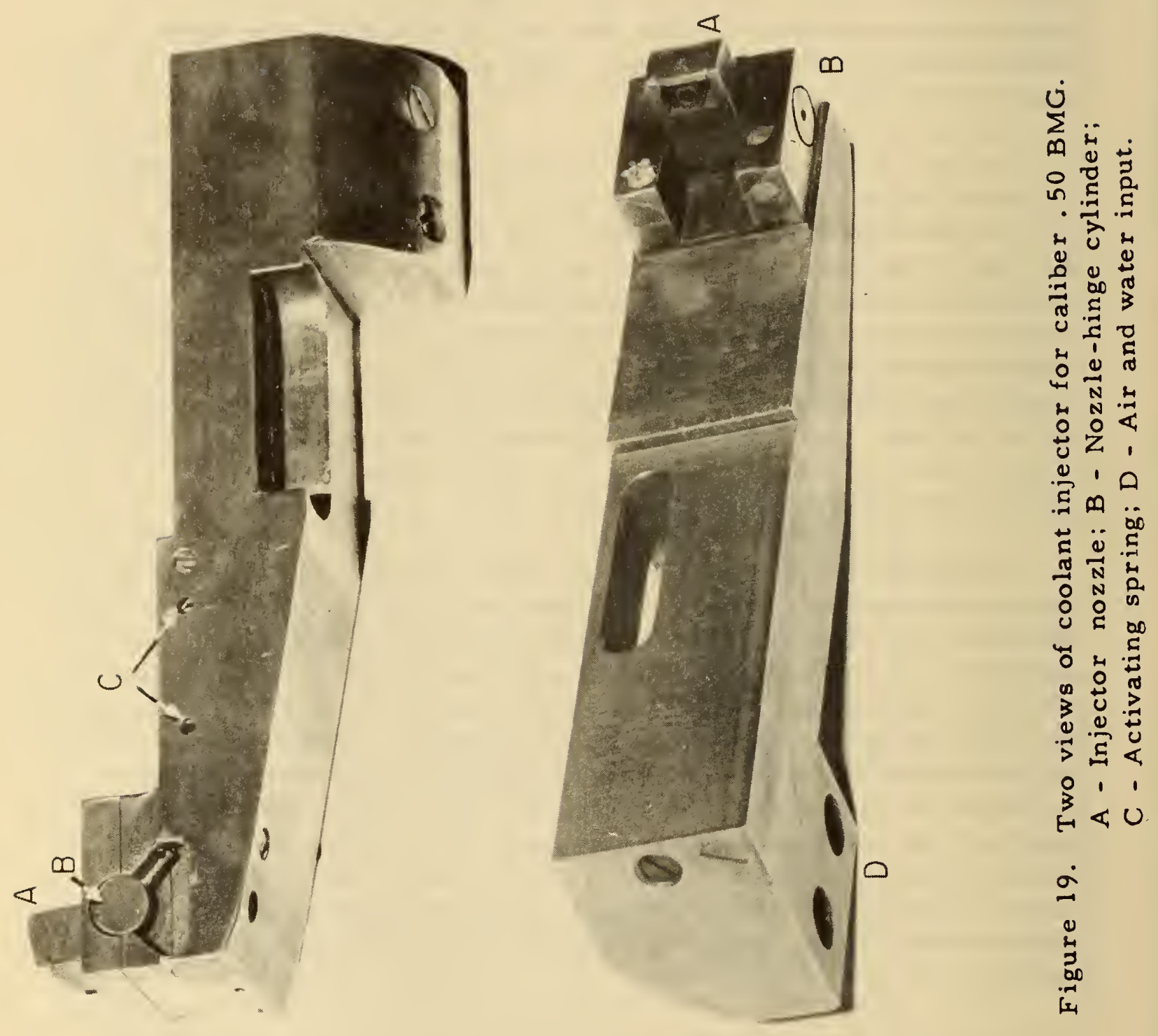


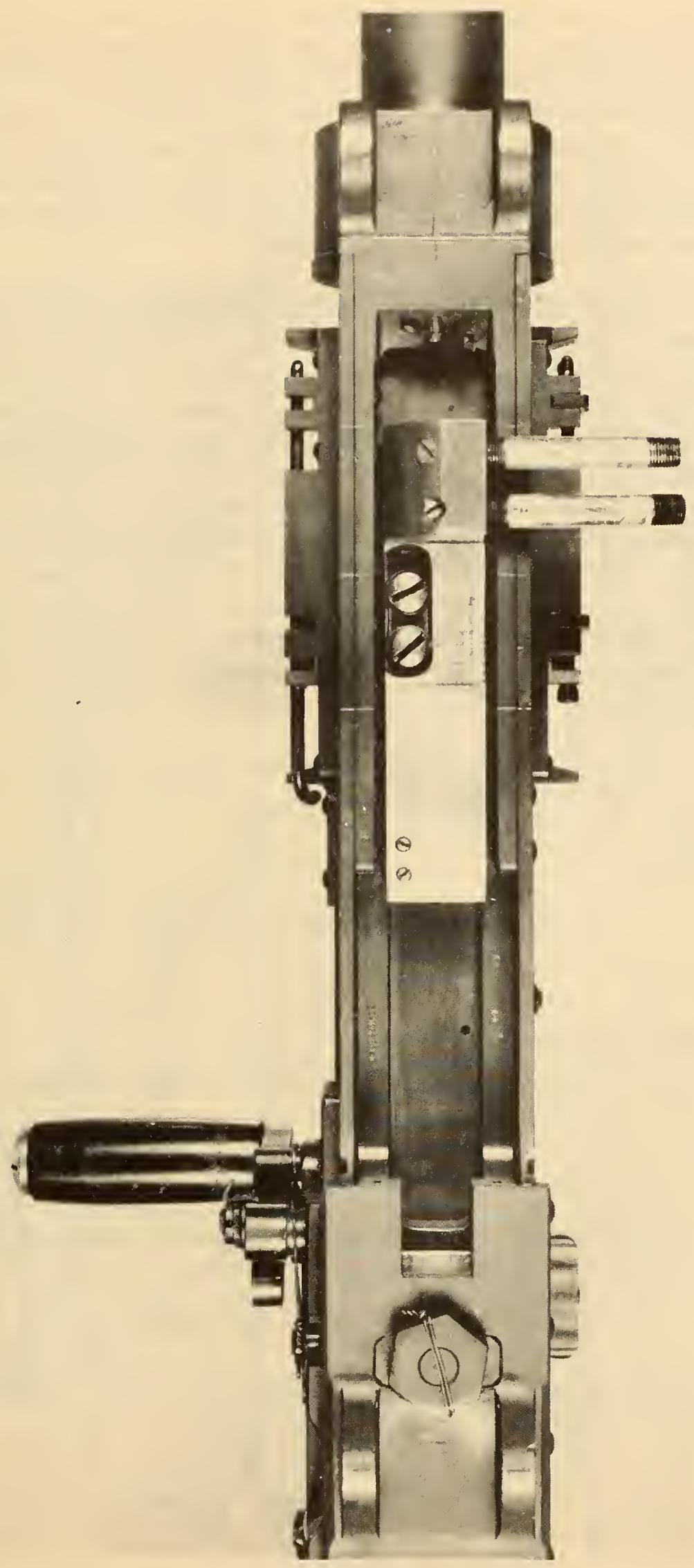

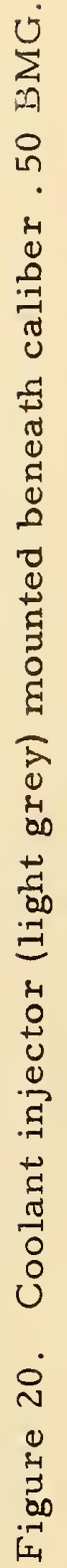


based, first, on the proportion of the energy of the propellant that heats the barrel, and second, on the heat capacity and temperature of the bore surface to a depth of about $1 / 16$ inch, both indicate that about 2500 calories/round must be absorbed to keep the temperature of the bore surface below about $600^{\circ} \mathrm{C}$. Four $\mathrm{ml}$ of water per round, if heated to $600^{\circ}$, would absorb a about 3400 calories. This rate of consumption of water is therefore of the required order of magnitude.

The results of the firing tests with this injection cooler are summarized in Figure 21. It is seen that injection cooling produced appreciable improvement in barrel life. However, before the injection cooler could be adopted, further improvement in design would be necessary, particularly to prevent leakage of water from imperfect valve seals into the gun mechanism. It would also be necessary to evaluate its performance at low temperatures, with a codant having a low freezing-point, and against high wind-pressures. These tests were not made.

Some work was done on the application of a similar injection. cooler to the caliber . 60 gun, but the mechanical design problems were not solved. 
8.3 Tests of barrels coated by the

"Chromizing" process

"Chromizing" is a process whereby a chromium-iron alloy is formed on the surface of steel by heating it at a high temperature in contact with chromium powder or a chromium compound such as chromic chloride. From time to time this process has been proposed as a means for producing an erosion resistant bore surface. Arrangements were therefore made by the Department of the Navy, Bureau of Ordnance, Section ReS5a, to have three MK-11 $20 \mathrm{~mm}$ barrels chromized by the Chromalloy Corporation, New York. They were test-fired by NBS in cooperation with the Dahlgren Naval Proving Ground. The results were the subject of a special report (27).

The barrels used for the test were cut off to a length of 28 inches owing to the size limitations of the chromizing equipment. The per formance of the short barrels could not be compared with that of fulllength barrels. Therefore two control barrels 28 inches long were fired along with the chromized barrels. One was an unplated steel barrel, and one was plated with 0.006 inch thickness of HC chromium.

Two disadvantageous effects of chromizing were noted. First, it causes definite "growth" of the steel. It was necessary to reduce the outside diameter of the chromized barrels by $0.004-6$ inch by electropolishing before they could be assembled in the gun mechanisms and it was also necessary to regrind the chamber before the cartridge case would enter. Second, the temperature used for chromizing anneals the steel, so that reheat-treatment is necessary.

The surface hardness of the chromized layer was about $1400 \mathrm{Knoop}$, both before and after firing, and its thickness as measured on a polished section with a microscope was in the range 0.0006 to $0.0010 \mathrm{inch}$.

The results of the tests are shown in Table 16. The average life of the chromized barrels was about half that of the chromium plated control barrel, but about 40 percent greater than that of the unplated steel barrel. This degree of improvement is about what one would expect from a chromium plate of the same thickness as that of the chromized layer. A chromized layer several mils thick might give barrel performance equivalent to that given by electroplated chromium. This would have to be determined by experiment. It is doubtful whether a thick chromized coating is practicable from the standpoint of application. 


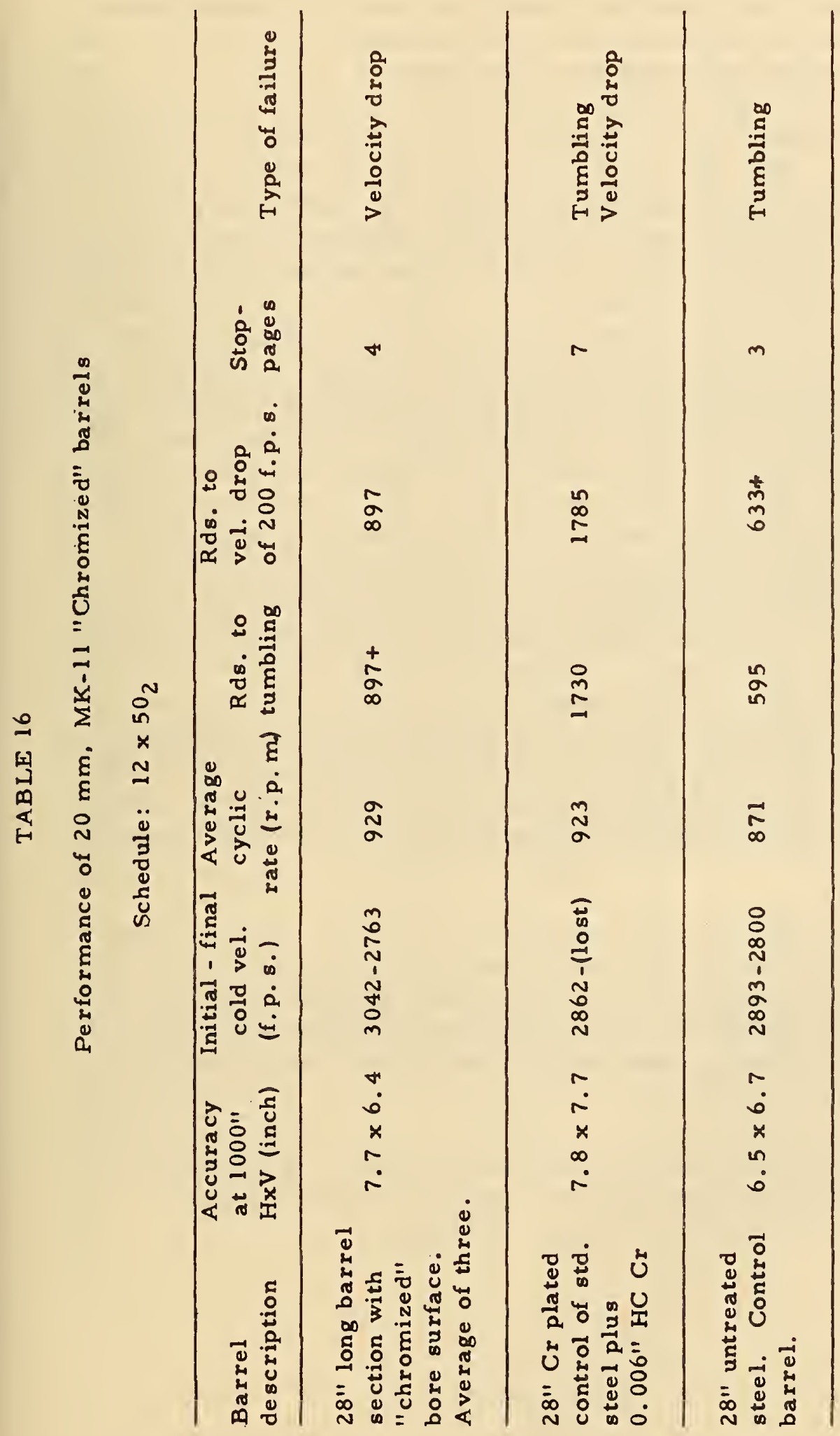


8.4 Tests of barrels prepared for plating by "Vapor-Honing"

So-called "Vapor-Honing" is a process for smoothing the surface of steel by removing machining burrs and rounding off sharp corners. In this process, a water suspension of a fine abrasive is blown against the steel surface with a high-pressure jet of air.

It has been pointed out in section 5.2 of this report that electropolishing has been widely used in gun bore plating to enlarge the bore, remove burrs, and round off land corners prior to chromium plating. However, electropolishing does have some disadvantages that have led to a search for substitute procedures by agencies concerned with plating of barrels in production quantities. One of the most troublesome difficulties thathas been encountered with electropolishing is that the segregations or slag streamers that sometimes are present in the bore surface are preferentially dissolved, leaving a pitted surface that is difficult to cover completely with chromium. It is, of course, probable that such a barrel will perform at least as well as one in which such defects are covered over with a chromium plate. Nevertheless, the barrel with the visible defects has the appearance of being inferior. Other objections that have been raised against electropolishing are that it is difficult to control the thickness of steel removed, the process is messy, the equipment costs are too high, or the process is too slow. Any process may have both advantages and disadvantages which must be weighed in deciding whether to use it, or some competing process. We believe that these disadvantages in the electropolishing process have been overemphasized, and that its practicability has been proved by its extensive successful use. On the other hand, the convenience of vapor-honing as a production operation is recognized.

Owing to its convenience as a production process, vapor-honing of bores that had been made oversize by machining was adopted as a method of surface preparation in some production plants. The question arose as to whether barrels prepared by the two methods were equally good in firing performance. To answer this question controlled tests were planned and carried out.

The tests included $20 \mathrm{~mm}, 40 \mathrm{~mm}$, and 3 inch - 50 caliber barrels. Vapor-honing and part of the plating was done by the Gerrity-Michigan Corporation, Adrian, Michigan. 
The Naval Gun Factory was responsible for the plating and testing of the 3 inch - 50 caliber barrels. The $20 \mathrm{~mm}$ barrels were prepared by NBS, but tested by Aberdeen Proving Ground. The tests of the $40 \mathrm{~mm}$ barrels were carried out entirely under the responsibility of NBS and will be described first. They are summarized in Table 17, which is an abstract of the more complete data reported in an NBS quarterly report (28).

It is seen from the table that differences in performance, with respect to overall barrel life, were within the limits of experimental variation.

The slightly better accuracy of the control barrel, which was prepared for plating by electropolishing, appeared to be real and was probably related to the fact that in this barrel, firing caused less chromium to be removed at the origin of rifling and along land corners than was removed in the vapor-honed barrels.

The data available for the 3 inch - 50 caliber barrels are based on the appearance of the barrels after a few rounds of prooffiring. At this stage there was no significant difference between the vapor-honed and the electropolished barrels.

The results of the tests of the $20 \mathrm{~mm}$ barrels have been reported by Aberdeen Proving Ground (29). Their report states that firing life of the electropolished barrels was about 35 percent greater than that of the vapor-honed barrels on schedules of $40 / 30 / 600$ and $100 / \mathrm{min} / 600$. * On a firing schedule of $250 / \mathrm{cc} * *$ the life of both types of barrels was about the same.

*40/30/600 represents 40 round bursts at 30 seconds intervals with complete cooling after 600 rounds. $100 / \mathrm{min} / 600$ represents 100 round bursts at 1 minute intervals with complete cooling at 600 round 8 .

**250 round bursts with complete cooling between bursts. 


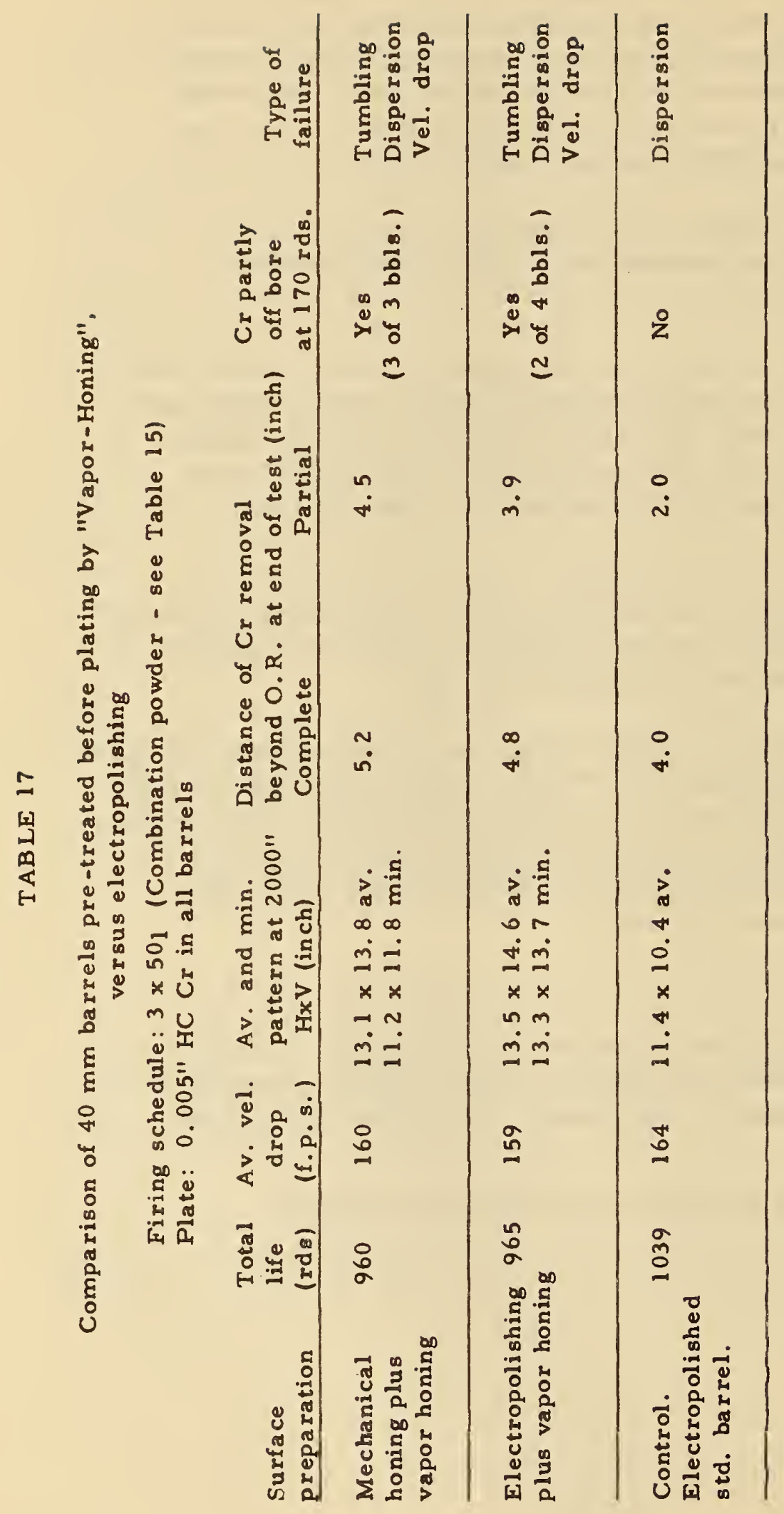


The Aberdeen test also included barrels that had been overbroached 0.0055 inch on radius, and electropolished 0.0005 inch on radius prior to plating. These were slightly inferior to the vapor-honed barrels. The conclusion stated in the Aberdeen report is: "It is concluded that tubes manufactured using the electropolish method (full depth polish) are superior to those manufactured using preplating methods of overbroaching with slight electropolish and overbroaching with vapor-honing."

To sum up, the evidence indicates that electropolishing does result in better barrel performance than vapor-honing, although the difference is not large.

8.5 Tests of barrels plated with "Crack-Free" chromium "Crack-free" chromium is a proprietary* chromium plate which, as the name implies, is free of the cracks characteristic of HC chromium. Its physical properties are probably similar to those of LC chromium.

Four $20 \mathrm{~mm}$ MK-11 barrels were electropolished by NBS and plated by United Chromium, Inc. Results of the testing of these barrels has been reported in dotail (30). The results were inconclusive as a consequence of the fact that the plate was extremely rough. Even though the plates were smoothed as much as possible by lapping, the residual roughness caused frequent schedule inter ruptions due to failure of cartridge cases to extract. This also caused the rate of fire to be low. The average firing life of the crack-free barrels on a schedule of $12 \times 50_{2}^{* *}$, based on a velocity drop of $200 \mathrm{ft} / \mathrm{sec}$, was 1766 rounds. This compared with 1088 rounds for a control barrel plated with $\mathrm{HC}$ chromium. It is not possible to decide whether the apparently better performance of the crack-free plate is due entirely to the stoppages and low rate of fire, or whether it really is better than standard chromium. A conclusion must depend on further tests of crack-free plates that are free of the surface roughness described above.

* United Chromium, Inc., New York, (a Division of Metal \& Thermit Corporation.)

**Twelve 50 round bursts at 2 minute intervals, followed by complete cooling. 
8.6 Bore coatings for combined corrosion and erosion protection of barrels for submarine service

Coatings of $\mathrm{HC}$ chromium in the range of thickness used in $40 \mathrm{~mm}$ barrels, namely 0.005 to $0.010 \mathrm{inch}$, do afford some corrosion protection. However, other coating systems, that are free of the crack-type porosity of $\mathrm{HC}$ chromium, would be expected to afford better resistance to corrosion, which is important in barrels for submarine service.

At the request of the Bureau of Ordnance, ReS5a, a study of the combined corrosion and erosion properties of other coating systems was undertaken. The program was divided into two parts. First, an experimental evaluation of coatings on steel panels, subjected to corrosion by aerated synthetic sea water, and second, firing tests of $40 \mathrm{~mm}$ barrels plated with coatings selected on the basis of the results of the tests of panels. The barrels were tested on a schedule that combined alternate firing and immersion in synthetic sea-water. The results have been described in detail in earlier NBS reports (31).

It was decided initially to include in the tests, coatings of chromium (both $\mathrm{HC}$ and $\mathrm{LC}$ ), nickel, and cobalt, in various combinations and thicknesses. The results of the tests of the plated steel panels are summarized briefly as follows:

(a) Nicke1, or combinations of nickel with chromium, were in general superior to corresponding cobalt coatings. This was due in part to the fact that we were unable to consistently obtain cobalt coatings that did not develop stress-cracks.

(b) A given thickness of LC chromium was markedly superior to the same thickness of HC chromium.

(c) Combination plates of thin nickel-thin chromium $(0.0005 \mathrm{Ni}-$. $0.001 \mathrm{Cr}$ ) were poorest of the combination plates, and corrosion resistance improved with increase in thickness of either the nickel or the chromium.

(d) There was no significant difference in corrosion performance of the following "best" coatings: (1) 0.005 inch $\mathrm{Ni}$; (2) 0.005 inch LC Cr; (3) 0.0005 inch Ni plus 0.005 inch $\mathrm{HC} \mathrm{Cr}$; (4) 0.001 inch Ni plus 0.005 inch $\mathrm{HC} \mathrm{Cr}$; (5) 0.002 inch $\mathrm{Ni}$ plus 0.001 inch $\mathrm{HC} \mathrm{Cr}$; (6) 0.002 inch $\mathrm{Ni}$ plus 0.005 inch $\mathrm{HC}$ Cr. 
No combinations of LC chromium over nickel were included because of the difficulties involved in obtaining good adhesion of LC chromium to nickel. The duration of the sea-water immersion tests was 120 days.

Because of the high cost of firing tests, it was decided to select only two of the most promising coating systems for application to $40 \mathrm{~mm}$ barrels. Coating (d-2) above (0.005 inch LC chromium) was chosen in preference to 0.005 inch nickel because of the known better erosion resistance of the former. From the above group of four "best" combination plates, $(d-3$ to $d-6)$ the thickest, namely 0.002 inch nickel plus 0.005 inch $H C$ chromium (d-6) was chosen. This selection was based on the fact that the duration of the immersion tests of the panels was too short for perforation of the thinner nickel layers to occur. However, in long-term submarine service, perforation of the nickel might occur, and therefore a longer life should be expected from the thicker coating. The combination with 0.005 inch chromium was chosen because this thickness is in the range previously found to be satisfactory from the standpoint of erosion resistance.

The description of the barrels and the results of the firing tests are summarized in Table 18. The test cycle consisted of the following steps:

(a) Fire one 50-round buxst.

(b) Cool, inspect, and submerge for six days in a vertical position in a solution of synthetic sea-water at room temperature.

(c) Remove from the salt solution, rinse, dry, and inspect.

(d) Fire another 50 round burst, etc.

This cycle was continued initially for twelve weeks. After an interruption of ten weeks, during which time the barrels were stored as fired, firing of one barrel plated with LC chromium and one unplated control barrel was resumed, and continued for an additional 38 weeks.

The LC chromium plate, 0.006 inch thick, gave by far the best overall protection to the barrels. The combination plate of nickel and chromium had superior corrosion resistance, but was lost from the region of the origin of rifling in the early stages of the firing period. This exposed the basis steel to erosion and corrosion. Poor adhesion of the nickel to the steel was responsible for this failure. The nickel was applied by a competent commercial plating firm (Chromium Corporation of America) experienced in nickel plating 


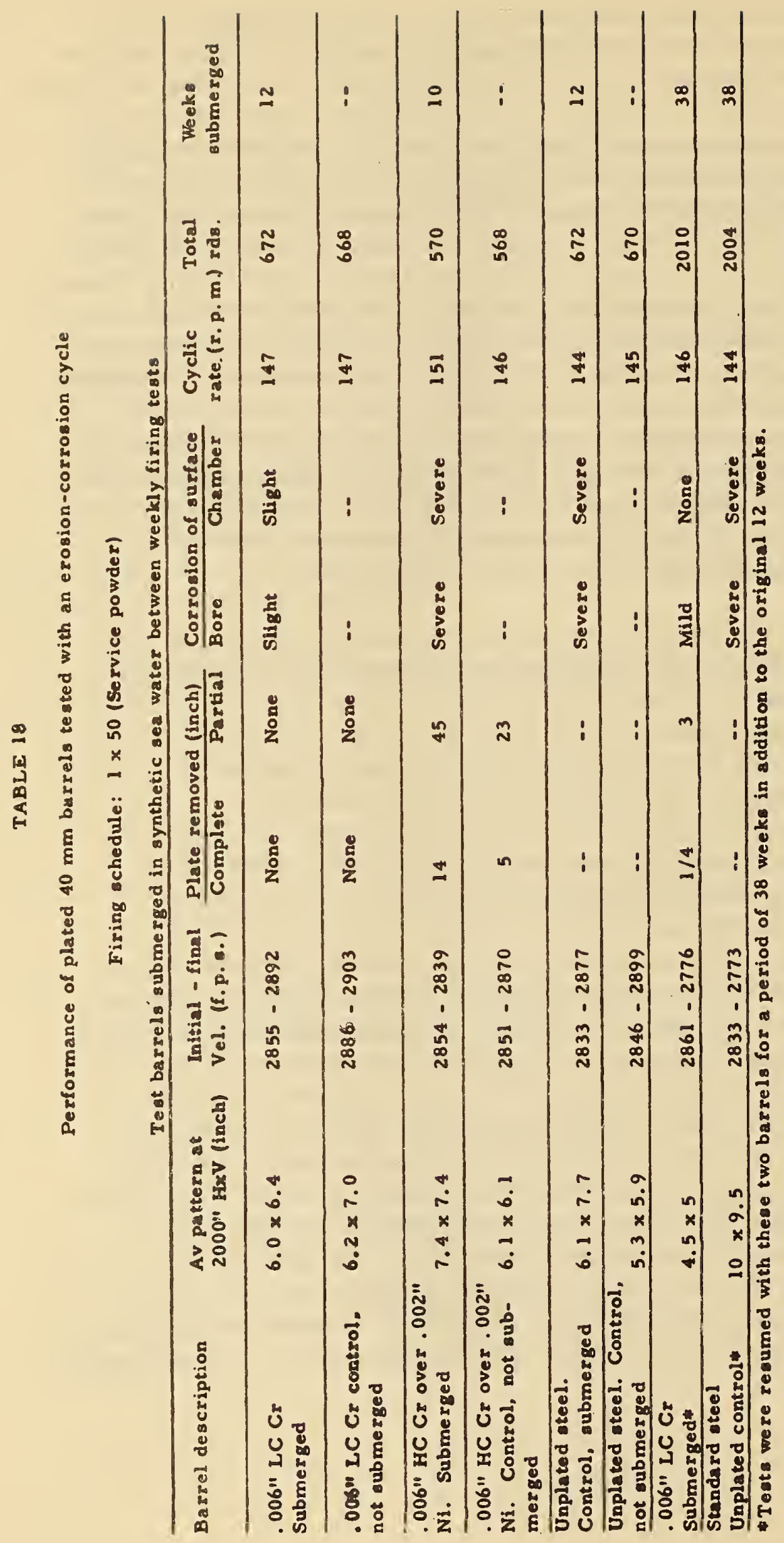


of tube bores. The sulfuric acid anodic etch procedure was used to obtain maximum adhesion of the nickel. Before the barrels were chromium plated, a ring was cut from the muzzle end of each nickel plated barrel and the adhesion was tested by bending and chiseling tests. It appeared to be excellent. The fact that nickel was nevertheless removed from the bore during firing indicates that the re is little chance for this type of coating to be applied successfully.

The barrels plated with LC chromium showed some corrosion products on the bore after firing and immersion, due to rusting through cracks and tiny areas of plate failure. The amount of rusting of this type was too small to affect firing performance. Erosion was negligible.

In conclusion, it may be stated that a thick plate of LC chromium was the best tried, and does afford marked protection against combined erosion and sea-water corrosion.

\subsection{Tests of chromium applied by the Hausner Process}

The Hausner process of chromium plating consists of plating from a chromic acid bath with a high-frequency alternating current added to the normal direct current. This process, which was promoted in Germany following the war, became the subject of investigations by both German and British technical groups. The findings of these investigators have been described in a Navy report (32) and in separate publications $(33,34)$.

Promoters of the process claimed the following improvements over conventional chromium plating: higher current efficiency, improved throwing power, less porosity of the deposits, harder deposits, and better adhesion of the chromium to the basis metal. The investigations of the process referred to above did not substantiate any of these claims except the one concerning throwing power. Data on throwing power were conflicting, but there was evidence that with respect to throwing power the process had some merit.

In the NBS gun barrel program, we have taken part in two tests of barrels plated by this process. The first was sponsored by Army Ordnance, ORDTS. It was carried out on November 19, 1953, at 
Aberdeen Proving Ground and consisted of the test firing of one caliber . 50 aircraft barrel plated by the Hausner process, * and two standard, full-length, taper-plated barrels prepared by Springfield Armory. The nominal thickness of the chromium in the Hausner barrel was 0.001 inch and in the Springfield barrels was 0.002 inch. They were fired on a schedule consisting of continuous 400 round bursts with complete cooling between bursts. The Hausner barrel, though fired a full 400 round burst, failed by 100 percent keyholing before the end of the burst and gave immediate keyholing on attempting to fire a second burst. One Springfield barrel was fired 400 rounds ( 1 burst) with no failure and was stopped at this point in order to compare its condition with that of the Hausner barrel. The second Springfield barrel was fired two 400 round bursts, at which point it was at, or close to, its endof-life.

The firing-life of the Hausner barrel was therefore one-third to one-half that of the standard plated barrel. This is about what would be expected of a barrel plated with a thickness of 0.001 inch of standard plate.

The second test was sponsored by the Navy Bureau of Ordnance, Section ReW4a. Three MK-11, $20 \mathrm{~mm}$ barrels which had previously been electropolished by us were plated with 0.002 to 0.003 inch of chromium by the Hausner process. ** They were fired at the Dahlgren Naval Proving Ground during January-March 1956. A full report of the results is given in our quarterly report for this period (35). Control barrels with standard HC chromium, 0.006 inch thick, had an average life 23 percent greater than that of the Hausner barrels. Again, the performance of the Hausner plate was about the same as would be expected of standard chromium of the same thickness.

*The plating was done by the Triumph Manufacturing Co., Chicago, II1.

* The plating was done by the Neotronic Corporation, Chicago, Ill. 
Neither test indicated that chromium deposited by the Hausner process was superior to standard chromium with respect to performance in gun barrels. Conversely, the tests did not indicate that it is inferior, when thickness is considered.

\subsection{Experimental rifling designs}

The lands in a gun barrel are subjected to severe stresses, especially at the origin run-up. As has been already stated in section 3, the physical properties of chromium are not all that is desired with respect to ability to withstand these stresses. Consequently failure of the chromium plate usually starts on land corners on the run-up or near the origin of rifling. If the stresses on the plate could be reduced in magnitude, performance should be improved. Modifications of the bore that have already been described that were made for the purpose of minimizing this weakness of chromium are (a) a smooth, unrifled bore, and (b) a long "land run-up". Another approach is to redesign the lands to minimize the forces that act on them, or to redistribute the forces acting on them, so that a local point, such as the corner of the driving side of the lands, does not receive the major part of the stress.

It was believed an empirical approach to this problem, namely the trial of a number of land designs, would be preferable to attempts to design an optimum form of land by a theoretical approach.

The six designs shown in Figure 22 were selected, and duplicate barrels were made with each design, by Springfield Armory. M-39, $20 \mathrm{~mm}$ barrels were used. They were plated at NBS with 0.006 inch thickness of HC chromium, and test-fired at Aberdeen Proving Ground. The results are summarized in an NBS quarterly report (35). Evaluation of the results was very difficult because of frequent schedule interruptions due to break-down of guns, and because of failure of the breech face by indentation or erosion prior to failure of the bore. The results are summarized in Table 19. Four of the special riflings performed appreciably better than standard rifling. Whether the differences are real cannot be decided because of the firing difficulties cited. Bands engraved by the sector and modified sector lands (Figure 23) showed less slippage and more uniform engraving during the early life of the barrels than did those engraved by any of the other types of lands. Bands engraved by standard lands (control bar rels) showed some slippage and shearing even when the barrels were new. These results have sufficient promise to warrant further trials in other types of barrels. 


\section{DESCRIPTION}

SPACED RATCHET

12 LANDS PER BARREL

MACRO LANDS

9 LANDS PER BARREL

SPACED RATCHET

MINOR LANOS

24 LANOS PER BARREL

MINOR LANDS

18 LANOS PER BARREL

SECTOR LANDS

12 LANDS PER BARREL

MODIFIED SECTOR LANDS 12 LANDS PER BARREL

CONTROL BARREL 9 STANDARD LANOS PER BARREL
CROSS SECTION

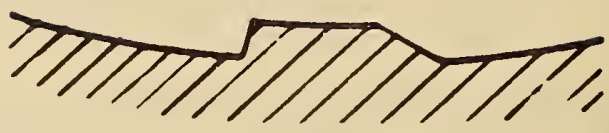

LAND HEIGHT .016

LAND WIDTH .090

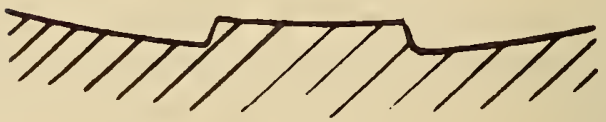

LAND HEIGHT .016

LAND WIDTH .090

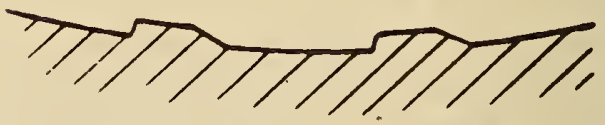

LAND HEIGHT .0085

LAND WIDTH .060

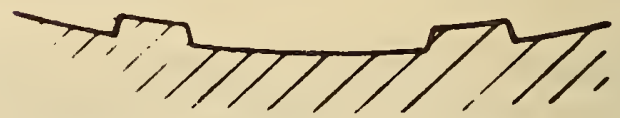

LAND HEIGHT .0085

LAND WIDTH .040

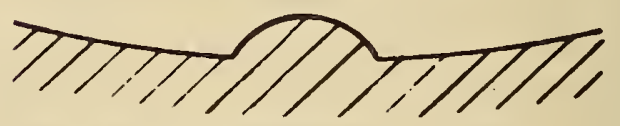

LAND HEIGHT .018

LAND WIDTH .060

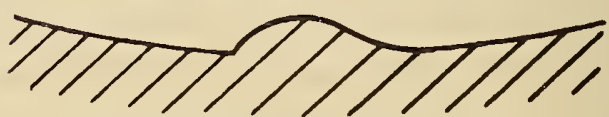

LAND HEIGHT .OIB

LAND WIDTH .080

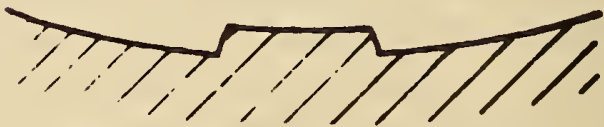

LAND HEIGHT .OIS

LAND WIDTH .058

Figure 22. Land designs used in tests of experimental riflings in $20 \mathrm{~mm} \mathrm{M} 39$ barrels. 


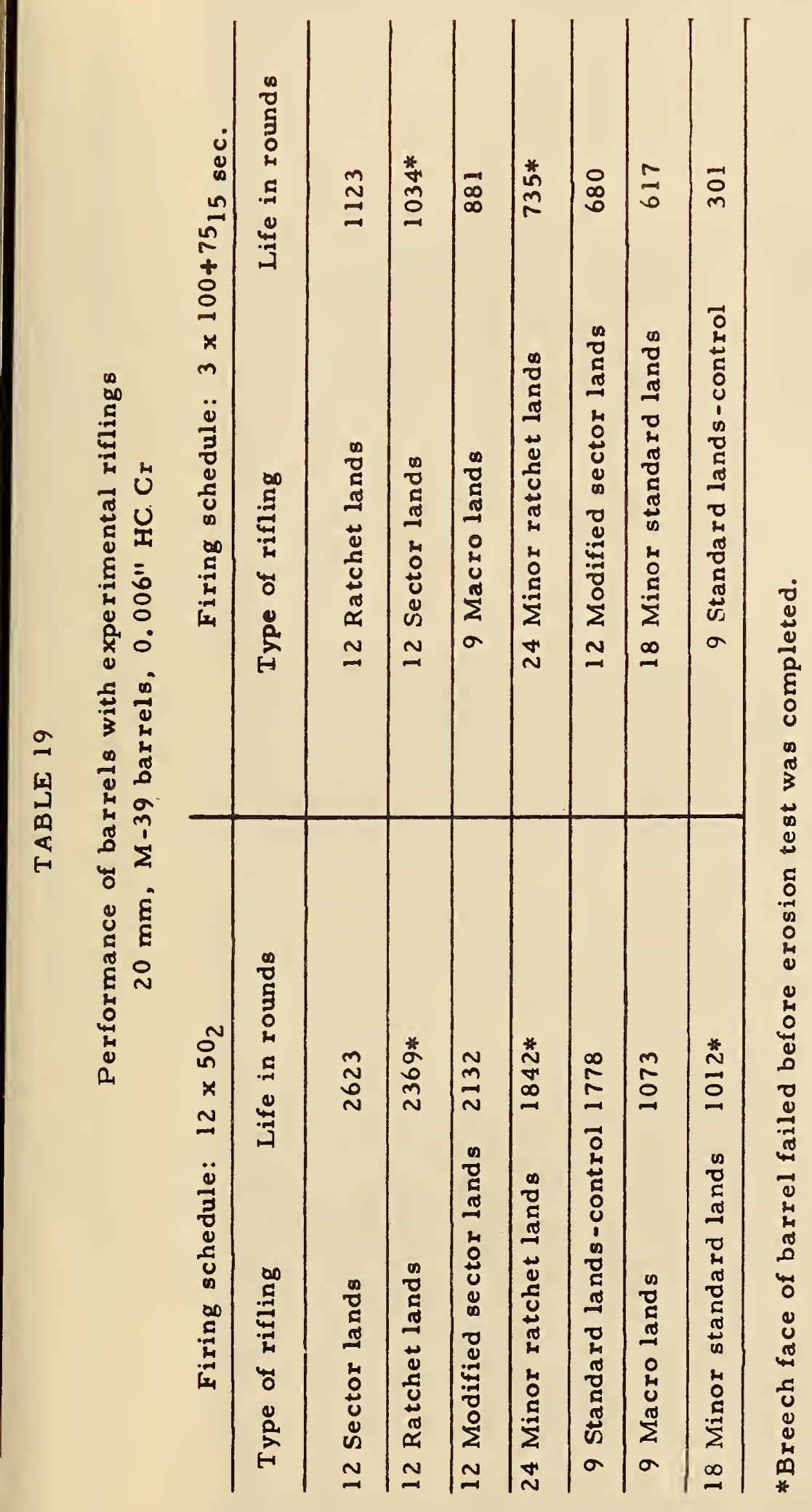




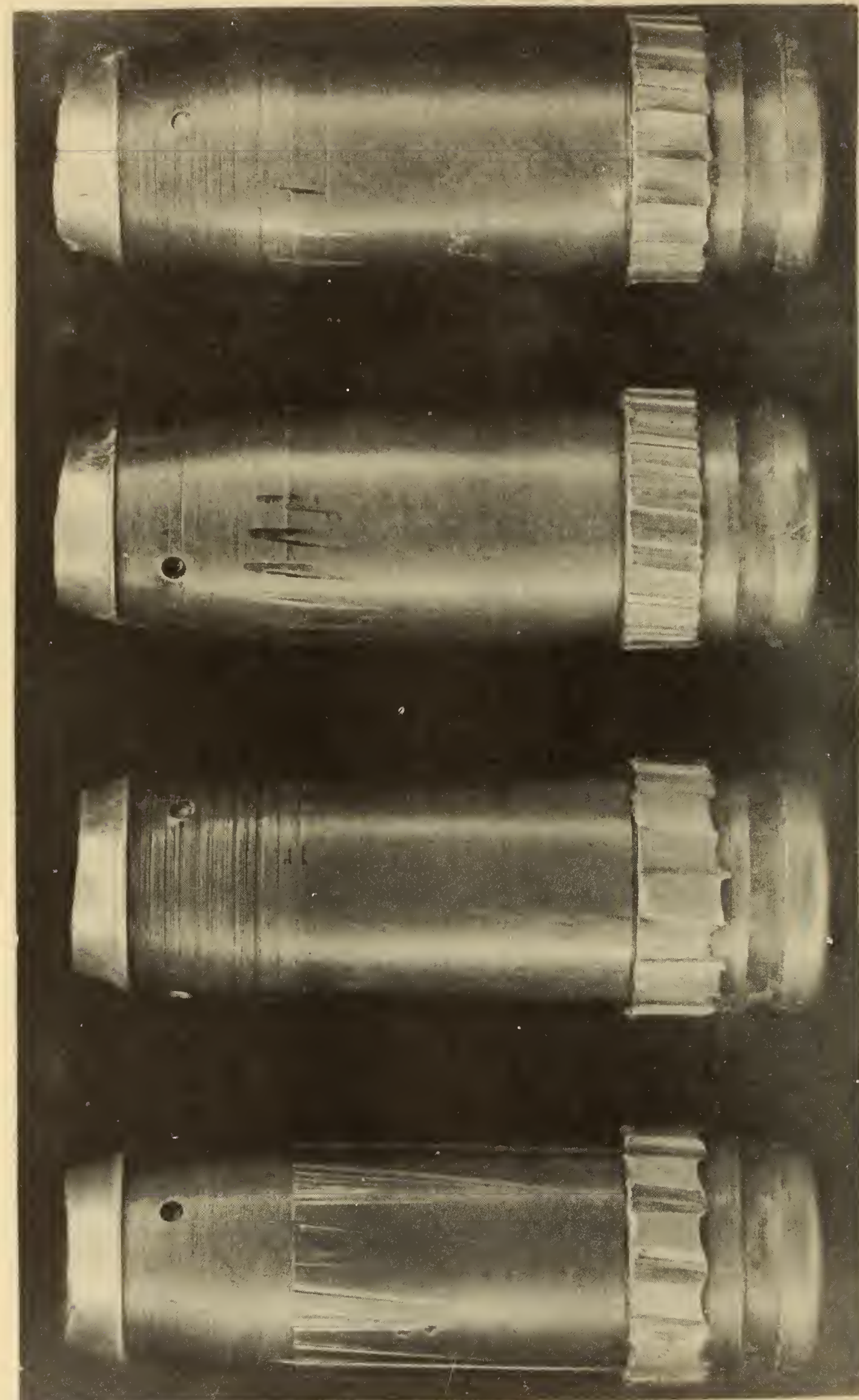

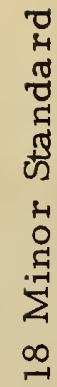

吾

$\dot{0}$

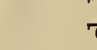

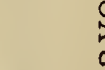

की

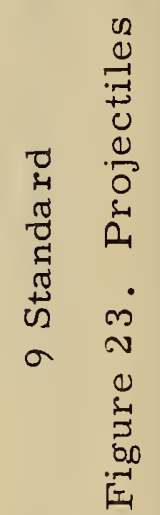

4
0
0
0
0
0
$N$
$N$ 


\section{OPERATING PROCEDURES}

A general discussion of operating procedures has already been given in section 5. Section 9 is therefore limited to a discussion of some special procedures and a description of recent efforts to plate and electropolish barrels at high rates. These experiments have been restricted to $20 \mathrm{~mm}$ barrels.

\section{1 High-speed plating}

At the beginning of the work with $20 \mathrm{~mm}$ barrels, $\mathrm{HC}$ chromium was applied at $50 \mathrm{C}$ and $20 \mathrm{amp} / \mathrm{dm}^{2}$. Under these conditions, 10 to 12 hours are required to deposit 0.005 to 0.006 inch thickness. This is an excessively long time for production operations, and therefore work was done to define conditions that would permit application of the plate in a shorter time. Table 20 shows the results obtained under several sets of conditions.

A few experiments with anodes of higher resistance, namely $1 / 4$ inch diameter tool steel or stainless steel (coated with 0.01 inch of lead-tin alloy), were also carried out, but are omitted from Table 20 because the results indicated that the higher resistance had no advantage. Since the plate in some of the runs under conditions yielding 0.006 inch thickness per hour (No. 6 in Table 20) tended to be nodular at land corners, several experiments were carried out to define the conditions more closely. It was found that the range of suitable conditions is quite narrow. Thus, a drop in temperature of 3 degrees (No. 7), or an increase in current of 50 amperes (to a total of 1050 amperes) caused formation of nodules. It was also found that the tendency for nodules to form at the high plating rates was less if the concentration of the plating bath is somewhat higher than the usual value of $250 \mathrm{~g}$ of $\mathrm{CrO}_{3} /$ liter. Therefore, as noted in Table 20, a concentration of $300 \mathrm{~g}$ of $\mathrm{CrO}_{3} /$ liter was used for most of these experiments.

9.1.1 Firing tests of barrels plated at a high rate

Five barrels plated at a rate of 0.006 inch per hour (essentially the conditions of No. 6, Table 20) were test-fired at the Dahlgren Naval Proving Ground. Table 21 shows a summary of the results with the performance of a standard HC plate for comparison. 
The performance of the high-speed plate was inferior to that of standard HC plate. Three of the barrels failed by tumbling of projectiles before a velocity drop of $200 \mathrm{ft} / \mathrm{sec}$. was reached. This was the result of swaging of the lands. In this respect the plate in these barrels was similar to "medium hardness" plate (Table 1). The hardness of a specimen of high-speed plate was measured and found to be about $1100 \mathrm{~V} . \mathrm{P} . \mathrm{N}$., which is somewhat higher than that of $\mathrm{HC}$ plate produced under customary conditions (Table 1). The behavior of the high-speed plate is therefore anomalous. It is possible that it would perform better on a nitrided base.

The work on high-speed plating has shown that it is possible to plate barrels at rates significantly higher than 0.0005 to 0.001 inch per hour. Intermediate plating rates, e.g., $0.003 \mathrm{inch} / \mathrm{hr}$ appear to be practicable and might lead to production economies. Barrels have been plated successfully at rates as high as 0.006 inch/hr. Rates this high do not appear to be practicable at the present stage of development because of the critical control required and because of the slightly inferior properties of the plate.

A decision as to whether a plant should be designed for the usual plating rates or for high plating rates would depend on a careful analysis of a number of factors, some of which are indicated as follows:

In favor of high plating rates: (a) reduced plating time and the consequent need for less tank capacity; (b) higher cathode current efficiency.

Against high plating rates: (a) operating conditions more critical, e.g., control of temperature, current density, surface smoothness, fixture accuracy, etc.; (b) higher investment in power facilities, e.g., 12 volts, higher current capacity rectifiers, higher investment in bus bars, etc. 


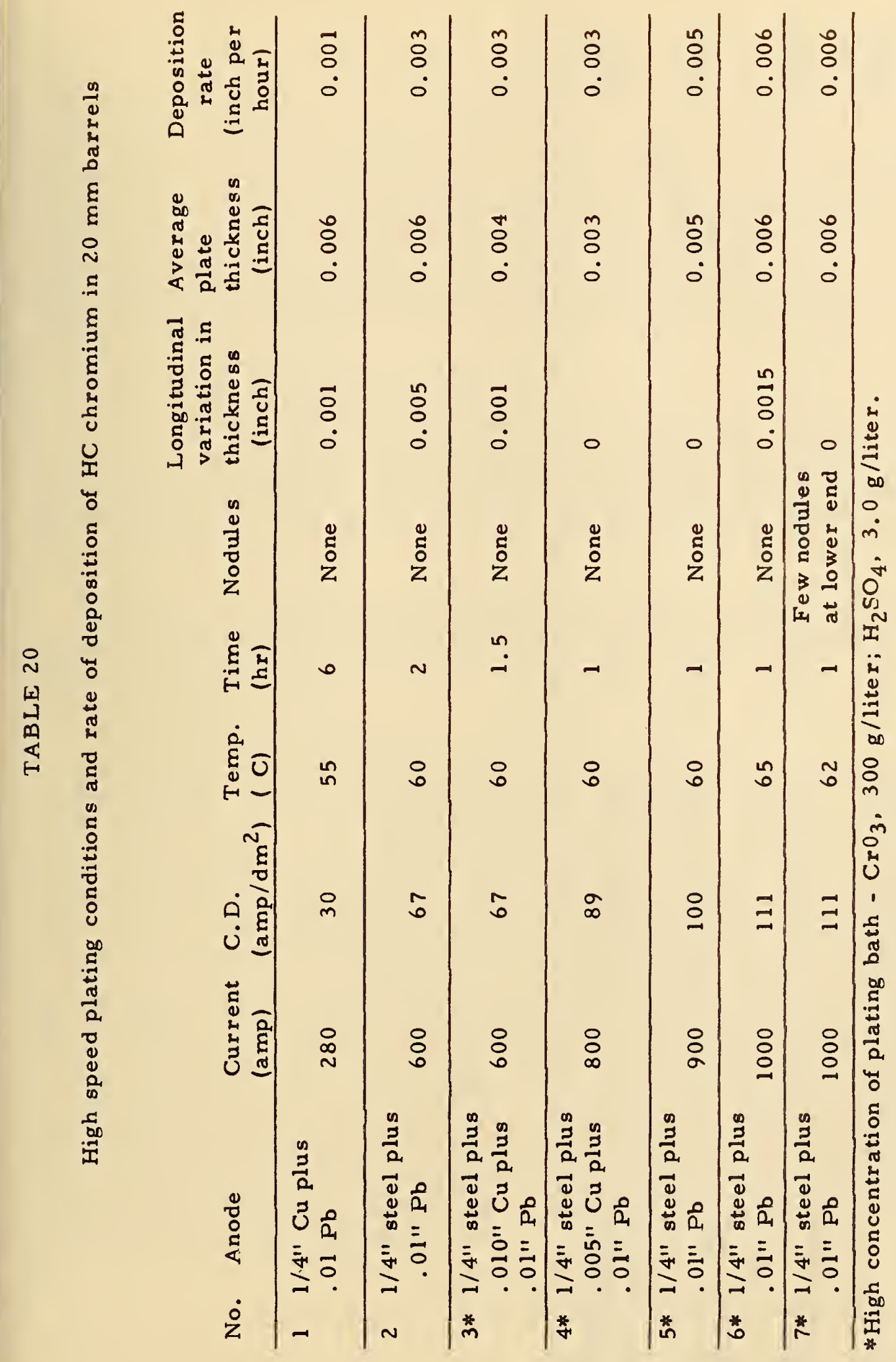




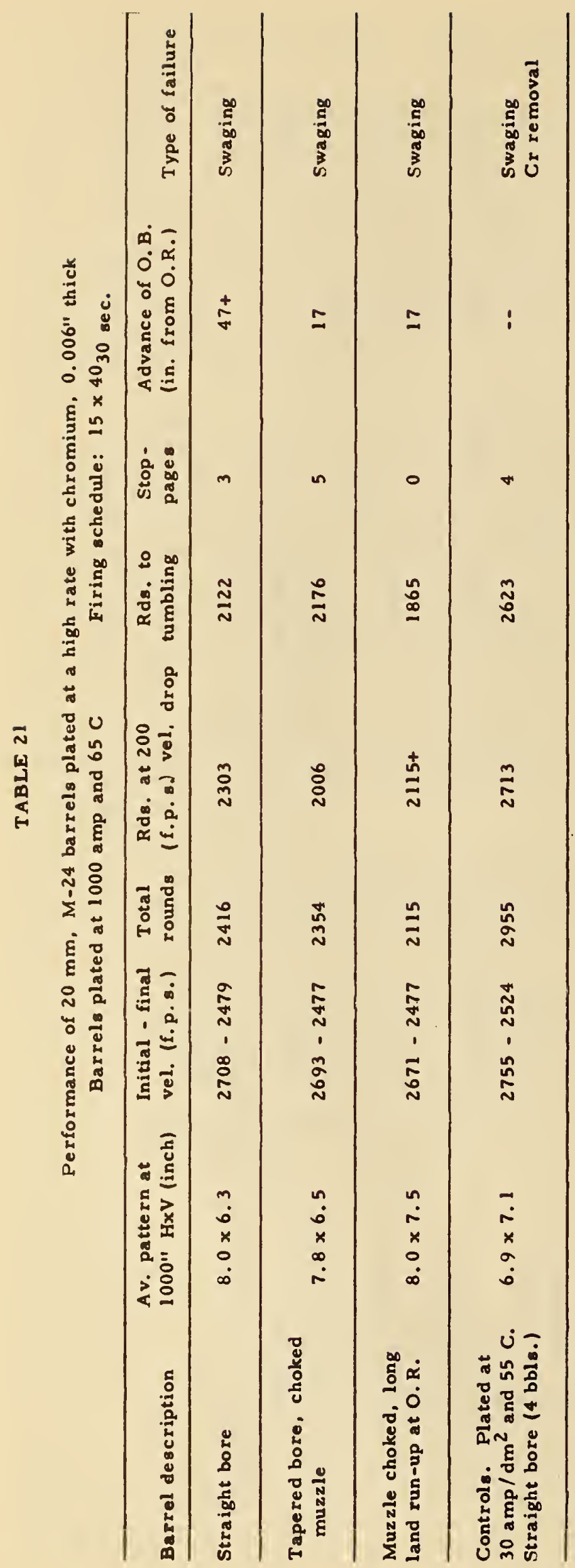




\subsection{Application of LC chromium to $20 \mathrm{~mm}$ barrels without forced solution flow}

It is possible to apply LC chromium to $20 \mathrm{~mm}$ barrels without forced solution flow by using a resistance anode. A 1/4-inch diameter steel anode with 0.010 to 0.015 inch thickness of lead-tin alloy plate yields an LC deposit under conditions of $85 \mathrm{C}$ and a total current of 680 to 700 amperes that is about 20 percent thicker at the lower end of the barrel than at the upper end. This results in an acceptable choke if the muzzle end is plated downward. A larger taper can be produced by increasing the current density. It is especially important when applying LC chromium that the anode be straight and accurately centered, since the eccentricity of the plate is even greater for a given anode eccentricity than with $\mathrm{HC}$ chromium (see Figure 12).

\subsection{High-speed electropolishing}

Under the usual conditions for electropolishing, namely 40 to $45 \mathrm{C}$ and $27 \mathrm{amp} / \mathrm{dm}^{2}, 1.5$ to 2 hours is required to remove 0.005 to 0.006 inch of steel. Shortening of this time would be advantageous in production. The results of a few experiments are shown in Table 22 and in Figure 5.

While more work will be required to define suitable conditions definitely, it appears that electropolishing can be readily done at twice the usual rate.

\section{4 Gas-port plating}

A sketch showing the construction and assembly of a fixture for plating the gas-port of a $20 \mathrm{~mm}$ barrel is shown in Figure 24. The gasport anode is an "intermediate" anode. Current for plating the gasport is adjusted by varying the distance between the main anode and the end of the gas-port anode. No outside connection to the latter is necessary. The fixture is centered by removing the anode height adjustment screw and sighting through the hole in the fixture, or by inserting a pin of correct diameter through the hole in the fixture into the gas-port. The point at which the gas-port anode just touches the bore anode as the guide is screwed into place is determined by testing for circuit continuity. The guide is then unscrewed the distance necessary to adjust the plating current in the orifice to the proper value. Usually the correct current density is obtained on the gas-port wall if contact between the two anodes is barely broken. The gas-ports of all barrels prepared for testing by NBS, unless they have molybdenum inserts, are plated with this fixture. 


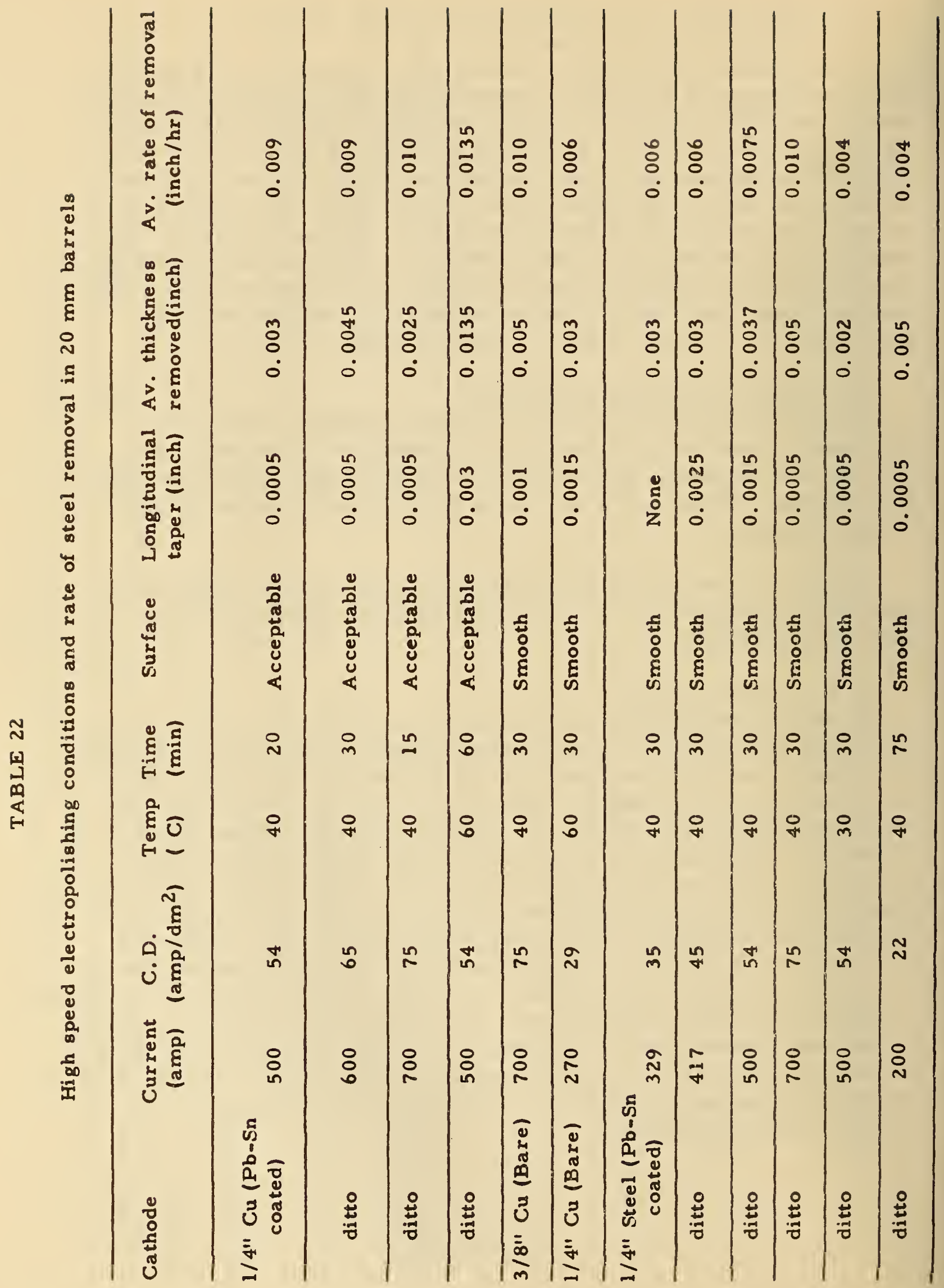




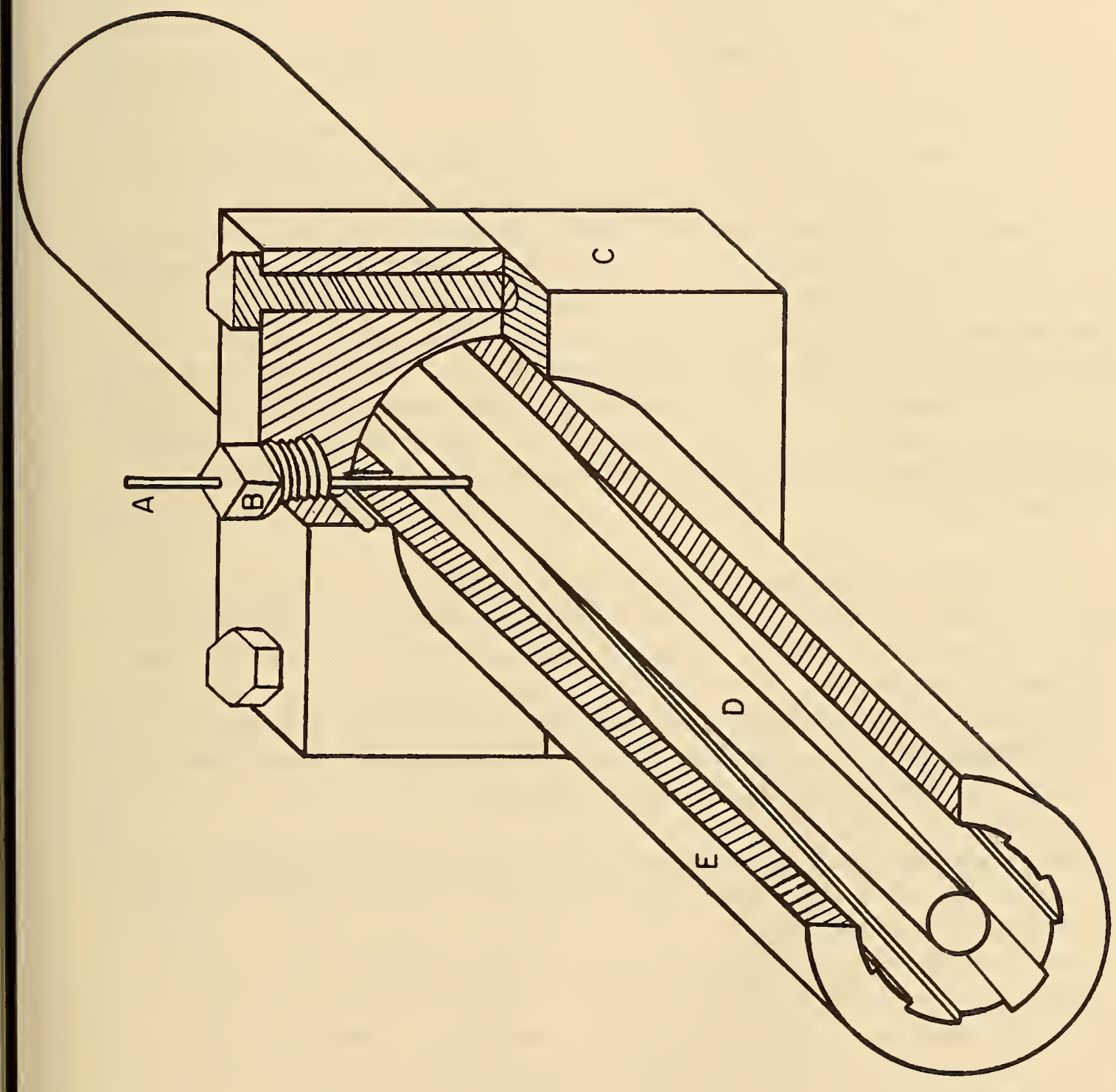

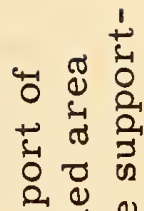

2. 0

ஸ

$0<4$

당

o 00

I

ช

2 +40

मी ती है

(1) 0 이

\& $\stackrel{2}{2}$

उ

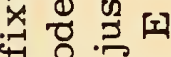

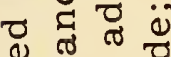

흔 至

द्वृ 0 ,

o 0 工

थ

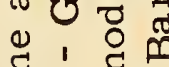

년 1

茂,

离

$>$ \& $\overline{0}$

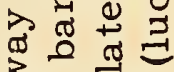

उ $\Xi$ bo

学

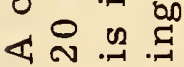

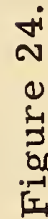


One might expect that research on gun barrel plating as extensive as has been described in this report should make it possible to predict specifications for any new model of barrel that would give, if not the best possible performance, something fairly close to the best. In spite of the fact that the data that have been accumulated permit an approach to this goal, areas remain in which there is still possibility for improvement, Some of these will be indicated very briefly.

Much testing has been done with isolated variations, which is necessary if the variation is to be evaluated. With some types of barrels there has been no previous opportunity to combine all of the favorable variations in one barrel. This is now being done in $40 \mathrm{~mm}$ barrels. More work is needed to define an optimum land contour for all calibers. High-altitude conditions raise questions concerning low temperatures; for example, does the stress resulting from a muzzle choke become an embrittlement hazard to the barrel or the projectile at: minus $70 \mathrm{C}$ ? Preliminary work on this question indicates a negative answer. Designers might well consider further questions concerning clearance between the bore and the projectile, and the possibility of improving driving band design, to eliminate balloting. Improvements here would add to the life of plated barrels.

In the field of plating procedures and techniques, it is still possible to improve plating fixtures. Deposition of chromium at very high rates may have potential production value, but still needs development before it is practicable. Significant savings could be made in the cost of electropolishing and in the cost of disposal of spent electropolish solutions if a simple method were developed for removing dissolved metals, especially iron.

Finally, in the field of testing, local measurement of thickness of chromium in the bore, non-destructively, would eliminate acceptance of production barrels in which the plate is eccentric. This is believed to be a common cause of large variations in life that are too trequently found in plated barrels. A gage for this purpose is under development. A non-destructive method for measuring adhesion of the plate in barrels plated in production would have much value. Test-firing procedures are in need of improvement. The suggestion has been made that barrels be pre-heated to a temperature approximating that reached in burst fire before test-firing. 
The firing cycle could then be shortened with resultant saving of ammunition (estimated as high as 75 percent). Furthermore, schedule interruptions would not vitiate test results, because the barrel would remain hot. A few preliminary experiments have been made with electrical pre-heating of the barrel.

New models of guns and barrels are continually being developed. As indicated above, accumulated data permit a logical guess as to specifications for chromium plating these new types of barrels. Nevertheless, test-firing of barrels plated with variations from the initially selected specifications will always be desirable.

\section{ACKNOWLEDGMENTS}

The contributions of the following persons to this program is acknowledged:

Dr. William Blum, Dr. Abner Brenner, Mr. Wm. H. Metzger, Jr., Mr. Arthur Fridinger, Mr. Robert Seegmiller, and others of the NBS staff who were engaged on this project.

Acknowledgment is also made to the following organizations for technical cooperation and financial support:

Department of the Navy, Bureau of Ordnance;

Department of the Army, Office of the Chief of Ordnance, and Springfield Armory.

Other cooperating organizations were the Naval Proving Ground, Dahlgren, Virginia, Aberdeen Proving Ground, the Washington Naval Gun Factory, and the Geophysical Laboratory. We regret that it is not practicable to list the names of all of the personnel of these organizations who have contributed to the program. 
(1) W. W. de Sveshnikoff and H. E. Haring Army Ordnance 5,503 (1924).

(2) J. Q. McDonald and W. M. Scott, Brit. Pat. 299, 298, Oct. 22, 1927.

(3) A. Willink, Frankford Arsenal Engineering Report, July 28, 1931

(4) Fabrique Nationale D'Armes de Guerre, Belgium Pat. 361,579, July 31, 1929.

(5) J. M. Olin and A. G. Schuricht (Western Cartridge Co.) U. S. Pat. 1,886, 218, Nov. 1, 1933.

(6) T. K. Vincent, Report No. 87, BRL-APG Aberdeen Proving Ground, Nov. 3, 1937.

(7) Symposium on Chromium Plating, Washington, D. C. May 14, 1943, Div. 1, NDRC, OSRD 6485, Report No. A-414.

(8) Investigation of Erosion in Caliber . 50 M2AC-BMG Barrels Partial Tech. Report on SA-WO311, Engineering Dept., Experimental Div., Springfield Armory, Nov. 12, 1943; March 1, 1944; and June 6, 1944.

(9) "Hypervelocity Guns and the Control of Gun Erosion" Summary Tech. Report of NDRC, Div. I, Vol. I, Washington, D. C., 1946 Chapters 20, 23, 24, 25, 31, and 32.

(10) See Ref. (9) Chapters 16 to 21.

(11) S. Senderoff and A. Brenner, J. Electrochem. Soc. 101, 16 (1954).

(12) A. Brenner, Polly Burkhead, and C. Jennings Journal Res. National Bureau of Standards 40, 31 (1948).

(13) A. Brenner, Polly Burkhead, and Emma Seegmiller Journal Res. National Bureau of Standards 39, 351 (1947).

(14) C. L. Faust, U. S. Pat. 2,334,699, Nov. 23, 1943.

(15) C. Williams and R.A.F. Hammond, Trans. Inst. of Met. Finishing (London), 31, 124 (1954).

(16) A. H. DuRose and D. M. Hutchinson, Plating 40, 470, 630 (1953).

(17) V. A. Lamb and E. F. Osborn, U. S. Pat. 2, 687, 591, Aug. 31, 1954.

(18) Firing Trials with 0.5 inch Browning $M / G$ Barrels with Chromium Plated Bores. ARD Met. Report 206/44 (WA-2926-7H) Sept. 1944.

(19) R. Seegmiller and V. A. Lamb, Proc. Am. Electroplaters' Soc. $1948,125$.

(20) R. F. Ledford and L. O. Gilbert, Plating 42, 1151 (1955). 
(21) Ministry of Supply, Armament Res. Establishment, Metallurgy

Branch, Woolwich Arsenal, Kent, England, Report No. MR 7614/72, 1953 (Confidential).

(22) V. A. Lamb and J. P. Young, NBS Report No. 5A106, Nov. 30, 1951.

(23) J. P. Young and W. H. Metzger, Jr., NBS Report No. 5B153,

Jan. 1, 1956.

(24) a. V. A. Lamb, Final Report on 1st Phase of Program on Chromium Plated Barrels, on Work Performed to Find Methods for Obtaining Maximum Adhesion of the Deposit. Aug. 26, 1949.

b. V. A. Lamb, Report II, Chromium Plated Barrels, Plating and Firing of Thickness Group, March 22, 1951.

c. J. P. Young, Report III, $40 \mathrm{~mm} \mathrm{M-1} \mathrm{Chromium} \mathrm{Plated}$ Barrels, Investigations of Various Types of Chromium Plate for the Improvement of Gun Barrel Performance and Life, NBS Report No. 3B101, Aug. 1, 1954.

(25) ARD Metallurgical Report No. 5/50, Woolwich, England July 1950.

(26) John P. Young, U. S. Pat. 2, 764, 914, Oct. 2, 1956.

(27) V. A. Lamb and J. P. Young, NBS Report No. 3297, May 13, 1954.

(28) V. A. Lamb and J. P. Young, NBS Report No. 5B136, Jan. 1, 1954.

(29) Erosion Tests of Bore Pre-plating Preparations, 88th Report on Proj. No. TS 3-3014, Aberdeen Proving Ground, Dev. and Proof Services, Dec. 1, 1954.

(30) V. A. Lainb and J. P. Young, NBS Report No. 5B151, Oct. 1, 1955.

(31) a. V. A. Lamb, NBS Report No. 3099 (3988) Feb. 8, 1954.

b. V. A. Lamb and J. P. Young, NBS Report No. 5B151, Oct. 1, 1955.

(32) Dept. of the Navy, Bureau of Ordnance, Technical Library.

Library No. ONI-F, OANAR, Mp-B.

(33) R. Bilfinger, Arkiv. fur Metalkunde, No. 4, 131, Nov. (1948).

(34) F. Müller, W. Eilender, and K. M. Wagner, ibid., April, 135 (1949).

(35) J. P. Young and W. H. Metzger, Jr., NBS Report No. 5B157, April 1, 1956. 

Frederick H. Mueller, Secretary

NATIONAL BUREAU OF STANDARDS

A. V. Astin, Director

\section{THE NATIONAL BUREAU OF STANDARDS}

The scope of activities of the National Bureau of Standards at its major lahoratories in Washington, D.C., and Boulder, Colorado, is suggested in the following listing of the divisions and sections engaged in technical work. In general, each section carries out specialized research, development, and engineering in the field indicated by its title. A brief description of the activities, and of the resultant publications, appears on the inside of the front cover.

\section{WASHINGTON, D.C.}

Electricity and Electronics. Resistance and Reactance. Electron Devices. Electrical Instruments. Magnetic Measurements. Dielectrics. Engineering Electronics. Electronic Instrumentation. Electrochemistry.

Optics and Metrology. Photometry and Colorimetry. Photographic Technology. Length. Engineering Metrology.

Heat. Temperature Physics. Thermodynamics. Cryogenic Physics. Rheology. Molecular Kinetics. Free Radicals Research.

Atomic and Radiation Physics. Spectroscopy. Radiometry. Mass Spectrometry. Solid State Physics. Electron Physics. Atomic Physics. Neutron Physics. Radiation Theory. Radioactivity. X-rays. High Energy Radiation. Nucleonic Instrumentation. Radiological Equipment.

Chemistry. Organic Coatings. Surface Chemistry. Organic Chemistry. Analytical Chemistry. Inorganic Chemistry. Electrodeposition. Molecular Structure and Properties of Gases. Physical Chemistry. Thermochemistry. Spectrochemistry. Pure Substances.

Mechanics. Sound. Mechanical Instruments. Fluid Mechanics. Engineering Mechanics. Mass and Scale. Capacity, Density, and Fluid Meters. Combustion Controls.

Organic and Fibrous Materials. Rubber. Textiles. Paper. Leather. Testing and Specifications. Polymer Structure. Plastics. Dental Research.

Metallurgy. Thermal Metallurgy. Chemical Metallurgy. Mechanical Metalhurgy. Corrosion. Metal Physics.

Mineral Products. Engineering Ceramics. Glass. Refractories. Enameled Metals. Constitution and Microstructure.

Building Technology. Structural Engineering. Fire Protection. Air Conditioning, Heating, and Refrigeration. Floor, Roof, and Wall Coverings. Codes and Safety Standards. Heat Transfer. Concreting Materials.

Applied Mathematics. Numerical Analysis. Computation. Statistical Engineering. Mathematical Physics.

Data Processing Systems. SEAC Engineering Group. Components and Techniques. Digital Circuitry. Digital Systems. Analog Systems. Application Engineering.

- Office of Basic Instrumientation.

- Office of Weights and Measures.

\section{BOULDER, COLORADO}

Cryogenic Engineering. Cryogenic Equipment. Cryogenic Processes. Properties of Materials. Gas Liquefaction.

Radio Propagation Physics. Upper Atmosphere Research. Ionospheric Research. Regular Propagation Services. Sun-Earth Relationships. VHF Research. Radio Warning Services. Airglow and Aurora. Radio Astronomy and Arctic Propagation.

Radio Propazation Engineering. Data Reduction Instrumentation. Modulation Research. Radio Noise. Tropospheric Measurements. Tropospheric Analysis. Propagation Ohstacles Engineering. Radio-Meteorology. Lower Atmosphere Physics.

Radio Standards. High. Frequency Electrical Standards. Radio Broadcast Service. High Frequency Impedance Standards. Flectronic Calibration Center. Microwave Physics. Microwave Circuit Standards.

Radio Communication and Systems. Low Frequency and Very Low Frequency Research. High Frequency and Very High Frequency Research. Ultra High Frequency and Super High Frequency Research. Modulation Research. Antenna Research. Navigation Systems. Symem Analyids. Field Operations. 
NBS 